Florida International University FIU Digital Commons

\title{
The Relationship of the Parental Involvement of Latino Immigrant Parents of Middle School Students and Student Academic Achievement
}

Cory R. Rodriguez

cvala004@fiu.edu

DOI: $10.25148 /$ etd.FIDC000275

Follow this and additional works at: https://digitalcommons.fiu.edu/etd

Part of the Educational Administration and Supervision Commons

\section{Recommended Citation}

Rodriguez, Cory R., "The Relationship of the Parental Involvement of Latino Immigrant Parents of Middle School Students and Student Academic Achievement" (2016). FIU Electronic Theses and Dissertations. 2449.

https://digitalcommons.fiu.edu/etd/2449 


\title{
FLORIDA INTERNATIONAL UNIVERSITY
}

Miami, Florida

\section{THE RELATIONSHIP OF THE PARENTAL INVOLVEMENT OF LATINO IMMIGRANT PARENTS OF MIDDLE SCHOOL STUDENTS AND STUDENT ACADEMIC ACHIEVEMENT}

A dissertation submitted in partial fulfillment of the requirements for the degree of DOCTOR OF EDUCATION

in EDUCATIONAL ADMINISTRATION AND SUPERVISION by

\author{
Cory R. Rodriguez
}


To: Dean Michael R. Heithaus

College of Arts, Sciences and Education

This dissertation written by Cory R. Rodriguez, and entitled The Relationship of the Parental Involvement of Latino Immigrant Parents of Middle School Students and Student Academic Achievement, having been approved in respect to style and intellectual content, is referred to you for judgment.

We have read this dissertation and recommend that it be approved.

$\begin{array}{r}\hline \text { Delia C. Garcia } \\ \hline \text { Thomas G. Reio } \\ \hline \text { Linda A. Spears-Bunton } \\ \hline \text { Peter J. Cistone, Major Professor }\end{array}$

Date of Defense: March 31, 2016.

The dissertation of Cory R. Rodriguez is approved.

Dean Michael R. Heithaus College of Arts, Sciences and Education

Andrés G. Gil Vice President for Research and Economic Development and Dean of the University Graduate School

Florida International University, 2016 
(C) Copyright 2016 by Cory R. Rodriguez

All rights reserved. 


\section{DEDICATION}

To my mother Nora and sister Nena, thank you for your inspiration and always believing in me. 


\section{ACKNOWLEDGMENTS}

I would like to thank my major professor, Dr. Peter J. Cistone for his guidance and continuous support for my doctoral study, his patience, motivation, and knowledge. His guidance and expertise inspired me throughout the dissertation process.

A wealth of gratitude goes to Dr. Thomas Reio for assisting me throughout the data analysis process. I could not have completed this task without his knowledge, mentorship and support. His belief in me never faltered. I could not imagine having a better mentor for my research study.

I would also like to thank Dr. Linda A. Spears-Bunton's for her ongoing support and encouragement and Dr. Delia C. Garcia for her knowledge and contribution, especially in the area of parental involvement. Dr. Garcia’s dedication and vision provided me and other Hispanic educators the opportunity to pursue a doctoral degree through the Creating Latino Access to a Valuable Education (CLAVE) Grant award.

Finally, I would like to thank the staff at the place where the study took place for donating their time to assist in this study. Their dedication made it possible for me to complete this study. 


\author{
ABSTRACT OF THE DISSERTATION \\ THE RELATIONSHIP OF THE PARENTAL INVOLVEMENT OF LATINO \\ IMMIGRANT PARENTS OF MIDDLE SCHOOL STUDENTS AND STUDENT \\ ACADEMIC ACHIEVEMENT \\ by
}

Cory R. Rodriguez

Florida International University, 2016

Miami, Florida

Professor Peter J. Cistone, Major Professor

The Latino population in the United States is projected to increase significantly in the upcoming years as well as the numbers of Latino students enrolled in public schools. These schools are challenged with a gap in Latino student achievement when compared to White non-Hispanic students. Studies indicate that parental involvement in school settings has been correlated to student achievement and that parental involvement is lower for Latino parents than White parents.

The purpose of this research study was to examine the relationship between parental involvement of seventh grade middle school Latino students and students’ reading and mathematics achievement. The study also examined selected relevant demographic variables, including socioeconomic status, parents’ level of education, single versus two-parent families, and the gender of the students and parents.

The theoretical framework that supported this research study was derived from Joyce Epstein’s (1991) model for parental involvement. 
The researcher implemented a non-experimental correlational research study to obtain a better understanding about the types and intensity of Latino immigrant parental involvement and the relationship to their children's reading and math grades in middle school. The participants in the study included 134 Latino immigrant parents. A parent survey questionnaire was utilized to collect information on the demographics of the parents and their degree of parental involvement. Correlational and multiple regression analyses were used to test the research questions and examine the hypotheses. The correlational results revealed that there was a statistically significant relationship between the reading and parental SES variables. The results of the multiple regression analyses did not find a significant association between parental involvement and their childrens' reading and math first-quarter grades., Still, after controlling for parental involvement, parents’ socioeconomic status was positively related to mathematics achievement, as measured by the quarter report card grades.

New research questions emerged and pertinent additional research is recommended that examines the relationship between specific characteristics of parental involvement and student achievement in larger samples or other geographical areas with similar demographics. Practical implications include suggestions that schools focus particularly on parents from lower SES backgrounds to help foster their children's optimal learning and achievement. 
CHAPTER

PAGE

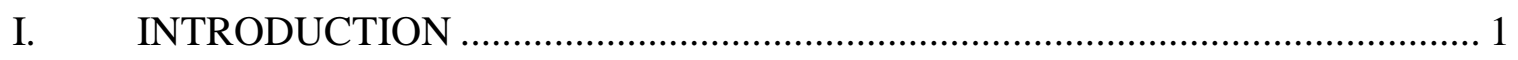

Statement of the Problem................................................................................... 5

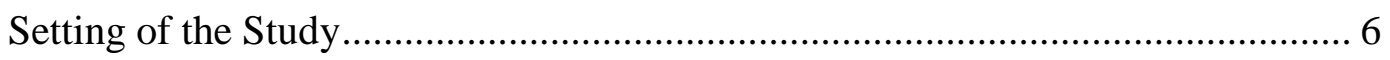

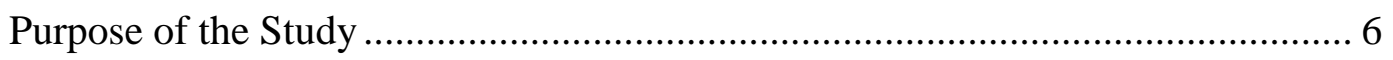

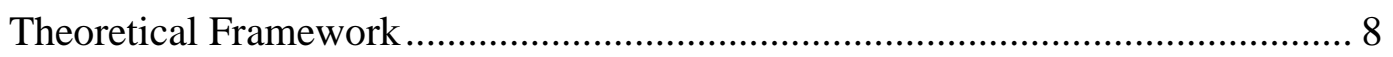

Research Questions and Hypotheses ................................................................. 10

Assumptions and Delimitations .................................................................... 12

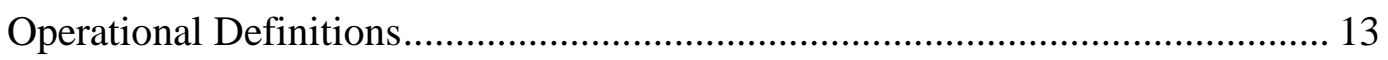

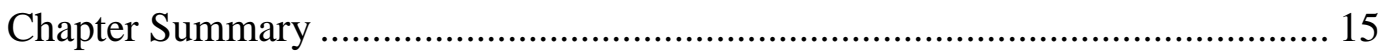

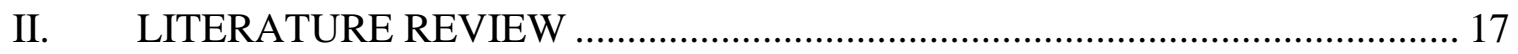

Barriers to Parental Involvement ...................................................................... 17

Types of Parental Involvement ............................................................................ 28

Parental Involvement in Reading and Mathematics ............................................... 39

Cross-Cultural Approach and Parental Involvement ............................................... 44

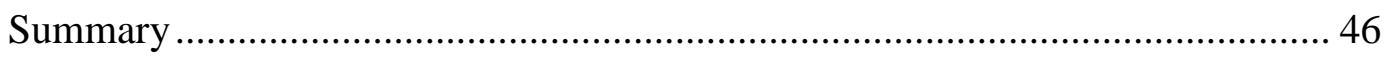

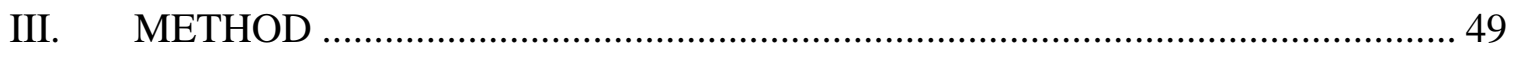

Dependent and Independent Variables ................................................................. 50

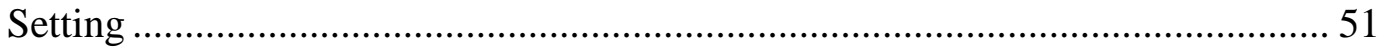

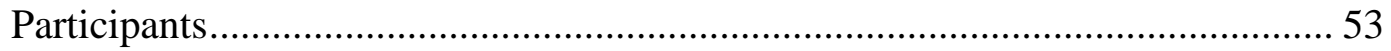

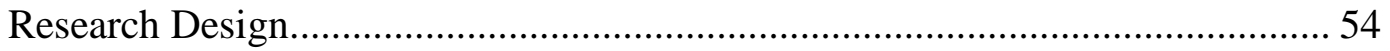

Research Questions and Hypotheses ………….............................................. 54

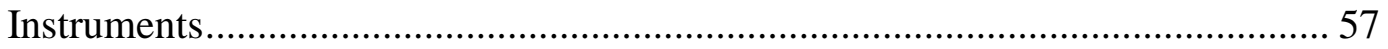

Parent Involvement Project (PIP): Parent Questionnaire........................................ 58

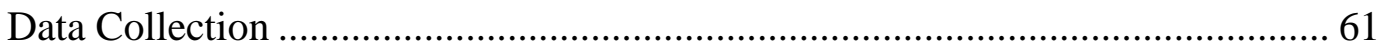

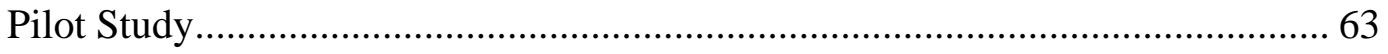

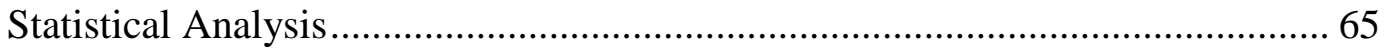

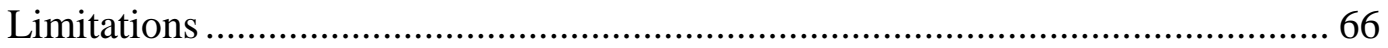




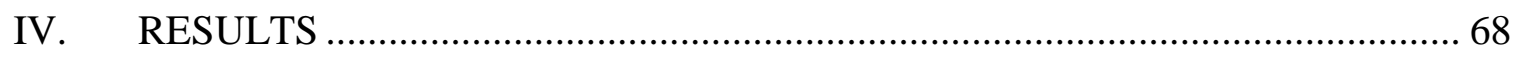

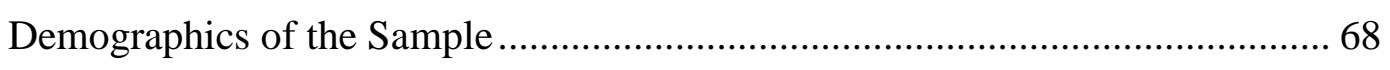

Analysis of the Hypotheses............................................................................. 73

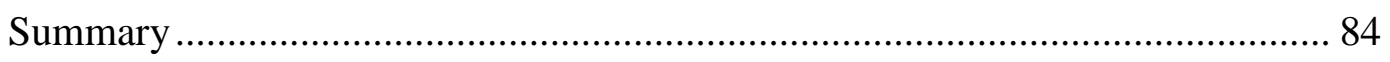

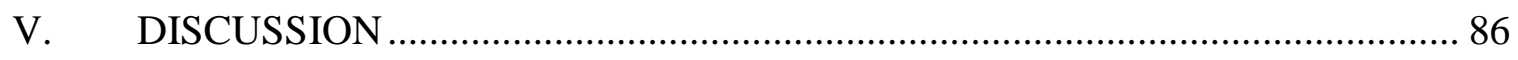

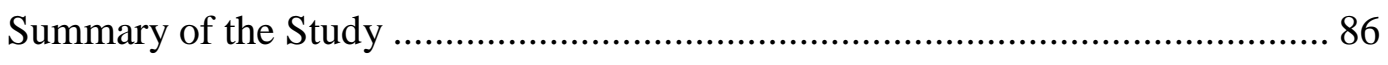

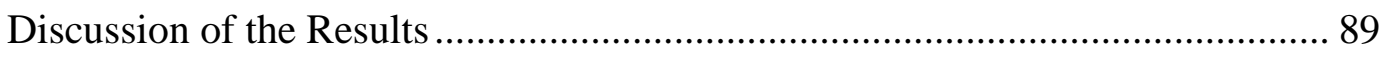

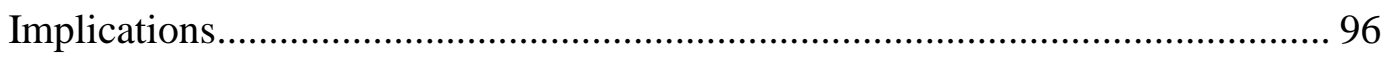

Recommendation for Further Research .............................................................. 99

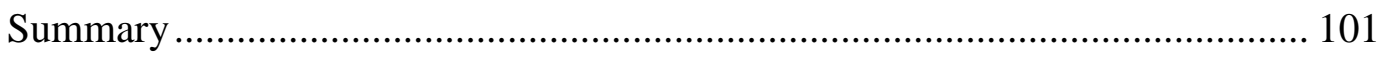

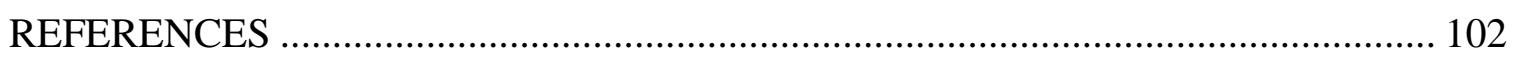

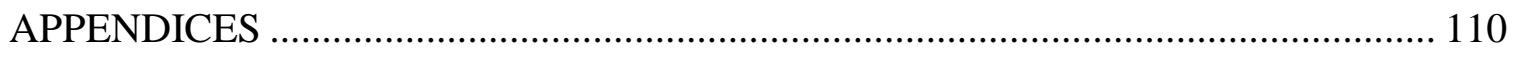

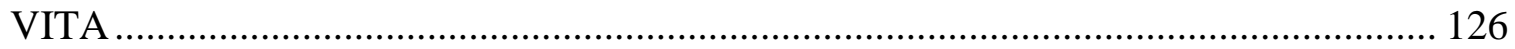




\section{LIST OF TABLES}

TABLE

PAGE

1. Frequency of Research Variable Occupations ................................................... 70

2. Frequency of Research Variable Occupations - Partners ........................................71

3. Frequency of Research Variable Education.................................................... 72

4. Frequency of Research Variable Family Income................................................ 73

5. Intercorrelations of Parental Involvement and Reading and Mathematics

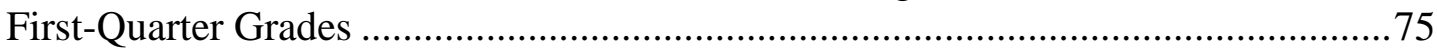

6. Summary of Regression Analysis with Parental Involvement Predicting Reading

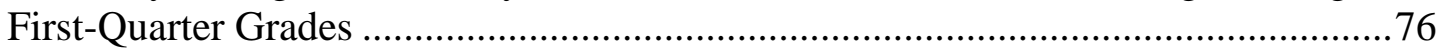

7. Summary of Regression Analysis with Parental Involvement Predicting First-Quarter Mathematics Grade

8. Summary of Hierarchical Regression with SES Predicting Reading First-Quarter Grades After Controlling for Parental Involvement - Step 1 ................................. 78

9. Summary of Hierarchical Regression with SES Predicting Reading First-Quarter Grades After Controlling for Parental Involvement - Step 2 .................................. 78

10. Summary of Hierarchical Regression Analysis of SES Predicting Mathematics First-Quarter Grades After Controlling for Parental Involvement - Step 1

11. Summary of Hierarchical Regression Analysis of SES Predicting Mathematics First-Quarter Grades After Controlling for Parental Involvement - Step 2.

12. Summary of Regression Analysis Predicting Reading First-Quarter Grades with Single versus Two-Parent Home Status

13. Summary of Regression Analysis with Single versus Two-Parent Homes Predicting Mathematics First-Quarter Grades

14. Summary of Hierarchical Regression Analysis between Type and Intensity of Parental Involvement in Predicting Reading First-Quarter Grades - Step 1.

15. Summary of Hierarchical Regression Analysis between Type and Intensity of Parental Involvement in Predicting Reading First-Quarter Grades - Step 2.

16. Summary of Hierarchical Regression Analysis between Type and Intensity of Parental Involvement in Predicting Reading First-Quarter Grades - Step 1. 
17. Summary of Hierarchical Regression Analysis between Type and Intensity of Parental Involvement in Predicting Reading First-Quarter Grades - Step 2................84 


\section{CHAPTER I \\ INTRODUCTION}

During modern times, the United States has attracted more immigrants than any place else in the world. Recently the nation has witnessed a rapid increase in the number of immigrants. Over one million entered the country in 2000 alone, with a total of 20 million entering between 1966 and 2001 after the passage of the 1965 Hart-Cellar Act, which reduced restrictions on non-European immigration (Suarez-Orozco, 2001). The post-1965 migration has been diverse in terms of socioeconomic status (SES), race, ethnicity and national origin and has contributed significantly to the growth of the Hispanic (also called Latino) population.

Immigration rates continue to grow as does the diversity of the immigrant population. Between 2000 and 2010, the Hispanic population increased overall by 43\% with a 54\% increase in Mexicans, a 44\% increase in Cubans, and an increase in other Hispanic nationalities by 22\%. According to the United States Census Bureau (2010), 16\% of the population was of Hispanic origin. The Census Bureau projections from 2012 reported that the Hispanic population would double from 53.3 million in 2012 to 128.8 million in 2060; meaning that approximately one in three United States residents would be Hispanic, compared to about one in six in 2016.

This increase in Hispanic immigration and population growth has created a number of challenges for K-12 education in the United States. According to the National Center for Education Statistics (2014), “from 2001 through 2011 the number of Hispanic students enrolled in public schools has increased from 8.2 million to 11.8 million” (p. 2). In contrast, "The number of White students enrolled in public schools decreased from 
27.7 million to 25.6 million” (National Center for Education Statistics, 2014, p. 2). The significant increase in the Latino population has intensified the need for schools to increase their efforts at strengthening parental relationships, addressing class size, and improving teacher preparation in order to collaboratively and successfully meet the needs of the culturally diverse population. Moreover, compared to $88.7 \%$ of non- Latino Whites, within the general population, only $57 \%$ of Latino over the age of 25 have graduated from high school and $21.4 \%$ are living below the poverty level, compared to 7.8\% of non- Latino (Niemeyer, Wong, \& Westerhaus, 2009).

There is a gap in Latino student achievement, as compared to White non-Hispanic students, and Latino performance is significantly lower in schools with larger numbers of low-income students. This gap has been linked to minimal parental involvement and various related factors pertaining to the parents of the students, including their socioeconomic status, their level of education, and language barriers. Studies have shown that parental participation is lower for Latino parents than White parents (Dockertman, 2011; Marschall, 2006) and Latino parental involvement rate has been described as low to nonexistent, when compared to Euro-American families (Lee \& Bowen, 2006). Research claims that the lack of parental involvement among Latino and immigrant parents may be due to barriers that discourage and reduce their involvement, especially in formal school settings (Marschall, 2006). This lack of parental involvement is often perceived as lack of caring, even though it is necessarily not the case. Activities, such as attending school meetings or functions, and assisting with home learning, are common parental roles in the United States; however, immigrant parents who lack an understanding of the cultural norms in the American educational system, or with limited 
English language skills, do not readily or easily partake in such activities. Parents of lowincome status may lack the necessary transportation needed to attend school functions, or may hold multiple jobs in order to provide for their families, thus limiting their ability to participate in school-related functions. Parents with low or limited educational ability may be unacquainted or uneasy about the educational school system in the United States. Further, although the majority of Latinos in the United States are native born, consideration must also be given to Latino immigrant families who have greater needs as they adapt to a new culture, language and education system (Dockertman, 2011).

The relationship between parental involvement and student achievement has been studied in various contexts and sample studies. In fact, parental involvement has been at the forefront of discussions in communities, and in state and government agencies for the last 30 years (Drake, 2000). As a result, greater emphasis has been placed on expanding options that encourage parental involvement while attempting to close the achievement gap between Latino students and their non-Latino peers. For example, various federal initiatives were passed in 1970s and 1980s, such as Public Law 94-142 (Individuals with Disability Education Act, IDEA) and the Education of the Handicapped Amendment of 1986, which provided parents the right to be included in the placement and evaluation decisions, and development of educational plans (Fishel \& Ramirez, 2005). In 1994, Congress reauthorized Title I, which acknowledges the importance of parental involvement at the state, district and school level. Schools that are allocated Title I funds (based on the number of students receiving free or reduced lunch fees) are required to allocate a percentage of the funds towards increasing parental involvement and academic programs that specifically meet the needs of the students. In addition, the No Child Left 
Behind Act (NCLB) of 2001 holds districts and schools responsible for student academic success, and requires schools to meet the academic standards set forth by the state. This act also mandates parent involvement in the planning process of how schools spend federal dollars, and that parents be provided with information and choices about their children's education while encouraging school-based participation (Epstein \& Sanders, 2002). Many schools share information with parents at parent nights, town hall meetings, and Educational Excellence Student Advisory Committee (EESAC) meetings. However the results of these efforts have not had a significant impact in increasing parental involvement, specifically at low-achieving schools and those with large Latino population. For example in the school where the study was conducted, where $95 \%$ of the children are Latino, parent participation in school-based activities was limited to a handful of parents.

Consequently, as the number of Latino students continues to increase, so does the need to build a bridge between the schools and their Latino communities. A positive relationship between all stakeholders could assist in addressing the diverse and cultural needs of the students. It is also critical to understand the role of parental involvement in improving the educational experience and achievement for the students. There is research that supports the need for parental involvement and evidence of its correlation to student achievement while other research argued that there is no definite correlation (Marchant, Paulson, \& Rothlisberg, 2001). The need for additional studies pertaining to parental involvement and student achievement, especially at the secondary level, is imperative in order to identify programs and strategies that have enhanced parental involvement in school and at home. 


\section{Statement of the Problem}

Currently, many urban schools across the Miami-Dade County Public School district are faced with the challenge of increasing the levels of student achievement, especially in the areas of reading and mathematics. This challenge was also intensified by the adoption of the new Florida Standards that require teachers to have ample knowledge of the content area in order to teach the concepts at a very rigorous level. Academic achievement information from the Florida Department of Education (2014) indicates a negative trend in the reading and mathematics scores, especially those in the lowest 25\% of the student population. At the middle school where the study was conducted, approximately $70 \%$ of the students are in this lowest quartile in reading and mathematics. Additionally, over 35\% of the students are English Language Learners (ELL) and over $85 \%$ are of low socioeconomic status.

Research indicates that parental involvement can make a difference in student achievement (Epstein, 2007; Hoover-Dempsey \& Sandler, 2005). However, there is little research that focuses on secondary schools and the impact that parents can have on their children's reading and mathematics achievement score. Additionally, studies indicate that the need for parental involvement is more significant for older students since achievement scores for secondary students are significantly lower (Epstein, 2007). Further parents who lack literacy skills or do not speak English can still support their children’s education by monitoring their homework, discussing their school day, attending events and volunteering at the school.

Instances of low scores in reading and mathematics serve to highlight the need for schools to collaborate with parents in an effort to remediate reading and mathematics 
deficiencies. Previous state and district assessment scores indicate that seventh grade students, at the middle school where the study was conducted, lagged in reading and mathematics as compared to students in sixth or eighth grade. In light of this concern, seventh grade students were identified for this study.

\section{Setting of the Study}

The study was conducted at an urban public middle school located in Miami in Miami Dade County. Florida. In Miami-Dade County Hispanics make up 65\% of the population. From that percentage, 2.1\% are Mexican, 3.7\% are Puerto Rican, 34.3\% are Cuban and 25\% are other Latinos (U.S. Census Bureau, 2010). The school where the study was conducted had approximately 960 students. Information from the school's database indicated that the ethnic makeup of the students is 95\% Latino, 2\% African American, 2\% White and 1\% others. The majority of the Hispanic students are of Central American descent (especially Honduras, Nicaragua, and El Salvador) and over 35\% of the students were English Language Learners (ELL). During the 2014-2015 school year, there were approximately 712 students at level 1 and 2, which are the lowest levels of achievement in reading, as indicated in the Florida Comprehensive Assessment Test (FCAT). Miami-Dade County Public School district requires that students who scored a level 1 or 2 on the reading FCAT must take a reading course in addition to a language arts course. In addition, $85 \%$ of the student population is low socioeconomic status. This is evidenced by the number of free and reduced lunch fees.

\section{Purpose of the Study}

The study was conducted at an urban middle school, located in Miami, in order to examine the relationship between parental involvement of Latino immigrant parents of 
middle school students and student academic achievement. Many of the families in the study were single parents of low socioeconomic status, as evidenced by the student database and number of students receiving free or reduced lunch fees. The involvement of the parents in school activities was minimal, as evidenced by sign in sheets and rosters. This may be because many of the parents where the study took place may hold multiple jobs or lack transportation.

Although it is presumptuous to assume that these parents do not care for their children's education, at the school where the study was conducted, parental involvement is mostly limited to disciplinary concerns, such as suspensions or classroom misbehaviors. In an attempt to increase parental involvement, the school provides parents the opportunity to meet with their child's teachers once a week. This is available throughout the entire school year for all grade levels. The conferences are open to all parents and do not require an appointment. This provides an opportunity for parents and teachers to collaborate and develop effective strategies that address areas of concerns, while building a relationship that will foster accountability and academic growth. However, parent conference logs indicate that attendance is minimal, with an average of about 20 parents out of a possible 890 attending conferences per week.

Studies argue that for cultural reasons, Latino families may not become as involved in their children's education as non-Latino parents (Niemeyer et al., 2009). One reason is that Latino parents hold the belief that it is the school's responsibility to deal with their child's misbehaviors or academic concerns. For this reason, the researcher attempted to examine the relationship between parental involvement and students’ reading and mathematics academic achievement in Latino immigrant families. The 
participants in the study included Latino parents of seventh grade students. The parents who participated in the study completed a parent survey questionnaire consisting of 73 Likert-type questions and eight demographic questions among nine constructs.

\section{Theoretical Framework}

The theoretical framework of this study was derived from Joyce Epstein's (1991) model for parental involvement. This comprehensive model infuses school, family, and community partnerships. The model highlights six approaches aimed at what schools should do to enhance parental involvement:

- Parenting: Assist families with parenting skills through understanding child and adolescent development. Also, collaborate with families to support the child at each grade level.

- Communication: Inform parents of school programs and student progress.

- Volunteering: Provide opportunities to encourage parental involvement at the school.

- Learning at home: Afford families with instructional strategies and resources to be incorporated at home, intended to help them assist their children with academic activities.

- Decision-making: Invite parents to be active participants in school decisions through parent meetings, committees, and other parent organizations. Invitations can be made via phone calls and written notifications, which can be sent home with the students. 
- Collaborating with the community: Identify the needs of the families in order to organize resources and services with community agencies to build the capacity of the families and students.

The model highlights the need for all stakeholders, school-family-community, to collaborate and build partnerships focused on students' holistic progress, which emphasizes both academic and social factors. Epstein (2002) described parental involvement as the partnerships that need to be made between schools, communities, and families in an effort to foster a nurturing educational environment. She further explained that parents who take an active role in their child's education constantly demonstrate good parenting skills, communicate with the school, volunteer their time in school, assist their child with academic learning at home, become active contributors in the decisionmaking process at school, and collaborate with the community (Epstein, 2002). For example, a parent involvement model utilizing Epstein’s parent involvement components was implemented at an inner city school in Chicago. The participants included 174 third grade students (48\% participated as the treatment group), faculty members, and community members. Parent and student surveys, as well as input from all participants, were obtained in the study and utilized to create activities that encouraged parents to take an active role in their child's education. The results of the study indicated that the treatment group significantly improved in reading, as compared to students whose parents did not actively participate in their children's education (Epstein, 2002).

Although mathematics was not emphasized in the above-mentioned study, the levels of mathematics achievement in the United States are of concern to educators. In the United States, males perform better than females on math achievement tests, White 
and Asian students perform better than African American and Hispanic students, and students from affluent families perform better than their peers from low-income families (Byrnes, 2003). For this reason, efforts to improve mathematics achievement in the United States must be implemented at all school levels. However, little is known whether the parental involvement strategies implemented in Epstein's 2002 study affected the students’ mathematic achievement.

Subsequent studies indicate that parental involvement has been found to play a crucial role in the academic achievement of adolescents (Tillman, 2007). In a recent research article, Epstein (2013) expanded her claim on the importance of family and community relationships for students' academic success by stating there is a "big gap between knowing and doing” (p. 115). She emphasized the importance of accurately preparing educators with research-based strategies in order to contribute to student learning and development.

The significance of using Epstein’s (2002) parental involvement model in this study was to allow the researcher to predict the relationship between the types of parental involvement and reading and mathematics achievement of selected seventh grade Latino immigrant students. Through the review and analysis of quantitative data, the researcher was able to predict if there is a relationship between parental involvement and student achievement.

\section{Research Questions and Hypotheses}

The following research questions and hypotheses were addressed in this study:

Q1. Does parent involvement predict students’ reading and mathematics achievement in first quarter report card grades? 
$\mathrm{H}_{0}$ : Parents' involvement as measured by the parent surveys will not predict the students' reading achievement as measured by first quarter report cards grades.

$\mathrm{H}_{0}$ : Parents' involvement as measured by the parent surveys will not predict the students' mathematics achievement as measured by the first quarter report cards grades.

Q2. Does parental socioeconomic status (SES) predict reading and mathematics achievement as measured by first quarter report card grades above and beyond parental involvement?

$\mathrm{H}_{0}$ : Parental SES will not be significantly related to reading achievement as measured by quarter report card grades above and beyond parental involvement.

$\mathrm{H}_{0}$ : Parental SES will not be significantly related to mathematics achievement as measured by quarter report card grades above and beyond parental involvement.

Q3. Is there a relationship between single-parent homes versus two-parent home and the students' reading and mathematics achievement and first quarter report card grades?

$\mathrm{H}_{0}$ : There will be no relationship between students from single-parent versus twoparent homes in reading achievement and first quarter report card grades.

$\mathrm{H}_{0}$ : There will be no significant relationship between students from single-parent versus two-parent homes in mathematics achievement and first quarter report card grades.

Q4. Does type and intensity of parental involvement account for a significant amount of unique variance in predicting reading and mathematics achievement when controlling for parents' level of education?

$\mathrm{H}_{0}$ : There will not be a relationship between the type and intensity of parental involvement in reading achievement when controlling for the parents' level of education. 
$\mathrm{H}_{0}$ : There will not be a relationship between the type and intensity of parental involvement in mathematics achievement when controlling for the parents' level of education.

\section{Assumptions and Delimitations}

There are various assumptions underlying this study. First, the researcher assumed that the parent surveys were completed with integrity, providing a transparent account of the parents' experience with the educational system in the United States. Second, the researcher assumed that parents read and answered each question in the survey with honesty and without bias. Lastly, report card grades are administered four times a year, every nine weeks, which depict the students' academic ability in a particular subject area. The researcher assumed that reading and mathematics grades on the first nine-week report cards reflected grade-level work, mastery of the set standards and evidence of authentic student work.

The study was delimited to an urban middle school located in a low socioeconomic community in the Miami-Dade County Public School district. Over 85\% of the students received free or reduced lunch fees, making this a Title I school and affirming that the majority of the students at the school have a significantly low socioeconomic status. The scope of this study was focused on seventh grade students in reading and mathematics courses. The study was delimited to parents of Latino students, therefore excluding parents of White or African American non-Latino students.

Academic achievement of the students was delimited to the reading and mathematics report card grades for the 2015-2016 school year. 


\section{Operational Definitions}

Barriers to parental involvement. Unlike affluent families who are able to work within the school's structure by partaking in traditional parent involvement opportunities, families represented in this study face a plethora of barriers. These barriers include, but are not limited to: economic, language, cultural, life circumstances, and lack of knowledge of the educational system in the United States (Delgado-Gaitan, 1991).

Cross-cultural education. Cross-cultural education refers to the method educators teach from different cultural perspectives in order to minimize cultural barriers and embrace diversity needed to maximize student academic potential.

Culture. Culture consist of patterns, explicit and implicit, of and for behavior acquired and transmitted by symbols, constituting the distinctive achievements of human groups, including their embodiments in artifacts; the essential core of culture consist of traditional (i.e. historically derived and selected) ideas and especially their attached values; culture systems may, on the one hand, be considered as products of action, and on the other as conditioning elements of further action (Kroeber \& Kluckhohn, 1952, p. 47).

Culturally responsive teaching. Culturally responsive teaching includes pedagogy that recognizes the importance of including students' cultural references in all aspects of learning (Ladson-Billings, 1994).

Hispanic/Latino. This is defined as people who come from Latin American countries where Spanish is the native language. In this study, both terms are used interchangeably (Tienda \& Mitchell, 2006).

Home-learning involvement. This is the degree to which parents assist their children with home learning of schoolwork. Home learning involvement may include: 
parents making room at home for schoolwork, monitoring homework completion, and helping with homework directly (Behnke \& DeBord, 2006).

Immigrant parents. The parents or guardians of the children who come to the United States from other countries.

Intensity of parental involvement. Intensity of parental involvement is the amount of time parents that participate in a given activity. In this study, this was assessed through the parent surveys.

Literacy practices. Literacy practices refers to educational activities such as labeling, singing, book-reading, storytelling, playing, and questioning that promote school readiness among young children (Kummerer \& Lopez-Reyna, 2006; Landry \& Smith, 2006; Neuman, 2006; Pianta,, 2006).

Mathematics achievement. Mathematics achievement was measured by the grade issued at the end of the quarter on the report cards for the mathematics course.

Parent/guardian. Parent or guardian refers to any person who assumes the responsibility for nurturing and caring for a child.

Parents' level of education. The parents' level of education was assessed in the survey as one of 5 levels: less than high school, high school or GED, some college or two year, bachelor's degree, some graduate work or post graduate studies. Studies show that parents with high educational attainment may serve as educational role model to their children, espousing high value of education thus inspiring motivation to achieve (Fuligni \& Fuligni, 2007). Conversely, parents with little or no education may have the opposite effect on their children. 
Parents' self-efficacy. This refers to the parents' belief whether or not their involvement positively influences their children’s education (Hoover-Dempsey \& Sandler, 2005). This was measured in the parent survey.

Reading achievement. Reading achievement was measured by the grade issued at the end of the quarter on report cards for the reading course.

School report card grades. Report card grades are issued every nine weeks based on a 4 -point scale: $0=\mathrm{F}, 1=\mathrm{D}, 2=\mathrm{C}, 3=\mathrm{B}$, and $4=\mathrm{A}$.

Socioeconomic status (SES). Socioeconomic status is a way of identifying individuals or groups within a social structure, and depends on a combination of variables, such as occupations, income, and wealth.

Types of parental involvement. Parental involvement includes school-based participation, such as attending teacher conferences and extracurricular activities, and home-based involvement, such as assisting with home learning and providing a home environment that fosters academic growth and supports the school's educational practices. Nord, Brimhall, and West (1997) suggested that parents can influence student achievement by engaging with their children in activities that promote cognitive skills, such as: playing games and sports, working on projects, visiting museums, attending community events, and discussing family history and current events. This was assessed through the parent survey questionnaire.

\section{Chapter Summary}

The Latino population has significantly increased in the United States in recent years and projections indicate that by 2060 they will constitute one-third of the population of the United States (Census Bureau, 2012). As the number of Latinos 
increases, so does the need to close the achievement gap between Latino students and other student populations. Hispanic students lag behind their peers, and policy makers and school officials are left with the task to overcome barriers, such as poverty, parents' level of education, and lack of English language skills, which can ultimately impede student progress. Research claims that the socioeconomic status and types of parental involvement are related to academic achievement (Barrueco, Lopez \& Miles, 2007). Further, types of parental involvement and beliefs about education may play an important role in preparing and assisting children to be successful in school. The purpose of this study was to explore the relationship of parental involvement of Latino immigrant parents of middle school students and student academic achievement.

Chapter 2 is a review of the literature covering areas relating to parental involvement: barriers that influence parental involvement, types of parental involvement, and parental involvement in reading and mathematics. Chapter 3 includes detailed information about the research problem and hypotheses, research design, setting, participants, instruments, data analysis, and procedures. Chapter 4 delineates the results of the study and addresses each of the four research questions. Lastly, Chapter 5 explores the implications of the study, offering specific recommendations both for practice and future research. 


\section{CHAPTER II}

\section{LITERATURE REVIEW}

This chapter examines research findings that are relevant to understanding the impact of parental involvement on academic achievement of Latino immigrant students. The majority of the findings emphasize that parental involvement plays a pivotal role in the education of students. For example, Hill and Tyson (2009) argue that family-school relations and parental involvement in education have been identified as a way to close the gaps in student achievement and maximize students' potential. In contrast, Jeynes (2012) argued that studies pertaining to parental involvement do not include large samples, and instead focused on small samples making it difficult to make generalizations regarding the general population. Furthermore, these limited studies focused on certain aspects of parental involvement as well as specific groups of students in specific situations (Jeynes, 2012).

This chapter is divided into four main areas of research related to parental involvement and in particular as they relate to Latino immigrant students. These include barriers to positive parental involvement, types of parental involvement, parental involvement in reading and mathematics, and dimensions of parental involvement as it relates to cross-cultural education. The review of the various studies aided in providing a multifaceted perspective on the relationship of parental involvement in Latino immigrant students.

\section{Barriers to Parental Involvement}

There are many barriers to parental involvement in the schools and in the academic achievement of the students. They include socioeconomic status of the family, 
cultural differences and expectations, parent motivation, school invitations, language, and self-efficacy of the parents.

\section{Socioeconomic Status}

According to Morrison, McDonald and Bachman (2006) socioeconomic status through its influence on family economic stress, affects family interactions that are directly linked to school performance. Economic stress generates tension and conflict amongst families. These conflicts may be associated with a decrease of parental warmth, and increase of irritability and anger. This may result in a less nurturing environment and lack of positive parental behaviors. Neuman (2006) claimed that parents of low socioeconomic backgrounds, usually African Americans or Latinos, have minimal dialogue with their children, which may influence their communicative style. This can be related to the parents work schedule, tension and stress.

Vernon-Feagans et al. (2002) found that "poverty is a complex wonder that is made up of biological and health issues, the environment in which these children are raised, and the discrimination they face during their school experience” (p. 200). Further, studies imply that children who live in destitute localities are at risk of academic failure (Chang, Park, Singh, \& Sung, 2009). Due to their impoverished environment, these children may have limited access to health services, which makes them more vulnerable to health risks affecting academic development. Barrueco et al. (2007) suggested that this concern is amplified by the datum that Latinos comprise $21.4 \%$ of the total population of children under five years old, accounting for nearly 34\% of young children living in poverty. 
Latino parents from low socioeconomic backgrounds face additional barriers to parental involvement such as rigid work schedules, lack of transportation, stress due to residing in underprivileged neighborhoods and frequently moving from the inability to pay rent. The barriers are intensified by the fact that many Latino immigrant parents have limited education and may have acquired negative school experiences causing them to be disengaged with their children schools. The absence of parental involvement creates the perception in schools the parents are not interested in their children's education which may pejoratively increase the academic achievement gap.

In addition to the socioeconomic barriers that plague Latino immigrant parents, the lack of an educational home environment is also of vital importance. Many of the students who live under these low socioeconomic conditions are often left at home unsupervised while their parents work in multiple jobs or with inflexible hours in order to provide for their family (Barrueco et al., 2007). This exacerbates the problem because students are not provided the academic support and guidance needed to inculcate the importance of an education, which in turn can aid in improving their academic achievement. Chang et al. (2009) argued "that when parents are directly involved in their children's schoolwork, the children demonstrate higher levels of academic motivation and performance” (p. 2).

\section{Culture}

Culture refers to "patterns of behavior, explicit and implicit, acquired and transmitted by symbols consisting of traditional ideas and values” (Kroeber \& Kluckhohn, 1952, p.47). This may include characteristics and knowledge of a particular group of people, typically defined by language, religion, and social lifestyles. Differences 
in culture can be another barrier that affects the academic success of Latino immigrant children in general. Many immigrant children come to the United States facing barriers such as lack of language skills or knowledge of the new culture. Niemeyer et al. (2009) claimed that " $34.4 \%$ of the Latino population in the United States is under the age of 18 and forecasts a guess that by 2020 Latinos will encompass $22 \%$ of the youth in the United States” (p. 630). Because family is the dominant source of sustenance in the Latino culture, it is rational to assume that parental involvement is a main factor in the academic achievement of Latino students. However, Latino parent's school involvement greatly differs from the school's definition, which is to be actively involved in school extracurricular activities or parent/teacher conferences (Niemeyer et al., 2009). Rather, Latino parents trust the schools with reverence towards teachers and school authority (DelgadoGaitan, 2004). This cultural belief often creates the perception that parents are not engaged in their children's education.

Furthermore, there are many cultural values held within the Latino immigrant families such as respeto, which consists of honoring adults and professionals in the community, and familismo, which emphasizes a close bond with the family (Niemeyer et al., 2009). Delgado-Gaitan (2004), explained that the scarcity of parental involvement stems from the family's values that resonate from respect to school authority. For example, questioning or disputing academic issues with school personnel is perceived as disrespectful among the Latino culture. These cultural values leave teachers and school personnel to assume full responsibility of the children's academic success.

Numerous Latino immigrant families come to the United States in anticipation of job advancement through an education. However, the language barrier and lack of 
understanding of the educational policies and practices in the United States creates another barrier that directly impacts the children’s academic success (Villalba, Brunelli, Lewis, \& Orfanedes, 2007). In an effort to assist parents acclimate to a new culture, Ramirez (2003) suggested that schools collaborate with families and learn about their belief system by inquiring what expectations the parents hold for their children's education. This approach will assist in creating a paradigm shift where teachers become the learners rather than transmitters of knowledge; thus understanding and acclimating to the parents' cultural values and beliefs (Ramirez, 2003).

\section{Parent Motivation}

Parent motivation is another barrier that impacts parental involvement. This barrier can be influenced by parents' psychological state, such as anxiety or depression (Hill \& Taylor 2004). These factors are often interconnected with low socioeconomic status, alongside language and cultural barriers. In order to minimize some of these challenges, schools need to make parents feel that their involvement is vital and necessary to the academic achievement of their children. This can be accomplished by inviting parents to academic meetings, community and school functions.

Hoover-Dempsey and Sandler (2005) provided a framework that examines major sources of motivation for parental involvement. These sources include parents' motivational beliefs and parents' perceptions of invitations to school involvement. Parental belief may be influenced by the norms of the group or family to which the parent belongs. Snell, Miguel and East (2009) explained that families with traditional cultural values may assume that in-school parental involvement is not their responsibility, rather that of the school. For Latino immigrant families to become directly involved in their 
children's schooling they must view their involvement as their responsibility. Because familismo is a cultural value among Latino immigrant families, assuming responsibility for their children's academic achievement in school would require a shift in their cultural beliefs (Niemeyer et al., 2009). Further, these cultural beliefs initiate from the parents' school experience that may impact the parents' motivation to participate in their children's education.

Likewise, these experiences may often hinder the parent's motivation and the belief that their assistance will produce the desired outcomes, which may impact the parents' self-efficacy. Self-efficacy suggests that parents make involvement decisions based in part on their thinking and personal school experiences. (Hoover-Dempsey et al., 2005). Delgado-Gaitan (2004) argued that there are inherent strengths among Latino immigrant families’ regardless of any challenge or prior experience. Schools must capitalize time and effort in learning the cultural beliefs and customs of parents in order to successfully meet the academic needs of the diverse students. Parents must also feel that schools care and want their involvement (Mapp, 2003). This in turn will motivate parents to become active participants in their children's education, thus enhancing parents' self-efficacy.

To make certain that parents are comfortable attending their child's school, schools should promote a culture where all parents are welcomed. Promoting a friendly environment and keeping parents well versed of school related issues such as their children's academic progress and other pertinent school information would help heighten parental motivation. This in turn could make parents feel like equal stakeholders in the school community. 


\section{School Invitations}

Invitations from the school, as emphasized by Hoover-Dempsey et al. (2005) are significant predictors of Latino parents’ school-based involvement. Invitations can vary from systematic invitations to attend parent-teacher conferences to suggesting ideas or activities for parents to implement at home to motivate students and/or assist them with their schoolwork. Stanley, Juhnke and Purkey (2004) argued that parental invitations from schools are a more critical variable in Latino parental involvement than selfefficacy. Although there are many practices that schools can put in place to encourage and ultimately increase parental involvement, schools must be cognizant that there are a wide range ways parents can be actively involved in their child's education and they must make an effort to communicate that message with parents (Stanley et al., 2004).

\section{Language}

Latino immigrant parents' determination to assist their children with academic tasks and school activities becomes more challenging when they have had limited exposure to a formal education and particularly if they lack fluency in the English language. This challenge is amplified when parents are unable to read or write in their native language, which significantly impacts children’s literacy (Ortiz \& Ordonez, 2005). This factor particularly contributes to the truncated academic attainment of Latino students as it results in parents not reading to their children or exposing them to a variety of literature in English or in their native language. These children are at a disadvantage at school because their cognitive level and prior knowledge is minimal as compared to their peers. To help remediate this issue, schools must reach out to parents, through home visits or phone calls, so as to engage immigrant parents and particularly utilizing 
bilingual school staff that can eliminate language barriers (Ortiz et al., 2005). Similarly, adult reading classes during flexible hours may also promote literacy and parental engagement with other parents.

Additionally, research suggests that Latino children from families where English is not spoken are more likely to live in impoverished conditions as opposed to their peers (Garcia \& Jensen, 2009). The language spoken at home as well as the socioeconomic level has an impact on literacy practices at home, and more specifically on the language development of Hispanic children in the United States (Hoff, 2006). Reardon and Galindo (as cited by Garcia \& Jensen, 2009), explained that language spoken at home may influence mathematics and reading achievement. For instance, families who do not speak English are limited when it comes to assisting their children with school assignments. In addition, studies argue that Hispanic children where Spanish was the primary language used, lagged behind their non-Hispanic White peers and even more so behind other Hispanic children who spoke English most of the time (Garcia \& Jensen, 2009).

Research also indicates that regardless of the language families choose to speak at home, parents should utilize language to contribute to their children's academic success (Reyes \& Azuara, 2008). For example, Latino immigrant parents can contribute to their children's education by reading to their children, exposing them to literature and storytelling in their native language, or encouraging and allowing the children to ask questions and initiate topics of discussion. This involvement would improve literacy practices while promoting critical thinking skills that will encourage self-efficacy and ultimately lead to academic achievement. 


\section{Parents' Self-Efficacy}

Research indicates that Latino students experience academic success in general at a lesser rate than their non- Latino peers (National Center for Education Statistics, 2011). High school dropout rates among Latino students are 26\% higher compared to students in any other racial or ethnic group. This is largely impacted by the academic achievement gap that often begins as early as elementary school. This problem emphasizes the need to identify factors that directly impact the academic achievement of Latino students. As previously mentioned in the chapter, low socioeconomic status and cultural factors have been linked to academic performance since low income families, unlike more affluent families, have limited access to resources that can support their child's education.

Chun and Dickson (2010) claimed that Latino families believe that teaching and learning occur through harmonious relationships. In addition to the challenges that plague Latino students, teachers' perception is that these students cannot perform at the same academic level as non- Latino students. A study conducted by Chun and Dickson (2010), examined how academic self-efficacy facilitates the relationship between parental involvement, culturally responsive teaching, a type of instruction that promotes equitable access to an education for all students from all cultures, and academic achievement among Latino students. The study focused on 478 Latino seventh grade students by probing the relationship of parental involvement, culturally responsive teaching, sense of school belonging, self-efficacy, and academic performance utilizing the Brofenbrenners ecological system theory. Each of the components was measured through a variety of questionnaires using Likert-type scales. The results of the study indicated that parental involvement, cultural responsive teaching, and sense of school belonging enhanced $\mathrm{H}$ 
Latino students' academic performance by increasing their academic self-efficacy (Chun et al., 2010). These findings are analogous with a previous study conducted by Kuperminc and Alvarez-Jimenez (2008) who claimed that the behavior of Hispanic parents and cultural values (familismo) enhance student achievement. However, these characteristics differ across different families who may have dissimilar educational values based on prior experience. Conversely, students’ perception of culturally responsive teaching by their teachers contributed to the sense of belonging and selfefficacy that led to higher grades.

The results of the above mentioned studies was extrapolated from students via questionnaires, rather than input from teachers or parents, and indicated that students seem to place great importance on self-efficacy. Chun et al. (2010) attributed the results to the support and expectations parent and teachers place on the students. Nonetheless, the fact that the author did not highlight where the questionnaires took place raises concerns in regards to threats to internal validity. For example, the participants in the study may not have answered the questions truthfully or possibly had someone else answer on their behalf. In the present study, an attempt to minimize threats to validity was done by having parents complete the parent survey in the presence of the researcher.

Another study conducted by Weiser and Riggio (2009) examined whether selfefficacy mediates the relationship between family backgrounds and academic achievement. The family background factors investigated included structure, socioeconomic status, parental school involvement, parent relationship quality, and parental school aspirations. The participants in the study included 193 college students, 15\% Euro American, 37\% Latino American, 37\% Asian American, 5\% African 
American and 5\% other. Out of the 193 participants, 67\% conveyed that their parents were married while $33 \%$ conveyed their parents were divorced. The participants were given four questionnaires using a Likert scale: a 17-item self-efficacy questionnaire; a 16item parental involvement questionnaire; a 48-item parental attachment questionnaire focusing on parental support and parent facilitation of independence; and a 6-item home affluence scale that measured socioeconomic status (Weiser et al., 2009).

Utilizing a series of regression analysis, the results of the study indicated that most of the family components predicted general and academic self-efficacy; however it was not a robust predictor of academic achievement. Furthermore, family structure, socioeconomic status, and parental aspirations did not significantly predict self-efficacy according to the study. Interestingly, higher socioeconomic status was correlated to lower levels of general and academic self-efficacy. Overall, self-efficacy was found to be the connection between parental involvement and expectation of academic success.

The above-mentioned studies emphasized that there was a correlation between parental involvement and parents' self-efficacy. As the public schools in urban Miami Dade County continue to increase in the enrollment of Latino immigrant population (U.S. Census Bureau, 2010), district and school leaders must do a better job in providing teachers the opportunity to participate in professional development that is geared towards facilitating training and providing strategies aimed at culturally responsive teaching. This will enhance the students' cultural knowledge and experience while fostering an environment where everyone has a voice and diversity is embraced. Moreover, the necessity for schools to afford parents the opportunity to become active participants in 
their children's education, both at home and in school is a paramount element to close the academic achievement gap that plagues the Latino students of the United States.

\section{Types of Parental Involvement}

There are many types of parental involvement and each play a pivotal role in the lives and educational progress of students. Epstein (2011) claims that when teachers make parental involvement a regular practice parents will increase their interaction with their children at home and feel more positive about their ability to help their children with academic tasks. Teachers who do not commonly involve parents in their children’s education made more stereotypic conclusions about the involvement and abilities of less educated parents, socioeconomically disadvantaged parents, and single parents (Epstein et al., 2009). This highlights that teachers' attitude and practice are as important as the education of the parents, socioeconomic level and single versus two parent families.

Epstein (2007) outlined six major types of parental involvement as part of schools' all-inclusive program to share responsibilities with families for the education of their children. These are:

- Basic obligations of families. This emphasizes the need for parents to provide their child with a safe and healthy environment as well as fostering positive parenting skills that will prepare the children for school. In addition, schools should assist families, through workshops and training, in an effort to assist families in the development of knowledge and skills needed to better understand their children at every grade level. 
- Basic obligations of schools. This component stresses the need for the schools to communicate the families in regard to their children's academic progress. This includes disseminating information to parents at parent/teacher conferences, home visits, telephone calls and academic progress reports.

- Involvement at school. School involvement is customarily spearheaded by schools allowing parents the opportunity to be part of the school's community through means of volunteering in classrooms, the library, main office or any other school activity. This increases a sense of belonging for parents and students as well as enhances the relationship between all stakeholders.

- Involvement in learning activities. This practice incorporates support and direction from teachers necessary to assist their children with academic tasks. School should also assist parents on how to monitor and support their children with home learning assignments.

- Involvement in decision-making. This element includes providing parents and community members the opportunity to actively participate and have a voice in council meetings, parent-teacher associations that are geared to the improvement of the school.

- Collaboration and exchange with community organizations. This component highlights the importance for all stakeholders and businesses to share responsibility for children's education. For example, after-school care for children and English classes for parents. 


\section{Parental Involvement Study}

Epstein (2008) explained in Improving Family and Community Involvement in Secondary Schools, that previous studies on family involvement leading to student success yielded three conclusions: parents possess a desire to know more about their children's education; students benefit from family and community involvement; and the development of goal-linked programs that reach all families help students succeed. The desire for parents to be involved in their children's education does not stop at the elementary school level.

As adolescents enter secondary school, their awareness of autonomy and independence increases, often leaving parents disengaged from their children's education. Parents want to be part of their children's educational journey and postsecondary plans in order to help them be better prepared for the future. Schools must keep parents informed of their child's academics, which includes grades, graduation requirements, assessments, as well as postsecondary training (Epstein et al., 2009). This can be accomplished through parent nights, invitations to grade level meetings, and meetings at local churches, parks and community centers. This will strengthen the collaboration between all stakeholders family, community and school, and provide students with the confidence and support needed to face the challenges that await them.

Presently, schools and colleges are faced with the task of preparing future teachers and administrators to understand and successfully implement research-based practices that will increase parental involvement. Epstein (2013) argues that a comprehensive course on partnership program development should familiarize future educators to four new directions for organizing and steering more effective schools and 
community partnerships that will contribute to student achievement. These partnerships include "teamwork, goal-linked partnerships, equitable partnerships and evaluation of program quality” (p.116). Teamwork requires schools to establish school-based team composed of teachers, administrators and parents in order to plan, construct, evaluate and continually improve activities that engage all stakeholders. Goal-linked partnerships are teams that ensure school-based activities contribute to student achievement. Equitable partnerships require teachers and administrators reach out to all families, regardless accessibility. Lastly, evaluating the quality of the program necessitates school teams to assess the school's progress in reaching all families to impact student achievement.

Equally important is the need for teachers and administrators to evaluate the goals needs and interest of their students and families in order to devise an effective community partnership program that is aimed at building positive relationships and student success.

\section{Impact of Parental Involvement Programs}

The implementation of educational programs for families also benefits students. For example, programs such as English or computer literacy classes for parents will aid in enhancing familiarity of the language and tools necessary to be more involved in their children's education. This encourages students to earn higher grades, complete more course credits and set higher aspirations (Epstein et al., 2008).

To meet the expectations of parents and teachers schools must implement strategic partnership programs aimed at the unique needs of schools and their community. Epstein (2008) explained that there are four components to effective and sustainable programs. First, action teams comprised of parents, teachers, students, and community member must collaborate to improve programs that are linked to the school's 
improvement goal. For example, schools in Miami-Dade County are required to create and implement a School Improvement Plan that encompasses five goals: content areas, career and technical education, parental involvement, early warning signs, and technology. The goals are geared to meet the specific diverse needs of the school and its community. A team comprised of school leaders, teachers, parents, and community leaders work together in the development of this document. Second, strategies and activities must focus on the six types of parental involvement that will provide parents the opportunity to become involved in their children's education in a variety of ways (Epstein, 1987). For example, at the school where the study was conducted, English classes are made available to parents who do not speak English through an evening class. Third, action plans should be linked to goals for student success. To ensure students’ success all stakeholders must work together. For example, businesses in the community can partner with the school to provide mentoring or incentives that are directly correlated to the school improvement goals. Lastly, to ensure that the activities and strategies are working, monitoring and evaluation must be conducted on an ongoing basis. This type of parental involvement encourages all stakeholders to have a voice in the success of their children's education which in hindsight will necessitate school leaders to share leadership and embrace input and suggestions that are geared towards the schools' improvement goal.

\section{School-based Parental Involvement}

Another form of parental involvement is school-based, consisting of attending school meetings, talking with teachers, attending school extracurricular activities and volunteering. Many Latino immigrant families who cannot speak English or who believe 
they have no right to interfere with the school's practices may avoid contact with the school and its teachers. This may account for the parents' cultural beliefs and lack of understanding of the educational school system in the United States that may result in minimal school-based involvement.

Furthermore, research shows that school-based parental involvement is greater among parents with high socioeconomic status and educational attainment (Pomerantz, Moorman, \& Litwack, 2007). In 2003, research indicated that 28\% of Latino parents versus 48\% of their American European counterparts participated in school-based activities (Pomerantz et al., 2007). This can be attributed to the parents’ own school experiences in their country of origin and contradictory viewpoints with teachers as to what constitutes a good parent. This matter is further embraced when parents feel that the only time they are contacted or invited to attend a school meeting is related to behavioral concerns or failing grades, which creates a negative experience. Because Latino immigrant families are usually unfamiliar with the educational system in the United States they may not be aware that they have the right to ask questions regarding behavior or academic issues concerning their children. Nevertheless, this does not indicate that Latino immigrant families do not care for their children’s education; rather, many Latino families are directly involved through home-based activities (Pomerantz et al., 2007).

\section{Home-based Parental Involvement}

Home-based involvement is generally defined in literature as interactions that take place between the child and parent outside of school (Hoover-Dempsey \& Sandler, 2005). These home-based interactions include helping with homework, reviewing for a test, and monitoring their academic progress. Parents who are actively involved with the 
education of their children ensure that learning continues at home by providing their children with an environment to study that is free from disruptions, as well as a time specified for home learning and academic tasks (Hoover-Dempsey et al., 2005). Parents may also get involved by checking homework or its completion, give incentives for grades, or remove privileges for poor grades. These types of interactions do not limit Latino families who may not speak English, since dialogue can be accomplished in their own language. Research specifies that when parents are involved in their children's academic lives they highlight the value of school, which in turn allows children to view school as valuable (Hill \& Taylor, 2004). Home-based parental involvement is not limited to school assignments; it could also integrate other experiences such as visiting libraries, museums, or participating in other academic activities. Unfortunately, these types of involvement are more common among non-Latino parents who are of higher socioeconomic status and education (U.S. Department of Education, 2006).

\section{Components of Parental Involvement}

To further elaborate Epstein et al. (2009) provided additional strategies to enhance parental involvement: parenting, communicating, learning at home, volunteering or attending activities, decision making and community connections. The parenting component suggests that schools should provide parents with a variety of services needed to help them transition to the new culture and better understand the school's educational initiatives and demands (Epstein et. al., 2009). This is beneficial in schools with large Latino immigrant student populations, such as where the study was conducted, since the large majority of the parents do not speak English and many are new to the United States and not yet acclimated to educational practices and guidelines. 
In order for parents, especially Latino immigrant parents, to take advantage of these services, schools must be able to communicate with the parents. This would require schools to disseminate information in the parent's native language, and provide translators during meetings while sharing information pertaining to their child's academic progress. Epstein et al. (2009) also redefined volunteering to mean "anyone who supports the schools goals not just during school hours.” However, this poses a challenge since it would require schools to make flexible schedules to ensure all parents are able to partake. For instance, parents of low socioeconomic status may hold multiple jobs which may restrict them from volunteering at their child's school. This may give the false perception to the school that they are not interested in their child's education. Epstein et al. (2009) also explained that parents could also assist their children by having them learn at home. This would require schools to provide parents with strategies, in their own language, on how to help their children with homework and other academic tasks. In order for many of these strategies to be effective, parents must be included in the decision making process and kept abreast of resources and services from the community (Epstein et al., 2009). Schools must learn to be resourceful and provide a variety of techniques to keep parents informed. These methods can include, but are not limited to, phone calls, home visits and updated information on the school's website, community agency and churches.

While research supports that parental involvement is a key factor in improving academic achievement, both at school and at home, Pomerantz et al. (2007) argued that the outcome of parental involvement at school versus at home differs. School based parental involvement has been directly correlated with academic achievement, because parental involvement is delineated by the school's goals (Pomerantz et al., 2007). On the 
other hand, the impact of home based parental involvement is unclear since the involvement may not be a positive experience; parents may be negatively affected by stress or other unforeseen barrier that may lead to frustration or irritability (Reay, 2000).

In addition to the aforementioned factors that influence the types of parental involvement, Marshall (2007) argued that high levels of parental involvement are directly related with greater teacher awareness of students' cultural and community issues, in addition to stronger efforts by the school to upsurge parental involvement. Schools can connect with the community by participating in community functions and local non-profit organizations. These indispensable tactics focus on communication, breaking down cultural barriers, mutual parent and school interactions and encouraging a stronger level of participation.

\section{Single Parent Involvement}

Single parent families and its impact on academic achievement also demand attention (Ricciuti, 2004), especially for Latino Immigrant students who are the focus of the study. Children living in single parent families is common. The United States Census Bureau (2007) reports that approximately 13.6 million single parents are responsible for raising 21.2 million children. The report also indicates that $84 \%$ of the single parents are mothers; 44\% are divorced and 33\% have never been married (U.S. Census Bureau, 2007). This concern is amplified by the language and socioeconomic barriers parents face. This critical issue is parallel to the population where the study will be conducted since $95 \%$ of the parents are Spanish speaking and low socioeconomic status as evidenced by $85 \%$ of students receive free or reduced lunch. 
Furthermore, studies suggest that the limited income and resources of single parent families account for some reasons why their children do not perform academically as well as children from two-parent families (Ricciuti, 2004). The lack of resources and income often impede single parents from providing their children the educational materials and resources needed to assist them with succeeding in school. In contrast, children from affluent families have access to a plethora of resources. For example, these children have access to technology, books, tutors, and other educational activities such as visiting museums and traveling. These resources and activities broaden their background knowledge while providing them with real world experiences.

Additionally, a study conducted by Ricciuti (2004) suggests that parents exhibiting positive parenting practices can counterbalance potential negative consequences of single parenting for children. These characteristics include the level of education and expectations towards schooling. In this study Ricciuti (2004) analyzed the years children (subgroups White, Black and Latino, ranging in age from six to seven years) spent in a single parent family over a six-year follow up period. Results of the study indicated that there was little evidence of a consistent association between years in a single parent home and child outcomes. The study also analyzed the interactions between years in a single-parent family and seven variables. These variables include currently single parents, years in a single parent family, maternal ability, mother's education, poverty status, and maternal employment (Ricciuti, 2004). Out of the 105 interactions only six were statistically significant at the $p<.05$ level; two interactions involved gender, two maternal employments, one poverty status, and one for maternal education (Ricciuti, 2004). These findings support the author's argument that maternal 
attitude and resources assuage the probability of negative child outcomes of single parenting. Another study conducted by Carslon and Corcoran (2001) found that changes in family configuration of seven to ten year old students' academic achievement and behavior were reduced when controlling for the mother’s education and ability.

\section{Gender}

In addition to the increasing number of single parent families, attention must also be directed to the relationship between parents' gender and their children's academic performance. Presently, there are limited studies on single father families (Zhan \& Pandey, 2004). Since 1990, there has been a 62\% increase in the number of single father families in the United States (U.S. Census Bureau, 2000). This has lead researchers to ponder whether the academic and social development of children would be healthier in households with single mothers versus single fathers.

Videon (2005) argued that prior studies have disregarded the possibility that single mothers and single fathers might influence their sons and/or daughters differently. Studies propose that a mother is crucial in forming their children's psychosocial characteristics and social competence, whereas a father's role is important in cognitive development (Stolz, Barber, \& Olsen, 2005). However, others would argue that socialization and other developmental factors are better understood by a parent of the same gender, since children learn by emulating the thoughts and actions of the parent with the corresponding gender (Lee, Kushner, \& Cho, 2007).

Lee et al. (2007) conducted a study to explore if there was a significant difference in academic achievement of adolescents who live in single father households compared to those who live in single mother households. Additionally, adolescents who live with the 
same gender parents as opposed to those who lived with different gender were investigated. The results of the study indicated that there was no significant difference in academic achievement between children who lived in single father homes and those who lived in single mother homes (Lee et al., 2007). Likewise, there was no significant difference between children who lived with the same gender parent and those who lived with a different gender parent.

However, the results of the study revealed that daughters who lived in single father homes obtained higher academic scores when their fathers were more involved in their school and academic activities (Lee et al., 2007). Conversely, Kalman (2003) explained that a reason why fathers may not be as involved in their daughters' education as they would with their sons may be that fathers are apprehensive with topics related to female adolescent development. Basically, fathers may feel more at ease with their sons because they are more likely to share similar interest and hobbies, and can better comprehend the adolescent development phase from their own experience. Fathers may perceive their sons' tomfoolery as immaturity and thus dismiss it and not take it seriously. This may cause concerns at school since the expectations for a son may be different than for a daughter.

\section{Parental Involvement in Reading and Mathematics}

The eighth U.S. educational goal in Goals 2000 states, "Every school will promote partnership that will increase parental involvement and participation in promoting the social, emotional, and academic growth of the children (U.S. Dept of Ed. 1994).” This accentuates the notion that parental involvement has long been considered a vital factor in increasing student academic achievement. An increase in parental 
involvement may be correlated with students' motivation for reading. This correlation may be a prominent issue for Latino immigrant children who already lag behind their peers, especially in reading (Lutkus, Gregg, \& Donahue, 2007). National data indicates that Latino students are academically behind their European American peers and consistently struggle to obtain the skills needed to be proficient in reading (NAEP, 2007).

\section{Literacy}

Latino parents view literacy practices, such as reading, writing, interpreting and analyzing multiple types of artifacts, and academic success a necessity for economic and social attainment, regardless of the amount of time they have lived in the United States or the myriad of challenges they face (Loera, Rueda, \& Nakamoto, 2011). In examining the relationship between Latino immigrant parents and school, culture must be taken into consideration. For example, communicating a good work ethic to their children is a way Latino parents prepare their children to be successful in school and work. Latino parents' views of literacy development are greatly influenced by their own experiences that often include poor or lack of formal schooling and poverty. Also, Reese and Goldenberg (2008) reported that Spanish-speaking families have less access to educational means when compared to more affluent families or English-speaking households.

A study conducted by Guthrie and Wigfield (2000) argues that the motivation to read is multidimensional and people will engage in reading tasks for various reasons. The study incorporated a range of variables necessary for measuring children's reading motivation. The variables included: self-efficacy, challenge, work avoidance, curiosity, involvement, importance, recognition, grades, completion, social motives, and compliance (Guthrie et al., 2000). The participants were 99\% Latino. Both students and 
parents completed a questionnaire on motivation for reading. The results of the study indicated that the children reported moderate levels of reading motivation. Conversely, the parents reported moderate involvement in their child's reading and higher levels of involvement in their child’s overall schooling (Guthrie et al., 2000). Moreover, parental involvement in reading such as reading to children, listening to children read, and providing choices in reading material was linked to higher reading achievement (Loera et al., 2011).

The result of the studies strongly reinforces the urgency for closing the reading achievement gap of Latino students. In view of this, schools need to take into consideration family factors like culture and prior experiences. Likewise, schools should engage parents with ongoing communication in order to provide clear expectations and instructional strategies they can utilize at home regardless of any barriers. Schools can provide parents with books and magazines in Spanish in an effort to promote and enhance the literacy skills of their children in their native language. When parents learn to encourage reading as enjoyable, in turn, it helps increase their children's motivation to read. Parents who do not speak English can also infuse this strategy by reading to their children in their native language.

To further highlight the importance of literacy, a study conducted by Reese and Goldenberg (2008) of Latino immigrant families and literacy, indicates that if parents do not take advantage of literacy resources, provided at school or in the community, such as public libraries, their children will lag behind their non-Latino peers. This places the responsibility on parents to seek out literacy resources and spend time listening and reading to their children. Unfortunately, the lack of infusing reading practices at an early 
age often results in students lacking the essential skills and intrinsic motivation to read (Reese et al., 2008). Alldred and Edwards (2000) explain that this concern increases when students enter middle and high school where they repeatedly resist and alter the degree to which they allow their parents to be actively involved in their education. The resistance is usually due to the sense of independence and autonomy students obtain, as they get older (Alldred et al., 2000).

\section{Mathematics}

To further analyze the impact of parental involvement in students' academic achievement, a study was conducted to examine parental styles and types of involvement, and its correlation to the motivation of Algebra I students (Gonzalez \& Wolters, 2006). The parental styles included in the study were permissive, authoritative and authoritarian. Two views were observed in this study: achievement goal theory and self-determination theory. Achievement goal theory (comprised of mastery and performance approach) highlights the motives students assume as they engage in an academic task. Selfdetermination theory describes the level of autonomy and individual experiences while engaging in a given task (Gonzalez et al., 2006). Students who practice the mastery approach spend time studying due to their intrinsic desire to learn information on a deeper level. In contrast, students who embrace the performance approach orientation are focused on competition. They learn and perform a task in order to demonstrate ability in comparison to other students.

Applying a multivariate analysis, the results of the study indicated that authoritative parenting was positively related to mastery goal orientation and higher autonomy. Students saw their engagement in academic tasks as a result of their own 
values and choices. Permissive parenting was negatively related to mastery orientation however positively related to performance approach theory. Students reported being less focused on improving themselves or overcoming challenges when completing their math work (Gonzalez et al., 2006). Authoritarian parenting was only positively related to performance approach orientation. Students reported a greater focus on doing their math work in order to outperform others. However, they were less likely to express feelings of autonomy (Gonzalez et al., 2006). These results stress that parental involvement is multifaceted and can be interconnected with intrinsic and extrinsic forms of motivation among young adolescents. This is parallel to Edward Deci's Cognitive Evaluation Theory (1985) that suggests that the environment impacts the development of a child's intrinsic motivation. The environment is not limited to the child's home; schools play a fundamental part in guaranteeing teachers create a classroom environment that fosters motivation to learn.

Additionally, Hong, Yoo, You and Wu (2010) conducted a study comparing the longitudinal associations between two types of parental involvement (values and reinforcement) and high school students' math achievement. The results of the study indicated no significant association between parents' academic reinforcement and math achievement. Also, there was no gender difference in the association between the types of parental involvement and students' math achievement. This is inconsistent with recent studies that argue that parents' involvement is different in regards to their female or male children’s education (Carter \& Wojtkiewicz, 2000). On the other hand, parental values led to an increase in their high school children's math achievement (Hong et. al., 2010). It 
is important to underline that irrespective of the decline in parental involvement as students enter secondary school, parents influence children's values and behavior.

\section{Cross-Cultural Approach and Parental Involvement}

Presently, schools are faced with a variation of culture, ethnicity, race, and social class in the student population, making the classroom environment increasingly diverse. This creates a concern because teachers may not be culturally sensitive to the needs of the diverse population (Epstein, 2013). In an effort to identify the uniqueness and parallels among the different cultures, teachers must become sympathetic to the needs of the distinctive cultures within the classroom.

Subsequently, the home and school environments are instrumental in the cognitive development of a child and attention should also be directed to teacher practices. Teachers have the responsibility for encouraging parental involvement and teaching students a set curriculum put in place by district that infuses cross-cultural literacy practices. A cross-cultural approach to literacy underlines how students can be knowledgeable about a variety of cultures ranging from one continent to the next (Mabry \& Bhavnagri, 2012). Teachers who embrace diversity draw from the experiences and knowledge of each student to understand and expand their schema of other cultures.

Becuase experiences of individual students differ, the understanding of preferred writing and reading material is often related to their individual experience which in turn impacts their ability to expand their schema (Mabry et al., 2012).

Reading and writing about their experiences allows students to expand their knowledge of their culture and embrace others as well. Gaskill (2006) explained that seeing a perspective different than your own is imperative in cross-cultural 
communication. This is important in schools that house a diverse student population, such as where the study will be conducted. Bhavnagri and Willette (2011) suggested that teachers should familiarize themselves with their students’ background and prior knowledge. This information will allow teachers to promote discussion of text and interject questions that are analogous to the lives of students, thus highlighting similarities between the characters and themselves, regardless of culture. Questions and topics of discussion should also accentuate on different cultural components or knowledge in order to build from their own experience and expand their knowledge.

Cross-cultural literacy practices can also be infused within Latino immigrant households. Parents can read with their children from a variety of culturally diverse literature or expose them to libraries and museums that foster cultural diversity. Unfortunately, many Latino immigrant families are unaware of the educational practices in the United States and thus are dubious as to how they can translate their support of education to daily practice. Likewise, teachers are often uncertain how to support immigrant children. Julia Menard-Warwick (2007) conducted a study of two Nicaraguan immigrant extended families. The study focused on the literacy practices and values of two sisters-in-law who shared a home and whose daughters attended the same low performing school. Both women attended the same school and were enrolled in the English as a Second Language (ESL) program. However, their approach to literacy and schooling differed. One of the women, who valued education, infused literacy strategies in her household by reading to her daughter in English and Spanish, providing a variety of educational activities such as computer games, and constant visits to the library. In contrast, the other woman in the study, had different educational standards, and promoted 
literacy practices in her household encouraging her daughter to read biblical stories to her siblings and incorporating biblical discussion with the family, while making connections to the real world (Menard-Warwick, 2007).

This study underlined the different approaches to literacy employed within the same household. Both mothers contributed to their daughters' education by attending school meetings and supervising their schoolwork. Although each mother's educational values, experiences, and methodologies differed, each was able to draw from a variety of English and Spanish literature to increase the knowledge and experience of their daughter's culture while enhancing cognitive development (Menard-Wawick, 2007). Infusing a cross-cultural approach in schools and at home contributes to the increase in knowledge and experience of students while fostering sensitivity to other cultures around them.

\section{Summary}

Research indicates that parental involvement is a chief component of the academic achievement in children. Additionally, the literature review supports the claim that more attention is given to Latino immigrant students who perform at a lower academic achievement levels than their White non-Hispanic peers (Marschall, 2006). Researchers claim that this is partly due to the impoverished conditions that many of the children live in and language barriers that underlie the low academic achievement and high dropout rates among Latino students (Singh \& Sung, 2009). This is augmented by a plethora of barriers, as described in the literature review, and culture differences that often discourage parents from being actively involved in their children's education. 
Regardless of the challenges Latino immigrant parents may face, Loera et al. (2011) claimed that the role and involvement in reading practices with their children is positively correlated to their children's reading engagement. Furthermore, parental involvement in reading such as reading to children, listening to children read, and providing them with choices in reading materials was positively linked to higher reading achievement (Loera et al., 2011). In light of this, schools need to make a better effort at building sounder relationships with their Latino families thus minimizing the perception that Latino families are not interested in their children's education. Also, understanding the cultural values among Latino immigrant families can assist schools to embrace the children's cultural background and experiences, as well as understand the parents' actions, thereby meeting the diverse needs of the children (Niemeyer et al., 2009). Findings from the literature indicated that all stakeholders should devote time, effort and commitment in order to build strong parental involvement within schools, especially among Latino immigrant families. Approaches suggested in the literature include on-going parent invitations to meeting or school activities, translators for parents who do not speak English, and a welcoming environment where parents feel they are cared for; thereby building trust between parents and school (Hoover-Dempsey \& Sandler, 2005). Likewise, research indicates that teachers should infuse a cross-cultural approach within their classrooms in an effort to encourage students to embrace their differences while teaching them to embrace and learn about other cultures (Mabry \& Bhavnagri, 2012).

As suggested by Jeynes (2003), there is a need for further studies pertaining to parental involvement, especially concerning Latino immigrant families, as well as single 
parent families. The studies should include a larger sample that would help all stakeholders, especially schools, better understand and meet the needs of the diverse student population. 


\section{CHAPTER III}

\section{METHOD}

The purpose of the study was to examine the relationship of the parental involvement of Latino immigrant parents of middle school students and student reading and mathematics academic achievement. There is a wide achievement gap between Latino students and other groups with Latino students scoring lower. Investigating this issue was critical because Latinos are the fastest growing minority group in the United States (U.S. Census Bureau, 2010). Although the majority of Latinos in the United States are native born, consideration must also be given to Latino immigrant families who have greater needs as they adapt to a new culture, language and education system (Dockertman, 2011). While Latinos are the largest minority group in the United States, the Latino parental involvement rate has been described as low to nonexistent, when compared to Euro-American families (Lee \& Bowen, 2006). More information about the types of parental involvement and the correlation to their children's academic success is imperative.

The study employed a non-experimental correlational research approach to obtain a better understanding about the types and intensity of Latino immigrant parental involvement and the relationship between the involvement and children's academic growth. To have sufficient statistical power to run the analyses associated with this research, Cohen (1988) recommended a sample size of at least 15 participants per predictor variable. Because there are seven predictors (sex of students and parents, parents' socioeconomic status, single versus two-parent families, parents' level of education, language, type and intensity of parental involvement) sample sizes of at least 
105 was necessary for this research. Academic performance was measured through the students' first quarter grades for reading and mathematics. A parent survey questionnaire was utilized to obtain an understanding about the perceptions of school-based and homebased parental involvement practices, level of education, expectations, self-efficacy, and knowledge and skills. The data gathered were analyzed using correlational analysis to identify the role of the independent variable, parental involvement, has in accounting for variance in the dependent variables, academic performance in reading and mathematics (Nathans, Oswald, \& Nimon, 2012).

The framework of the present study was founded on Joyce Epstein’s (2001) six types of parental involvement. The theory was focused on the need for schools to implement programs that will improve the partnerships between schools, families, and communities. Epstein's six forms of parental involvement are: parenting, communicating, volunteering, learning at home, decision making, and communicating with the community. Epstein argued that schools and communities need to make a greater effort in learning more about their students and families and collectively design programs that will meet the needs of all stakeholders while increasing student achievement. Examining the partnership between Epstein’s six forms of parental involvement assisted in predicting the relationship between seventh grade students' academic achievement and parental involvement.

\section{Dependent and Independent Variables}

To examine the relationship of the parental involvement of Latino immigrant parents and student academic achievement, the dependent variables in the study were the selected seventh grade students' reading and mathematics first quarter report card grades. 
The independent variables were the types of parental involvement. Demographic variables such as sex of the students and parents, socioeconomic status, single versus two-parent families, parents' level of education, parents' self-efficacy and language were used to predict the relationship each had with the dependent variables.

\section{Setting}

The study was conducted in a South Florida public school. Miami-Dade County Public Schools is the fourth largest school district in the nation and is made up of 460 schools with approximately 353,000 students. It has rapproximately 50,000 employees and 24,546 teachers at an average salary of \$54,615.00 (Miami-Dade County Public Schools, Office of Research and Data Analysis, 2014).

The school district provides a wide range of innovative and educational programs designed to give parents and students an active voice in choosing learning opportunities that foster student diversity, academic excellence, and real-world learning. Currently, the district offers a choice of over 475 magnet programs. These programs provide educational options that focus on technology, language immersion, and visual and performing arts with innovative instructional approaches designed to attract student from a variety of ethnic and economic backgrounds. Recently, magnet schools have been utilized to increase school choice options, retain students in public schools and enhance academic achievement (U.S. Department of Education, 2010).

Because of the large size of the school district, it is apportioned into six regional offices each supervised by administrator directors and one regional superintendent. Each regional office contains various feeder patterns. The feeder patterns are designed to have several high schools as well as middle schools and elementary schools which feed 
students into the high schools. The different regions allow the district to better meet the needs of its distinct student population.

This setting was selected because there is limited research with regards to Latino parental involvement and student achievement in middle schools (Reio, Whitehead, \& Dzhuryak, 2014). The middle school where the study was conducted houses a large Latino population where the majority of the students are low performing in reading and mathematics. Additionally, the middle school is part of the Education Transformation Office (ETO) region which consists of 78 schools - 42 elementary, 10 K-8, 13 middle, and 13 high schools. All the schools in this region have a high population of students at risk, with a low performance on state assessments (Florida Comprehensive Assessment Test and End of Course exams), and low socioeconomic status. Because many of these schools are state sanctioned, they receive additional federal resources such as instructional coaches, technology, and funding for tutoring before school, after school, and on Saturdays. Consequently, they are under more scrutiny by the community, school board members, the superintendent, and the media, as compared to other school regions.

The middle school where the study was conducted is made up of approximately 900 sixth, seventh, and eighth grade students: 95\% Latino, 2\% Black, 2\% White and 1\% other. It houses a staff of 84 full time employees. The full-time employees consisted of 57 teachers, 11 paraprofessionals and 16 non-instructional personnel, which includes administrators, security, and office staff. Part-time personnel are not included because their hiring depends on the budget that is allocated to the school on a yearly basis. 


\section{Participants}

The study was conducted during the 2015-2016 school year in a middle school located in a low socioeconomic neighborhood in South Florida. The student population often fluctuates due to the high rate of mobility, especially among sixth graders. For example, throughout the school year many immigrant parents migrate to the United States in search of employment as well as relocate to other areas, thus impacting their children's academic stability. The researcher chose to focus on seventh grade Latino students because the rate of mobility was minimal and assessment data indicated that they performed academically lower than the six and eighth grade students. This will also allowed the researcher to track the academic growth and level of parental involvement when students transition to the eighth grade.

Although the total number of seventh grade students in the middle school where the study was conducted consisted of approximately 340, only students who performed at academic achievement level of 1 or 2 (based on the Florida Comprehensive Assessment Test), were English Language Learners, and of Latino origin were considered for the study. The researcher included 134 seventh grade students, which was 34\% of the total seventh grade students, and their parent/guardian who met the ethnic and academic achievement criteria and parents were willing to participate. This sample included 91 students of Central American origin and 43 of Cuban origin. The gender breakdown of the participants was comprised of 80 boys and 54 girls. Because the percent of African American, White, and other students is proportionally small, a generalization could not be made. Students in the study were in the lowest percentile of academic achievement as determined by their most recent state assessment scores in reading and mathematics. 
Demographic data on student participants included the following areas: gender, ethnicity, special education eligibility, English Language Learner (ELL) status, and school reduced meal status percentages

\section{Research Design}

The purpose of this study was to investigate the relationship of parental involvement in predicting reading and mathematics achievement of Latino immigrant students in an urban South Florida public school. The study also examined theoretically relevant demographic variables such as socioeconomic status, level of education, single versus two-parent family, sex of the students and parents, type and intensity of parental involvement.

The type of design that was utilized in the study was a quantitative correlational design. The quantitative component of the research utilized in the study was data collection from parent questionnaires and the selected seventh grade students' first quarterly grades. The researcher chose this design in order to examine the strength of the relationship between the various independent and demographic variables and the dependent variables (reading and mathematics achievement). However, only the parent questionnaires were analyzed using a multiple regression analysis.

\section{Research Questions and Hypotheses}

The following are research questions and null hypotheses that were addressed in the study:

Q1. Does parent involvement predict students' reading and mathematics achievement as measured by the first quarter report card grades? 
H01a: Parents' involvement as measured by the parent surveys will not predict the students' reading achievement as measured by the first quarter report cards grades.

$\mathrm{H}_{01 \mathrm{~b}}$ : Parents' involvement as measured by the parent surveys will not predict the students' mathematics achievement as measured by the first quarter report cards grades.

To test the two null hypotheses related to the first research question, a linear regression was run to predict the two dependent variables, reading and mathematics achievement. Parent involvement was the independent and predictor variable in the research question.

Q2. Does parental socioeconomic (SES) predict reading and mathematics achievement as measured by the first quarter report card grades above and beyond parental involvement?

$\mathrm{H}_{02 a}$ : Parental SES will not be significantly related to reading achievement as measured by the first quarter report card grades above and beyond parental involvement.

$\mathrm{H}_{02 \mathrm{~b}}$ : Parental SES will not be significantly related to mathematics achievement as measured by the first quarter report card grades above and beyond parental involvement.

To test the two null hypotheses related to the second research question, a linear regression was run to predict the two dependent variables, reading and mathematics achievement. Parent socioeconomic status (SES) was the independent and predictor variable in the research question.

Q3. Is there a relationship between single-parent homes versus two-parent homes and the students' reading and mathematics achievement and first quarter report card grades? 
$\mathrm{H}_{03 a}$ : There will be no relationship between students from single-parent versus two-parent homes in reading achievement and first quarter report card grades.

$\mathrm{H}_{03 \mathrm{~b}}$ : There will be no significant relationship between students from single parent versus two-parent homes in mathematics achievement and first quarter report card grades. To test the two null hypotheses related to the third research question, a linear regression was run to predict the two dependent variables, reading and mathematics achievement. Single-parent homes versus two-parent homes was the independent and predictor variable in the research question.

Q4. Does type and intensity of parental involvement account for a significant amount of unique variance in predicting reading and mathematics achievement when controlling for parents' level of education.

$\mathrm{H}_{04 a}$ : There will not be a relationship between the type and intensity of parental involvement and reading achievement when controlling for the parents' level of education.

$\mathrm{H}_{04 b}$ : There will not be a relationship between the type and intensity of parental involvement and mathematics achievement when controlling for the parents' level of education.

To test the two null hypotheses related to the fourth research question, a hierarchical regression was run to predict the two dependent variables, reading and mathematics achievement. Type and intensity of parental involvement are the independent and predictor variables in the research question. 


\section{Instruments}

The instruments in this study consisted of a parent survey questionnaire, The Parent Involvement Project (PIP). The questionnaire authored by Hoover-Dempsey and Sandler in 2005 underwent face and validity evaluation by a panel of experts who were

authorities in the constructs being evaluated. Satisfactory face and content validity were achieved for all the questionnaires. Permission to use or modify this scale was granted by Kathleen Hoover-Dempsey and Howard Sandler on the Family-School Partnership Lab webpage.

Further, Hoover-Dempsey and Sandler (2005) provided predictive validity evidence and implemented the above-mentioned questionnaires in a project focused on parental involvement in elementary and middle school students' education. The study concentrated on two goals: to develop reliable measures for assessing constructs included in the model and to test model-driven hypothesis about the causes and consequences of parental involvement in students' education. Both goals were tracked in a series of four studies collected over a 3-year period. Results of the study indicated reliable measures for assessing all constructs in the model of parental involvement. The first study (model level 1) focused on parents' motivation for involvement and supported satisfactory reliability. Hierarchical regression analysis indicated, "that parent role construction was the strongest motivator for parent involvement (Adj. $R^{2}=.162, F=58.18 p<.000$ )” (p. 39). The second study (model level 2) that focused on parents' choice of involvement suggested, "that a substantial subset of the construct accounted for $64.6 \%$ of the variance in total involvement $(F=.181, p<.000)$ and the strongest predictor was perceptions of specific child invitations ( $B=.428)$ ) (p. 43). The third study (model level 3 ) focused on 
mechanisms parents used during their involvement activities found regression results were, "significant in predicting proximal academic outcomes (Adj. $R^{2}=.039, F=17.89$, $p<.000 ; \mathrm{t}=4.230, p<.000$ ” (p. 48-49). Additionally, student reports of parent involvement were also significant “Adj. $R^{2}=.357, F=234.393, p<.000 ; \mathrm{mt}=15.310, p$ $<.000$ " (pp. 48-49). The fourth study examined all levels of the models and summary measures of student achievement. The regression results suggested that constructs at level 1 of the model predict a significant portion of the variability in parent involvement. Reports of mechanisms engaged during involvement were positively related to student proximal academic outcomes. In the third study, "students' perception of parents' involvement mediated the influence of that involvement on student proximal academic outcome” (p. 62). Further, parent and student reports of parental modeling reinforcement, and instruction were positively related.

The constructs of the questionnaires were directly related with the empirical work of Epstein (2001) who claimed that children learn and grow from their families, schools, and community simultaneously and continuously. Because these contexts are interconnected, Epstein claimed that it is vital to create strong and positive approaches that will enhance and strengthen the development of children.

\section{Parent Involvement Project (PIP): Parent Questionnaire}

The parent questionnaire survey, available in English and Spanish, was adopted and modified from the work of Hoover-Dempsey and Sandler (2005), which consisted of 73 Likert-type items and eight status items, amongst nine constructs. These questionnaires both appear in the Appendices. The constructs included parent's school experience, invitations for involvement, reinforcement, parent's perception of knowledge 
and skills, involvement activities, encouragement, instruction, self-efficacy, and status variables. Although the parent survey included items about parental role belief, time and energy, modeling and specific child demands, these topics were not analyzed because they were not the focus of the study. A Likert-type scale ranging from 1 to 6 measured the constructs.

\section{Parents' school experience.}

In this construct, parents responded to 5 Likert-type items, for example $M y$ overall school experience... Each item was on a range; one end attached by negative experience, the other by positive experience (e.g., My school: 1 = disliked, 6 = liked). Data for this scale were gathered during the 3-year study conducted by Hoover-Dempsey and Sandler (2005) and yielded an alpha reliability of 0.84 .

\section{Invitations for involvement.}

In this construct, parents responded to 6 Likert-type items, for example I feel welcome at this school. The responses are measured on a 6 point Likert-type response scale: disagree very strongly $=1$, disagree $=2$, disagree just a little $=3$, agree just a little $=4$, agree $=5$, agree very strongly $=6$. . Data for this scale was gathered during the three - year study conducted Hoover-Dempsey \& Sandler (2005) and yielded an alpha reliability of 0.83 .

\section{Reinforcement.}

In this construct, parents responded to 5 Likert-type items, for example We show our child we like it when he/she works hard on homework. The scale was modified from Martinez-Pons (1996) and was used during the three-year study of the parental 
involvement process (Hoover-Dempsey \& Sandler, 2005) and yielded an alpha reliability of 0.96 .

\section{Parent's perception of knowledge and skills.}

In this construct, parents responded to 6 Likert-type items, for example I know how to supervise my child's homework. Data for this scale was gathered during the three - year study conducted by Hoover-Dempsey and Sandler (2005) and yielded an alpha reliability of 0.83 .

\section{Involvement activities.}

In this construct, parents responded to 6 Likert-type items, for example Someone in this family helps this child study for tests. The construct was adapted from Epstein and Salinas (1993) and Hoover-Dempsey, Sandler, Walker, Jones, and Reed (2002). This construct was divided into two scales, child specific and school general. Both constructs measure parents' preference of involvement in their child's education. The alpha reliability for the child specific scale yielded 0.85 and 0.82 for the school general scale.

\section{Encouragement.}

In this construct parents responded to 4 Likert-type items, for example We encourage this child when he or she doesn't feel like doing schoolwork. The scale was modified from Martinez-Pons (1996) and was used during the three-year study of the parental involvement process (Hoover-Dempsey \& Sandler, 2005) and yielded an alpha reliability of 0.87 .

\section{Instruction.}

In this construct parents responded to 4 Likert-type items, for example We teach this child to follow the teacher's directions. The scale was modified from Martinez-Pons 
(1996) and was used during the three-year study of the parental involvement process (Hoover-Dempsey \& Sandler, 2005) and yielded an alpha reliability of 0.86 .

\section{Self-efficacy.}

In this construct parents responded to 5 Likert-type items, for example I don't know how to help my child do well in school. This scale derives from literature on personal efficacy and teacher self-efficacy (Ashton, Webb \& Doda, 1983; Bandura 1977, 1984, 1986; Dembo \& Gibson, 1985). The scale was later modified from the three-year study of the parental involvement process (Hoover-Dempsey \& Sandler, 2005) reducing the number of items and yielded an alpha reliability of 0.78 .

\section{Status-variables.}

In this construct, parents responded to eight status variables. These variables included: gender, marital status, family income, educational level, type of employment, and ethnicity/race.

\section{Data Collection}

The researcher obtained approval to conduct the study from the Institutional Review Board of Florida International University and Miami-Dade County Office of Research and Analysis. Once approval to conduct the study was granted, the researcher scheduled meetings for the participant group to explain the purpose of the study and the requirements needed to participate in the study.

Various office employees agreed to volunteer and assist the researcher with the data collection. In turn, the researcher trained the identified volunteers to obtain fidelity and confidentially in the data collection process. The data utilized in the study included a 
parent survey questionnaire, student demographic information, and students' first quarter reading and mathematics academic grades depicted on their district report cards.

In order to secure a high turnout for the initial meeting, the researcher and volunteers contacted parents by phone as well as created flyers that were sent home with the students. The meeting was held at night by the researcher, when most parents were available, to highlight the purpose of the study and address the importance of parental involvement and the relationship on students' academic achievement. The researcher explained how the information was utilized, reviewed consent forms, and elaborated on the format and process needed to complete the surveys. Moreover, the researcher explained how the surveys along with the information obtained would be confidentially maintained. Once the researcher concluded with the overview of the study, consent forms were distributed to the parents who agreed to participate in the research study.

The researcher and trained volunteers collected the signed consent forms and coded them using students' school identification number. Parents who signed the consent form were provided the opportunity to complete the survey that same day. Parents who were unable to complete the survey that day were provided with other flexible dates and times. The survey was available in both English and Spanish, and accessible on computers, via a Google survey, for parents who were technology proficient. Classrooms were also accessible with paper-based versions of the survey for parents who were less comfortable with computers. The researcher provided trained volunteers in each classroom to assist the parents. The volunteers were trained by the researcher to limit support to only reading the questions verbatim, defining words, and explaining the 
Likert-type tool. Additionally, the researcher kept a log of everyone who attended or rescheduled meetings, submitted signed consent forms, and completed the survey.

Parent surveys were administered and collected between October and November of the 2015-2016 academic school year. The reason the researcher chose this time frame was because during the beginning of the school year parents' seem to be more willing to attend school functions. A reason for this may be that parents make an effort to get to know the teachers and develop positive relations. Once all the data was collected from the parent survey questionnaires, the responses were analyzed through Statistical Package for the Social Sciences (SPSS).

\section{Pilot Study}

A pilot study, administered via a Google survey and paper base, was conducted with 10 volunteer parents who are not identified as participants in the study. The purpose of the pilot study was to provide the researcher with relevant information with regards to the clarity of the directions and questions as well as the amount of time needed to complete the survey. This was accomplished by asking the volunteers for feedback to identify ambiguities and difficult questions, record the time taken to complete the survey, decide whether it was sensible, and to re-word or re-scale any question that was not answered. Prior to the administration of the survey the researcher met with the volunteer parents to inform them of the purpose of the study and how the results will be utilized. In addition, parents were informed that all records would be kept confidential.

The pilot study was conducted on September 14, 2015 during a teacher workday at the middle school where the study was conducted. The researcher chose this day because school was not in session and therefore it did not affect instruction. The pilot 
study was administered in the school's computer lab where the survey was available in English and Spanish via a Google survey. Student desks were also available for parents who did not want to use the computer. Five of the parents chose to complete the survey in English while the remaining chose Spanish. Further, four of the parents chose to complete the survey via paper/pencil while the rest utilized the computers. The researcher along with office volunteers were present during the administration of the survey to monitor the length of time, address any questions the parents may have and note areas of concern.

The results of the pilot study indicated that the completion time of the survey took approximately 30 minutes; two parents completed the survey in 45 minutes, three in 30 minutes, three in 25 minutes, and two in 20 minutes. Concerns gathered from the pilot study with regards to the questions included: removing the title of the constructs from each section to avoid confusion; correcting some minor misspelled words in English and Spanish; removing three questions from the construct "Involvement Activities” (Attends PTA meetings, Open House, or Special Events) because it was early in the school year and the Likert-type answers did not correlate with the questions; adding “Other” under job choices in the demographic section; and rephrasing questions 8 and 50 to make them more clear.

Because of the feedback provided by the participants, the researcher removed the title of the constructs from the survey, corrected all misspelled words identified in the English and Spanish Survey, and within the same construct, "Involvement Activities" the researcher placed the three questions under a yes or no choice response. "Other” was also added under job choices in both the English and Spanish survey, and questions eight and 
50 were reworded for clarity (“I don’t know if I’m getting through to my child” to “I don't know if I'm communicating well with my son/daughter" and "Preguntar a su maestro por ayuda" to "Pide ayuda a su maestro").

Overall, the implementation of the pilot study and the feedback obtained from the participants completing study provided the researcher with the opportunity to adjust and clarify questions on the survey. This in turn assisted in increasing the success of the main study

\section{Statistical Analysis}

The study employed a non-experimental correlational research design to investigate the association between the types and intensity of Latino immigrant parental involvement and their child's academic achievement. The parental involvement questionnaire scores and demographic data were tested for their links to predictions of student first quarter reading and mathematics grades. This type of research design was appropriate for collecting the data required to investigate the hypothesized correlations between parental involvement, and the dependent variables, reading and mathematics academic achievement, and also the degree to which parental involvement predicted the dependent variables (Newman \& Newman, 1993). $\mathrm{H}_{01 \mathrm{a}} \& \mathrm{~b}$ and $\mathrm{H}_{03 \mathrm{a}} \& \mathrm{~b}$ were tested through simple linear regressions, while $\mathrm{H}_{02 \mathrm{a}}$ \& $\mathrm{b}$ and $\mathrm{H}_{04 \mathrm{a}}$ \& b were tested through hierarchical regression analyses. Hierarchical regression analysis was appropriate for determining that the unique variance accounted for in a multiple regression equation after statistically controlling for theoretically relevant demographic variables, such as the ones being measured in this research: sex of the students and parents, socioeconomic status based on the parents' income level, single versus two- parent families, parents' level of 
education, and language (Cohen, 1988; Newman \& Newman, 1993). Data from the parent survey was entered, merged and screened for outliers or missing data, and then analyzed by SPSS 20 .

Additionally, the Pearson Product-Moment Correlation was utilized to determine if there was a significant relationship between predictor and criterion variables. The means for the independent and dependent variables were computed and compared to determine if a relationship existed between the two. If a high correlation were found between two variables it would indicate that an increase in one variable accompanies an increase in another, showing a direct relationship. In contrast, if a negative correlation were found, it would indicate that the value of one variable increases while the other decreases. (Hawes \& Plourde, 2005).

\section{Limitations}

In view of the increasing number of Latinos in South Florida (U. S. Census Bureau, 2010), this study was limited in the fact that a sample size of 134 seventh grade students were chosen and it may not have been large enough to ensure a representative distribution of the population or groups of people to whom results will be generalized. Further, because this research employed a convenience sample, it may have introduced systematic bias into the study (Newman \& Newman, 1993), although it is consistent with prior social science research practice

Moreover, the collection of the surveys was limited because many of the parents who met criteria to participate in the survey chose not to do so. Frequently Latino immigrant students are withdrawn from school due to their parents’ work relocation. However, this was not case in the study. 
Although the researcher utilized self-reporting surveys, external factors such health and mental state, previous schools experiences, and reading level may have limited the study. 


\section{CHAPTER IV}

\section{RESULTS}

The variables in this study included parental involvement and reading and mathematics achievement as measured by first-quarter grades. Linear and hierarchical regression statistical analyses were utilized to determine if relationships among the variables could be supported, in particular, whether parental involvement correlated with their children's reading and mathematics academic grades. This chapter delineates the demographic information of the participants, a statistical analysis of the hypotheses as well as a brief summary of the results.

\section{Demographics of the Sample}

The sample included the parents or guardians of 134 seventh-grade Latino students with low academic performance in reading and mathematics. The parents who participated in the study completed a Parent Involvement Questionnaire authored by Hoover-Dempsey and Sandler (2005), which consisted of 73 Likert-type questions distributed among nine constructs and eight demographic questions. Getting parents to attend the research study meeting and participate in completing the questionnaire was an arduous task that required the researcher to schedule frequent meetings, both in the day and at night. The meetings and survey completions were held from September through November 2015. Regardless of the incentives utilized to encourage parental involvement, the average number of parents that participated at each meeting was 10 . Once the parent questionnaires were completed, the results with the corresponding constructs were transferred to an Excel file. Further, a frequency analysis of the 134 participants' gender, 
marital status, occupation, education, income and race/ethnicity were examined successively.

\section{Gender}

A frequency analysis of gender indicated that 21 (15.7\%) were male and 113 (84.3\%) were female.

\section{Marital Status}

A frequency analysis of the marital status indicated that 66 (49.3\%) were single and 68 (50.7\%) were married or with a partner.

\section{Occupation}

A frequency analysis of occupation indicated that 25 (18.7\%) of the parents/guardians were unemployed, with the remaining 109 (81.3\%) working in a range of occupations as shown in Table 1. 
Table 1

Frequency of Research Variable Occupations

\begin{tabular}{lcc}
\hline Category & $f$ & Percent \\
\hline Unemployed & 25 & $18.7 \%$ \\
Warehouse, factory workers & 16 & $11.9 \%$ \\
Food services & 20 & $14.9 \%$ \\
Retail sales, clerical, customer service & 7 & $5.2 \%$ \\
Bookkeeping, accounting & 0 & $0 \%$ \\
Real estate/Insurance sales & 0 & $0 \%$ \\
Teachers, nurse & 10 & $7.5 \%$ \\
Labor, custodial & 9 & $6.7 \%$ \\
Driver & 1 & $.7 \%$ \\
Skilled craftsman & 4 & $3 \%$ \\
Service technician & 134 \\
Singer, musician & & $.76 \%$ \\
Social services, public service & 0 & $.7 \%$ \\
Professional, Executive & 1 & $3 \%$ \\
Other & 4 & $00 \%$ \\
\hline Total & & \\
\hline
\end{tabular}

Table 2 shows a frequency analysis of occupation of the partner which indicated that 6 (8.8\%) were unemployed, with the remaining 62 (91.2\%) working in a range of occupations. 
Table 2

Frequency of Research Variable Occupations - Partners

\begin{tabular}{lll}
\hline Category & $f$ & Percent \\
\hline Unemployed & 6 & $8.8 \%$ \\
Warehouse, factory workers & 10 & $14.7 \%$ \\
Food services & 5 & $14.9 \%$ \\
Retail sales, clerical, customer service & 1 & $5.2 \%$ \\
Bookkeeping, accounting & 0 & $0 \%$ \\
Real estate/Insurance sales & 0 & $0 \%$ \\
Teachers, nurse & 2 & $7.5 \%$ \\
Labor, custodial & 11 & $6.7 \%$ \\
Driver & 5 & $.7 \%$ \\
Skilled craftsman & 15 & $3 \%$ \\
Service technician & 9 & $.7 \%$ \\
Singer, musician & 1 & $0 \%$ \\
Social services, public service & $26.9 \%$ \\
Professional, Executive & $0 \%$ \\
\hline Other & $0 \%$ & $.7 \%$ \\
\hline
\end{tabular}

\section{Education}

A frequency analysis of educational attainment shown in Table 3 indicated that most of the respondents of the parent/guardians had less than a high school diploma, 23 (17.2\%), or had a high school diploma or GED, 73 (54.5\%). The partners had similar 
educational attainments with 24 (35.3\%) less than a high school diploma and 36 (52.9\%) a high school diploma or GED. The remaining parent/guardian and respondents had some type of college experience or degree.

Table 3

Frequency of Research Variable Education

\begin{tabular}{lrrrr}
\hline Category & \multicolumn{2}{c}{ Yours } & \multicolumn{2}{c}{ Partner } \\
& $f$ & Percent & $f$ & Percent \\
\cline { 2 - 5 } Less than high school & 23 & $17.2 \%$ & 24 & $35.3 \%$ \\
High school or GED & 73 & $54.5 \%$ & 36 & $52.9 \%$ \\
Some college, 2-year & 18 & $13.4 \%$ & 4 & $5.9 \%$ \\
Bachelor's degree & 16 & $11.9 \%$ & 4 & $5.9 \%$ \\
Some graduate work & 2 & $1.5 \%$ & 0 & $0 \%$ \\
Post-graduate & 2 & $1.5 \%$ & 0 & $0 \%$ \\
\hline Total & 134 & $100 \%$ & 68 & $100 \%$ \\
\hline
\end{tabular}

\section{Income}

A frequency analysis of the family income shown in Table 4 indicated that the majority of the families (111 or $82.9 \%$ ) had an annual income of less than $\$ 30,000$. Only 4 (3\%) families had an annual income of $\$ 40,000$ or more. 
Table 4

Frequency of Research Variable Family Income

\begin{tabular}{lcr}
\hline Income Range & $f$ & Percent \\
\hline Less than $\$ 5,000$ & 9 & $6.7 \%$ \\
$\$ 5,000-\$ 10,000$ & 17 & $12.7 \%$ \\
$\$ 10,001-\$ 20,000$ & 47 & $35.1 \%$ \\
$\$ 20,001-\$ 30,000$ & 38 & $28.4 \%$ \\
$\$ 30,001-\$ 40,000$ & 19 & $14.2 \%$ \\
$\$ 40,001-\$ 50,000$ & 2 & $1.5 \%$ \\
Over $\$ 50,000$ & 2 & $1.5 \%$ \\
\hline Total & 134 & $100 \%$ \\
\hline
\end{tabular}

\section{Race/Ethnicity}

A frequency analysis of race/ethnicity indicated that 5 (3.7\%) of the parents/guardians are Black/African-American and 129 (96.3\%) are Latino/LatinoAmerican.

\section{Analysis of the Hypotheses}

To test the hypotheses, a correlation analysis between the research variables was conducted first to understand to what extent the variables were associated with each other. The results of the correlation analysis represented in Table 5 illustrates that the correlations among the parental involvement variable scores were not statistically significant with this sample of seventh grade Latino students' reading and mathematics grades. Statistically significant associations between the parental involvement variables 
were as expected. However, in analyzing the students' reading and mathematics firstquarter report card grades, the students' reading grades were higher than their mathematics grades (Reading $M$ grade $=3.22 ; S D=.76$; Math $M$ grade $=2.89 ; S D=.94$ ), This was noteworthy because the sample population was comprised of English Language Learners (ELL). Further, as revealed by the two-way ANOVA analyses, the reading grades did not vary by gender $(F(1,122)=0.84, p=.37)$, income $(F(6,122)=0.21, p=$ .97 ) or gender $\mathrm{X}$ income interaction $(F(3,122)=1.16, p=.33)$. However, although math grades did not vary by gender $(F(1,123)=1.28, p=.25)$ or the gender $\mathrm{X}$ income interaction $(F(3,123)=.18, p=.91)$, it did vary by income $(F(6,123)=1.96, p=.04)$. Those from higher SES scored significantly higher math grades. 
Table 5.

Intercorrelations of Parental Involvement and Reading and Mathematics First-Quarter Grades

\begin{tabular}{|c|c|c|c|c|c|c|c|c|c|c|}
\hline & Total V & Total PE & Total GSI & Total K & Total INV & Total E & Total R & Total INS & Total RDG & Total M \\
\hline $\begin{array}{ll}\mathrm{V} & \text { Pearson Corr. } \\
& \text { Sig. (1-tailed) }\end{array}$ & 1 & & & & & & & & & \\
\hline $\mathrm{N}$ & 134 & & & & & & & & & \\
\hline PE Pearson Corr. & $.164 *$ & 1 & & & & & & & & \\
\hline Sig. (1-tailed) & .029 & & & & & & & & & \\
\hline $\mathrm{N}$ & 134 & 134 & & & & & & & & \\
\hline GSI Pearson Corr. & $.472 * *$ & $.327 * *$ & 1 & & & & & & & \\
\hline Sig. (1-tailed) & .000 & .000 & & & & & & & & \\
\hline $\mathrm{N}$ & 133 & 133 & 133 & & & & & & & \\
\hline Pearson Corr. & $.187 *$ & $.644 * *$ & $.371^{* *}$ & 1 & & & & & & \\
\hline Sig. (1-tailed) & .015 & .000 & .000 & & & & & & & \\
\hline $\mathrm{N}$ & 134 & 134 & 133 & 134 & & & & & & \\
\hline INV Pearson Corr. & .092 & $.533 * *$ & $.268 * *$ & $.443^{* *}$ & 1 & & & & & \\
\hline Sig. (1-tailed) & 144 & .000 & .001 & .000 & & & & & & \\
\hline $\mathrm{N}$ & 134 & 134 & 133 & 134 & 134 & & & & & \\
\hline Pearson Corr. & $.298 * *$ & $.479 * *$ & $.590 * *$ & $.416^{* *}$ & $.535 * *$ & 1 & & & & \\
\hline Sig. (1-tailed) & .000 & .000 & .000 & .000 & .000 & & & & & \\
\hline $\mathrm{N}$ & 134 & 134 & 133 & 134 & 134 & 134 & & & & \\
\hline Pearson Corr. & $.246^{* *}$ & $.420 * *$ & $.465 * *$ & $.252^{* *}$ & $.449 * *$ & $.712^{* *}$ & 1 & & & \\
\hline Sig. (1-tailed) & .002 & .000 & .000 & .002 & .000 & .000 & & & & \\
\hline $\mathrm{N}$ & 134 & 134 & 133 & 134 & 134 & 134 & 134 & & & \\
\hline INS Pearson Corr. & $.251^{* *}$ & $.410^{* *}$ & $.559 * *$ & $.387 * *$ & $.437 * *$ & $.808^{* *}$ & $.809 * *$ & 1 & & \\
\hline Sig. (1-tailed) & .002 & .000 & .000 & .000 & .000 & .000 & .000 & & & \\
\hline $\mathrm{N}$ & 134 & 134 & 133 & 134 & 134 & 134 & 134 & 134 & & \\
\hline \multirow{3}{*}{$\begin{array}{l}\text { RDG Pearson Corr. } \\
\text { Sig. (1-tailed) } \\
\text { N }\end{array}$} & .025 & -.037 & -.053 & -.001 & -.021 & .016 & .044 & .048 & 1 & \\
\hline & .390 & .335 & .272 & .495 & .406 & .428 & .309 & .292 & & \\
\hline & 133 & 133 & 132 & 133 & 133 & 133 & 133 & 133 & 133 & \\
\hline \multirow{3}{*}{$\begin{array}{l}\text { M Pearson Corr. } \\
\text { Sig. (1-tailed) } \\
\text { N }\end{array}$} & -.010 & .019 & .107 & .060 & .015 & .015 & .025 & .073 & $.298 * *$ & 1 \\
\hline & .456 & .413 & .110 & .247 & .430 & .433 & .386 & 199 & .000 & \\
\hline & 134 & 134 & 133 & 134 & 134 & 134 & 134 & 134 & 133 & 134 \\
\hline \multirow{3}{*}{$\begin{array}{l}\text { INC Pearson Corr. } \\
\text { Sig. (1-tailed) } \\
\mathrm{N}\end{array}$} & .104 & -.097 & .073 & -.128 & -.118 & -.035 & -.030 & -.014 & -.018 & $.160 *$ \\
\hline & .115 & .131 & .201 & .071 & .087 & .343 & .364 & .435 & .418 & .032 \\
\hline & 134 & 134 & 133 & 134 & 134 & 134 & 134 & 134 & 133 & 134 \\
\hline
\end{tabular}

Note. ${ }^{*}$ Correlational is significant at the 0.05 level (1-tailed) $\quad$ Note. ${ }^{* *}$ Correlational is significant at the 0.01 level (1-tailed) 


\section{Research Hypothesis 1a}

The results of the regression analysis where $\mathrm{H}_{01 \mathrm{a}}$ was tested showed that parents' involvement did not significantly predict the students' reading first-quarter grades as shown in Table 6. The original full model $R$-square value was .02 $(p=.96)$. Therefore, the results failed to reject $\mathrm{H}_{01 \mathrm{a}}$, which is in contrast to prior research, especially among Latino immigrant parents, that parental involvement is positively associated with students’ reading achievement (Guthrie \& Wigfield, 2000).

Table 6

Summary of Regression Analysis with Parental Involvement Predicting Reading FirstQuarter Grades

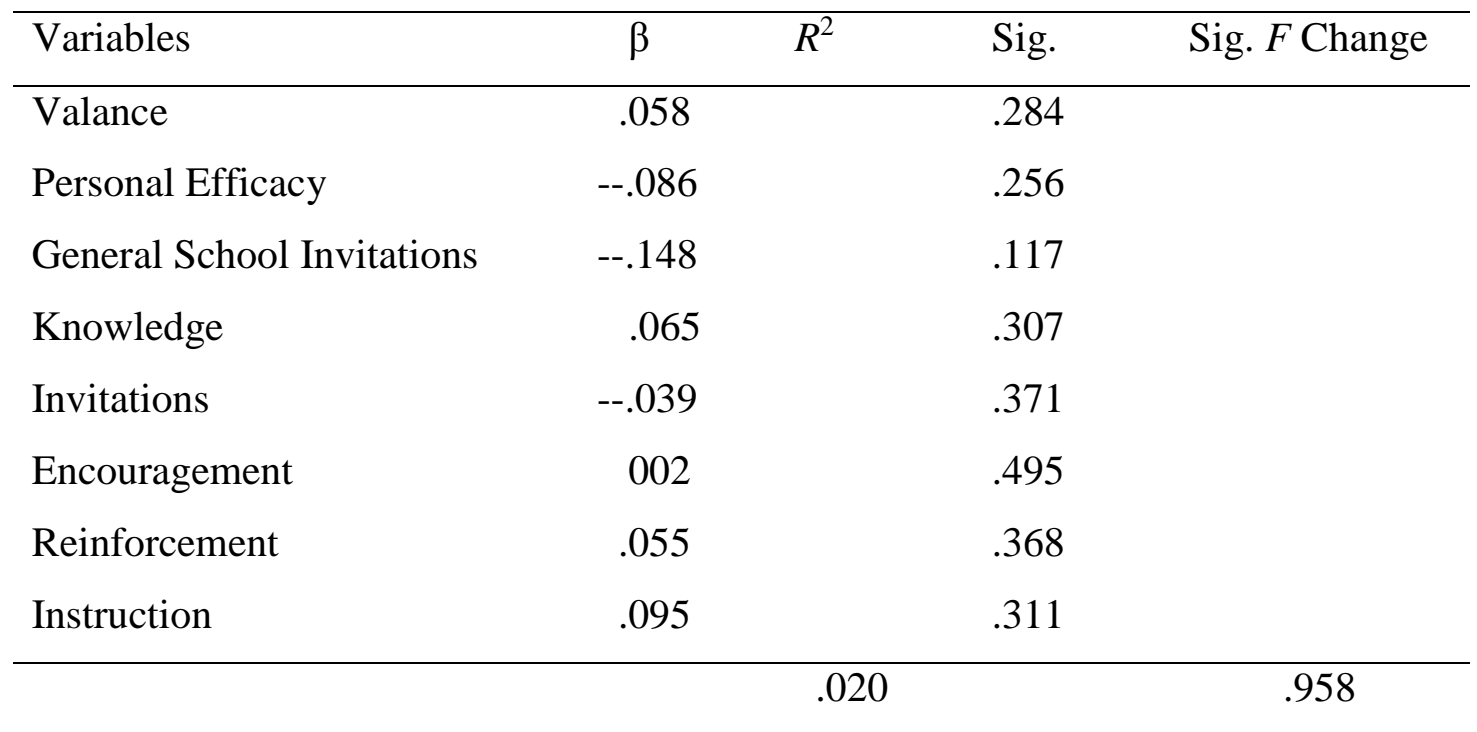

\section{Research Hypothesis 1b}

The results of the regression analysis where $\mathrm{H}_{01 \mathrm{~b}}$ was tested, showed that parental involvement did not significantly predict the students’ mathematics first-quarter report card grades as shown in Table 7. The original full model $R$-square value was .03 ( $p=$ .88). Consequently, the results failed to reject $\mathrm{H}_{01 \mathrm{~b}}$. 
Table 7

Summary of Regression Analysis with Parental Involvement Predicting First-Quarter Mathematics Grade

\begin{tabular}{lcccc}
\hline Variables & $\beta$ & $R^{2}$ & Sig. & Sig. F Change \\
\hline Valance & --.068 & & .252 & \\
Personal Efficacy & -.015 & & .455 & \\
General School Invitations & -.158 & & .199 & \\
Knowledge & .035 & .391 & \\
Invitations & -.015 & .448 & \\
Encouragement & -.176 & .151 & \\
Reinforcement & -.060 & & .355 & \\
Instruction & .180 & & .172 & \\
\hline & & .030 & & .882 \\
\hline
\end{tabular}

\section{Research Hypothesis 2a}

The results of the regression analysis where $\mathrm{H}_{02 \mathrm{a}}$ was tested showed that parents' SES did not significantly predict reading first-quarter report card grades beyond parental involvement (see Table 8). The parental involvement variables were entered in the first step, which explained $2.0 \%$ of the variance $(p=.96)$ in reading. For the second step, income was entered into the regression equation as shown in Table 9, which did not explain any additional unique variance $\left(R^{2}=.00 ; p=.85\right)$; therefore, $\mathrm{H}_{02 \mathrm{a}}$ was not rejected. 
Table 8

Summary of Hierarchical Regression with SES Predicting Reading First-Quarter Grades After Controlling for Parental Involvement - Step 1

\begin{tabular}{|c|c|c|c|c|}
\hline Variables & B & $R^{2}$ & Sig & Sig. $F$ Change \\
\hline Valance & 058 & & 283 & \\
\hline Personal Efficacy & 086 & & .256 & \\
\hline General School Invitations & 148 & & .117 & \\
\hline Knowledge & 065 & & .157 & \\
\hline Invitations & 039 & & .371 & \\
\hline Encourage & .002 & & 495 & \\
\hline Reinforcement & .055 & & .368 & \\
\hline \multirow[t]{2}{*}{ Instruction } & .095 & & .311 & \\
\hline & & .02 & & .958 \\
\hline
\end{tabular}

Table 9

Summary of Hierarchical Regression with SES Predicting Reading First-Quarter Grades After Controlling for Parental Involvement - Step 2

\begin{tabular}{|c|c|c|c|c|}
\hline Variables & $\beta$ & $R^{2}$ & Sig & Sig. $F$ Change \\
\hline Valance & .036 & & .376 & \\
\hline Personal Efficacy & -.086 & & .257 & \\
\hline General School Invitation & -.146 & & .122 & \\
\hline Knowledge & .062 & & .316 & \\
\hline Invitations & -.040 & & .368 & \\
\hline Encouragement & .001 & & .498 & \\
\hline Reinforcement & .054 & & .371 & \\
\hline Instruction & .097 & & .309 & \\
\hline \multirow[t]{2}{*}{ Income } & -.017 & & .427 & \\
\hline & & .020 & & .854 \\
\hline
\end{tabular}




\section{Research Hypothesis $2 b$}

The results of the hierarchical regression analysis where $\mathrm{H}_{02 \mathrm{~b}}$ was tested, showed that parents' SES did significantly predict mathematic first-quarter report card grades above and beyond parental involvement as shown in Table 10. In the first step, the parental involvement variables were entered to examine the relationship between parental involvement and mathematics first-quarter grades, which explained $2.0 \%$ of the variance $(p=.44)$. For the second step, income was entered in the regression equation, which explained an additional 3.0\% of variance $(p=.04)$ in predicting mathematics first-quarter grades. The overall variance was $R^{2}=.05(p<.05)$, indicating a relationship between SES as measured by parental income and math first-quarter grades above and beyond parental involvement; therefore, $\mathrm{H}_{02 \mathrm{~b}}$ was supported. This is shown in Table 11.

Table 10

Summary of Hierarchical Regression Analysis of SES Predicting Mathematics FirstQuarter Grades After Controlling for Parental Involvement - Step 1

\begin{tabular}{lcccllll}
\hline Variables & $\beta$ & $R^{2}$ & Sig. & F Change & $d f 1$ & $d f 2$ & Sig. F Change \\
\hline (Constant) & & & .08 & & & & \\
Valance & & -.068 & & .25 & & \\
Pers. Efficacy & -.015 & & .45 & & & \\
Gen. School Inv. & & .158 & & .10 & & \\
Knowledge & .035 & & .39 & & & \\
Invitations & .015 & & .45 & & & \\
Encouragement & -.176 & & .15 & & & \\
Reinforcement & -.060 & & .35 & & & \\
Instruction & .180 & & .17 & & & \\
& & .02 & & .456 & 8 & 124 & \\
\hline
\end{tabular}


Table 11

Summary of Hierarchical Regression Analysis of SES Predicting Mathematics FirstQuarter Grades After Controlling for Parental Involvement - Step 2

\begin{tabular}{|c|c|c|c|c|c|c|c|}
\hline Variables & $\beta$ & $R^{2}$ & Sig. & F Change & df1 & df2 & Sig. F Change \\
\hline (Constant) & & & .14 & & & & \\
\hline Valance & & -.083 & & .21 & & & \\
\hline Pers. Efficacy & -.017 & & .45 & & & & \\
\hline Gen. School Inv. & & .139 & & .13 & & & \\
\hline Knowledge & .061 & & .31 & & & & \\
\hline Invitations & .026 & & .41 & & & & \\
\hline Encouragement & & -.167 & & .16 & & & \\
\hline Reinforcement & -.048 & & .38 & & & & \\
\hline Instruction & .166 & & .19 & & & & \\
\hline Income & .162 & & .04 & & & & \\
\hline & & .05 & & 3.27 & 1 & 123 & .037 \\
\hline
\end{tabular}

\section{Research Hypothesis 3a}

The results of the regression analysis where $\mathrm{H}_{03}$ a was tested showed that there were no significant relationships between students’ reading first-quarter grades and being from single-parent versus two-parent homes as shown in Table 12. The results of the analysis were $F(1,131)=.008, p=.93 ; r^{2}=.00$; thus, $\mathrm{H}_{03 a}$ was not rejected. 
Table 12

Summary of Regression Analysis Predicting Reading First-Quarter Grades with Single versus Two-Parent Home Status

\begin{tabular}{|c|c|c|c|c|c|c|c|}
\hline Variables & $\beta$ & $\mathrm{r}^{2}$ & Sig. & $F$ Change & df1 & df2 & Sig. $F$ Change \\
\hline \multirow[t]{2}{*}{ Marital Status } & .008 & & .93 & & & & \\
\hline & & .000 & & .008 & 1 & 131 & .93 \\
\hline
\end{tabular}

\section{Research Hypothesis $3 b$}

The results of the regression analysis where $\mathrm{H}_{03 \mathrm{~b}}$ was tested, show that there were no significant relationships between students' mathematics first-quarter grades and being from single-parent versus two-parent homes (see Table 13). The results of the analysis were $F(1,132)=1.49, p=.23 ; r^{2}=.01$; thus, $\mathrm{H}_{03 \mathrm{~b}}$ was not rejected.

Table 13

Summary of Regression Analysis with Single versus Two-Parent Homes Predicting Mathematics First-Quarter Grades

\begin{tabular}{|c|c|c|c|c|c|c|c|}
\hline Variables & $\beta$ & $r^{2}$ & Sig. & $F$ Change & df1 & $\mathrm{df} 2$ & Sig. $F$ Change \\
\hline (Constant) & & & .000 & & & & \\
\hline \multirow[t]{2}{*}{ Marital Status } & .105 & & .225 & & & & \\
\hline & & .011 & & 1.485 & 1 & 132 & .225 \\
\hline
\end{tabular}

\section{Research Hypothesis 4a}

The results of the hierarchical regression analysis where $\mathrm{H}_{04 a}$ was tested showed that there were no significant relationships between the type and intensity of parental involvement on reading performance when controlling for parents’ level of education (see Table 14). The results of the analysis in the first step were $F(1,130)=.21, p<.65$, $R^{2}=.00$. The results of the analysis in the second step, where parental involvement 
variables were included along with the parents' educational variable, were $F(8,122)=$ $.30, p<.97, R^{2}=.02$; thus, $\mathrm{H}_{04 a}$ was not rejected These results are shown in Table 15 .

Table 14

Summary of Hierarchical Regression Analysis between Type and Intensity of Parental Involvement in Predicting Reading First-Quarter Grades - Step1

\begin{tabular}{llllllll}
\hline Variables & $\beta$ & $R 2$ & Sig. & $F$ Change & df1 & df2 & Sig. $F$ Change \\
\hline
\end{tabular}

Dependent Variable: Reading

(Constant)

.000

Education

$-.040$

.38

.002

.209

$1 \quad 130$

.649

Table 15

Summary of Hierarchical Regression Analysis between Type and Intensity of Parental Involvement in Predicting Reading First-Quarter Grades - Step 2

\begin{tabular}{|c|c|c|c|c|c|c|c|}
\hline Variables & $\beta$ & $R 2$ & Sig. & F Change & df1 & df2 & Sig. F Change \\
\hline (Constant) & & & .000 & & & & \\
\hline Education & -.030 & & .38 & & & & \\
\hline Valence & .067 & & .26 & & & & \\
\hline Pers. Efficacy & -.072 & & .29 & & & & \\
\hline Gen. School Inv. & -.148 & & .12 & & & & \\
\hline Knowledge & .055 & & .33 & & & & \\
\hline Invitations & -.039 & & .37 & & & & \\
\hline Encouragement & .005 & & .49 & & & & \\
\hline Reinforcement & .046 & & .39 & & & & \\
\hline \multirow[t]{2}{*}{ Instruction } & .098 & & .31 & & & & \\
\hline & & .021 & & .300 & 8 & 122 & .965 \\
\hline
\end{tabular}




\section{Research Hypothesis 4b}

The results of the hierarchical regression analysis where $\mathrm{H}_{04 \mathrm{~b}}$ was tested showed that there was no significant relationship between the type and intensity of parental involvement in mathematics when controlling for parents' level of education (see Table 16). The results of the analysis in the first step were $F(1,131)=.73, p=.40, R^{2}=.01$. The results of the analysis in the second step, where parents' educational variable was included, were $F(8,123)=.47, p=.88, R^{2}=.04$; thus, $\mathrm{H}_{04 \mathrm{~b}}$ was not rejected. This is shown in Table 17.

Table 16

Summary of Hierarchical Regression Analysis between Type and Intensity of Parental Involvement in Predicting Reading First-Quarter Grades - Step 1

\begin{tabular}{llllllll}
\hline Variables & $\beta$ & $R^{2}$ & Sig. & $F$ Change & $d f 1$ & $d f 2$ & Sig. $F$ Change
\end{tabular}

Dependent variable: Mathematics

Step 1

(Constant) .000

Education .074 .20 
Table 17

Summary of Hierarchical Regression Analysis between Type and Intensity of Parental Involvement in Predicting Reading First-Quarter Grades - Step 2

\begin{tabular}{|c|c|c|c|c|c|c|c|}
\hline Variables & $\beta$ & $R^{2}$ & Sig. & F Change & $d f 1$ & $d f 2$ & Sig. $F$ Change \\
\hline \multicolumn{8}{|c|}{ Dependent variable: Mathematics } \\
\hline (Constant) & & & .192 & & & & \\
\hline Education & .082 & & .19 & & & & \\
\hline Valence & -.082 & & .21 & & & & \\
\hline Pers. Efficacy & -.038 & & .39 & & & & \\
\hline Gen. School Inv. & .157 & & .10 & & & & \\
\hline Knowledge & .046 & & .36 & & & & \\
\hline Invitations & .017 & & .44 & & & & \\
\hline Encouragement & -.176 & & .15 & & & & \\
\hline Reinforcement & -.041 & & .40 & & & & \\
\hline \multirow[t]{2}{*}{ Instruction } & .173 & & .18 & & & & \\
\hline & & .035 & & .471 & 8 & 123 & .875 \\
\hline
\end{tabular}

\section{Summary}

The frequency analysis data indicated that the majority of the participants completing the parent questionnaire were women. The occupation that was chosen most frequently by the parents completing the questionnaire was unknown and by their partners was labor. The education level chosen with more frequency by both parents and 
partners was high school diploma or GED. The average family income depicted in the frequency analysis was between $\$ 10,000$ and $\$ 20,000$.

The results of the regression analyses indicated that there was a statistically significant relationship $\left(R^{2}=.05\right)$ between parental socioeconomic status and math firstquarter grades, but there was not a statistically significant relationship between parental socioeconomic status and reading first-quarter grades. Furthermore, the regression results indicated that there was not a significant relationship between parental involvement and reading or mathematics grades. In addition, there was not a significant relationship between single-parent versus two-parent homes and reading and mathematics grades. Chapter 5 addresses the results and implications of these outcomes for research, theory, and practice. 


\section{CHAPTER V}

\section{DISCUSSION}

This chapter offers a summary and a discussion of the results of the study.

Implications for research, theory, and practice proposed are followed by recommendations for further research that could benefit from amplifying the results of this study.

\section{Summary of the Study}

The number of Latino population has increased by 43\% between 2000 and 2010 (United States Census Bureau, 2010). These numbers are projected to increase in upcoming years. The surge of the Latino population has directly affected the increase of Latino students enrolled in public schools, especially in Miami-Dade County where the Hispanic or Latino population is 66\% (United States Census Bureau, 2014). Along with these demographic changes, schools are challenged with a gap in Latino student achievement, as compared to White non-Latino students. Marschall (2006) claims that the achievement gap has been associated with minimal parental involvement due to various factors including: socioeconomic status, level of parents' education, and language barriers. The purpose of this research study was to examine the relationship between parental involvement of seventh grade middle school Latino students and students' reading and mathematics achievement. The study also examined theoretical relevant demographic variables, such as socioeconomic status, parents' level of education, single versus two parent families, sex of the students and parents, type and intensity.

The theoretical framework that supported this research study was derived from Joyce Epstein’s (1991) model for parental involvement. The model includes six 
approaches to enhance parental involvement: parenting, communication, volunteering, learning at home, decision-making, and collaborating with the community. Four research questions were addressed in this study:

1. Does parent involvement predict students' reading and mathematics achievement in quarterly report card grades?

2. Does parental socioeconomic status (SES) predict reading and mathematics achievement as measured by quarterly report card grades above and beyond parental involvement?

3. Is there a relationship between single-parent homes versus two-parent home and the students' reading and mathematics achievement and quarterly report card grades?

4. Does type and intensity of parental involvement account for a significant amount of unique variance in predicting reading and mathematics achievement when controlling for parents' level of education?

Additionally, the following statistical hypotheses were tested to examine the research questions:

$\mathrm{H}_{01 \mathrm{a}}$ : Parents' involvement as measured by the parent surveys will not predict the students' reading achievement as measured by the first quarter report cards grades.

$\mathrm{H}_{01 \mathrm{~b}}$ : Parents' involvement as measured by the parent surveys will not predict the students' mathematics achievement as measured by the first quarter report cards grades. 
$\mathrm{H}_{02 a}$ : Parental SES will not be significantly related to reading achievement as measured by the first quarter report card grades above and beyond parental involvement.

$\mathrm{H}_{02 \mathrm{~b}}$ : Parental SES will not be significantly related to mathematics achievement as measured by the first quarter report card grades above and beyond parental involvement.

$\mathrm{H}_{03 a}$ : There will be no relationship between students from single-parent versus two-parent homes in reading achievement and first quarter report card grades. $\mathrm{H}_{03 \mathrm{~b}}$ : There will be no significant relationship between students from single parent versus two-parent homes in mathematics achievement and quarterly report card grades.

$\mathrm{H}_{04 \mathrm{a}}$ : There will not be a relationship between the type and intensity of parental involvement in reading achievement when controlling for the parents' level of education.

$\mathrm{H}_{04 \mathrm{~b}}$ : There will not be a relationship between the type and intensity of parental involvement in mathematics achievement when controlling for the parents' level of education.

A parent involvement questionnaire, in English and Spanish, adapted from Hoover-Dempsey and Sandler (2005), consisted of 79 Likert-type items dispensed among nine constructs: parents' school experience, invitations for involvement, reinforcement, knowledge and skills, involvement activities, encouragement, self-efficacy, instruction, and status variables. Correlational and multiple regression analyses were utilized to examine the relationship between the variables. 


\section{Discussion of the Results}

The following section examines the results of each hypothesis that was tested. Initially, a correlational analysis was conducted among the research variables. The results of the correlational analysis shown in Table 5 indicated that most of the correlations between the variables were not significant in the sample of seventh grade Latino students. However, there was a correlation between the reading and parental SES variables. This is nonconventional because the student sample in the study consisted of English Language Learners (ELL) and many are not fluent in English. A possible reason could be the grading criteria or scale teachers utilized because the school district in this study does not recommend failing a student who is at ELL levels 1 or 2. Further, ELL students are required to take an ELL reading class, in addition to a language arts class, where they are grouped by ELL level, providing them the opportunity to work together at their academic level. However, this is not the case in other core subjects where students are grouped by grade level rather than ELL level.

The results of the linear and hierarchical regression analysis rejected the null hypotheses with the exception of null hypothesis $\mathrm{H}_{02 \mathrm{~b}}$, where the parents’ higher socioeconomic status was significantly related to mathematics achievement, as measured by the quarter report card grades. This was consistent with Gordon and Cui (2014) that claim that students who live in affluent communities perform academically better than students who live in impoverished communities. Further, the lack of significant relationship between parental involvement and reading and mathematics achievement was not consistent with research studies that claim that students whose parents are directly involved in their academics demonstrate higher levels of academic performance 
(Chang et al., 2009). Other supporting studies indicated that parental involvement plays a pivotal role in the lives and educational progress of students as well as establishing positive relationships between student grades, motivation and students’ self-efficacy (Hoover-Dempsey \& Sandler, 2005). Because of the number of studies supporting the relationship between parental involvement and student achievement, the researcher expected the results of the parent questionnaire, adopted from Hoover-Dempsey and Sandler, to support current research. Accordingly, the results of the study did not mirror current studies.

Further, there was not a significant relationship between single parent homes versus two parent homes, and reading and mathematics achievement. A study conducted by Ricciuti (2004) suggests that the possible negative outcome of single parenting may be counterbalanced by the parents' characteristics of positive parenting, such as level of education and school expectations.

\section{Discussion of Ho1a}

The results of the regression analysis where $\mathrm{H}_{01 \mathrm{a}}$ was tested showed that parents' involvement did not significantly predict the students’ reading first-quarter grades (see Table 6). The results of the full model $R=$ square was $.02(p=.958)$. The sample size of 134 minus the three outliers produced a $d f$ value of 131 . There was sufficient evidence to not reject $\mathrm{H}_{01 \mathrm{a}}$. These findings were not consistent with previous research which suggested that there is a relationship between parental involvement and reading achievement (Hill \& Tyson, 2009; Hoover-Dempsey \& Sandler, 2005). The results also contradict research that claims that parental involvement, especially among Latino 
immigrant parents, positively impacts students’ reading achievement (Guthrie \& Wigfield, 2000).

\section{Discussion of $\mathrm{H}_{01 b}$}

The results of the regression analysis where $\mathrm{H}_{01 \mathrm{~b}}$ was tested showed that parental involvement did not significantly predict the students' mathematics first-quarter report card grades (see Table 7). The results of the regression analysis was run to predict the reading variable that explained $30 \%$ of the variance $F(8,124)=.46, p=.88$. $), R^{2}=.03$. Regression analysis utilizing the full and restricted models indicated an $R$ square value of .03. Because the number of outliers was two, the sample size of 134 minus the three outliers produced a $d f$ value of 132 . Further, the statistical significant $\mathrm{F}$ test value was .88 which provided sufficient evidence to reject $\mathrm{H}_{01 \mathrm{~b}}$. These results contradicted with existing research that claim that parents' behaviors and values such as communicating set values to their children and reinforcing academic outcomes are associated with student achievement (e.g. Hong et al., 2010).

\section{Discussion of Ho2a}

The results of the regression analysis where $\mathrm{H}_{02 a}$ was tested showed that parents' SES did not significantly predict reading first-quarter report card grades above and beyond parental involvement (see Tables 8 and 9). In the first step, a regression analysis was conducted testing for income while the predictor variable was reading, $F(8,123)=$ .32, $p=.96 ; R^{2}=02$. The second step included income and tested for parental involvement $F(1,122)=.28, p=.98 ; R^{2}=00$; thus $\mathrm{H}_{02 a}$ was not rejected. However studies indicate that SES affects family interactions through economic stress that often creates tension and divergence among families (Morrison et al., 2006) and that children 
who live in impoverished environments have limited resources, and may be more vulnerable to health risks that ultimately may impact academic growth (Chang et al., 2009). Further, penurious living conditions may have an adverse influence on the effectiveness of school-related parental involvement on adolescents' academic achievement (Gordon \& Cui, 2014).

\section{Discussion of $\mathrm{H}_{02 b}$}

The results of the hierarchical regression analysis where $\mathrm{H}_{02 \mathrm{~b}}$ was tested showed that parents' SES did significantly predict mathematic first-quarter report card grades above and beyond parental involvement (see Tables 10 and 11). In the first step, a regression analysis was conducted testing for income, while the predictor variable was mathematics, $F(8,124)=.46 p=.44 ; R^{2}=.03$. The second step, included income, which resulted in an $F(8,123)=.3 .27 p=.04 ; R^{2}=.035$. The square values for both steps, restricted and full, were.054 and .029 , respectively. The $F$ test of the difference in the $R^{2}$ values of both steps and its corresponding probability value are 3.26 and .073 . The overall $R^{2}$ was .05, which resulted in a significant correlation between parents' SES and mathematics achievement; therefore, $\mathrm{H}_{02 \mathrm{~b}}$ was supported.

As previously mentioned, Latino parents from low socioeconomic backgrounds face many barriers, such as lack of transportation, rigid work schedules, and limited education which may be the underlying factor for the lack of educational home environment. Studies suggest that these factors also contribute to the disengagement of parents from their children schools (Barrueco et al., 2007). However, these factors do not necessarily impede Latino parents from being involved in their children's education. Teachers and administrators should not presume that minimal or lack of involvement in 
school-based activities implies that parents are not interested in their children's education. Many Latino parents who do not participate in school-based functions engage in home-based activities, such as reviewing homework, monitoring academic progress, and speaking with their children regarding school related issues (Epstein, 2011).

\section{Discussion of $\mathrm{H}_{03 a}$}

The results of the regression analysis where $\mathrm{H}_{03 a}$ was tested show that there was no significant relationship between students' reading first-quarter grades and being from single-parent versus two-parent homes (see Table 12). A regression analysis was conducted where the dependent variable was reading and the constant was marital status. The results of the analysis were $F(1,131)=.008 p=.93 ; R^{2}=.00$;; thus, the results of the regression analysis supported rejecting $\mathrm{H}_{03 a}$. Findings were consistent with studies that claim that there is no significant evidence to support a connection between the years a child spends in a single parent family and student outcomes (Ricciuti, 2004). Conversely, Ricciuti suggested that if positive parenting and competencies are present in the household, the adverse effects of single parent experience may be diminished.

\section{Discussion of $\mathbf{H}_{03 \mathrm{~b}}$}

The results of the regression analysis where $\mathrm{H}_{03 \mathrm{~b}}$ was tested showed that there were no significant relationships between students’ mathematics first-quarter grades and being from single-parent versus two-parent homes (see Table 13). A regression analysis was conducted where the dependent variable was mathematics and the constant was marital status. The results of the analysis were $F(1,132)=1.49 p=.23 ; R^{2}=.01$. The $F$ test value difference between the $R 2$ values of the full and restricted model and its probability value were .008 and .930 , respectively. The results of the regression analysis 
supported rejecting $\mathrm{H}_{03 \mathrm{~b}}$. Analogous to the previous study Lee et al., (2007) claimed that parent's gender or child's gender did not have a significant influence on academic achievement.

\section{Discussion of $\mathrm{H}_{04 a}$}

The results of the hierarchical regression analysis where $\mathrm{H}_{04 a}$ was tested showed that there was no significant relationships between the type and intensity of parental involvement in reading when controlling for parents' level of education (see Table 14 and 15). In the first step, a hierarchical regression analysis was conducted testing for education, while the dependent variable was reading. The results of the analysis were $F$ $(1,130)=.21 p<.65 ; R^{2}=.02$. In the second step the regression analysis included education which resulted in $F(8,122)=.30 p<.97 ; R^{2}=.02$. The square values for both steps, restricted and full, were .002 and .021 , respectively. The $F$ test of the difference in the $R^{2}$ values of both steps and its corresponding probability value were .300 and .965 , which did not result in a significant correlation between the type and intensity of parental involvement in reading achievement; therefore, it did support rejecting $\mathrm{H}_{04 a}$.

The results of the regression analysis are not consistent with research conducted by Joyce Epstein (2002), which claims that parents who are involved in their child's education, while cooperating with the community, promote a nurturing educational environment. Another supporting study claims that when schools take proactive measures to stimulate parental involvement, in turn, they support parents' effectiveness in helping their children learn (Hoover-Dempsey, Walker, Sandler, Whetsel, Green, Wilkins, \& Closson, 2005). Moreover, Green et al. (2007) refuted the results of the regression analysis in a study conducted to examine the theoretical model (the same 
utilized in this study) to predict types and levels of parental involvement during elementary and middle school years. They found that although parental involvement decreased as the students got older, specific student and teacher invitations were important for parental involvement.

\section{Discussion of $\mathbf{H}_{04 b}$}

The results of the hierarchical regression analysis where $\mathrm{H}_{04 \mathrm{~b}}$ was tested showed that there was no significant relationship between the type and intensity of parental involvement in mathematics when controlling for parents' level of education (see Table 16 and 17). In the first step, a hierarchical regression analysis was conducted testing for education, while the dependent variable was mathematics. The results were $F(1,131)=$ $.73 p=.40, R^{2}=.01$. In the second step, education was included in the regression analysis which resulted in $F(8,123)=.47 p=.88 ; R^{2}=.04$. The R-square values for both steps restricted and full, were .006 and .035 , respectively. The $F$ test of the difference in the $R^{2}$ values of both steps and its corresponding probability value were .471 and .875 ; which did not result in a significant correlation between the type and intensity of parental involvement in reading achievement; therefore, $\mathrm{H}_{04 \mathrm{~b}}$ was not rejected. The results indicated that there was not a significant relationship between the type and intensity of parental involvement and mathematics achievement. This does not support a study conducted by Epstein (2010), utilizing the framework of the six types of parental involvement, which assessed 39 schools (elementary and secondary) on the relationship between family and community involvement activities and the school's level of math achievement. The results indicated that better implementation of math related activities is 
associated with stronger parental support which help explain the math proficiency of students.

\section{Implications}

The conclusions obtained from this research study rests on theory, research and practical implications for educators, parents, and researchers. The subsequent sections highlight the results of this study for each area as well as the need for further research.

\section{Theoretical Implications}

Research has indicated that parental involvement among Latino students is minimal, compared to White non-Latino students (Marschall, 2006). Added to this concern is the increasing numbers of Latino students enrolled in public schools. Research supports the claim that minimal school based parental involvement is linked to various factors: socioeconomic status, parents' level of education, and language barriers (Morrison et al., 2006). To analyze the relationship between parental involvement and student achievement, while taking into consideration the barriers, the researcher's theoretical evidence was drawn from Epstein’s (2002) comprehensive model for parental involvement. The model highlights six types/frames aimed at assisting schools increase parental involvement, regardless of the barriers. The approaches include parenting skills, communication, volunteering, learning at home, decision-making, and collaboration with the community. Epstein argues that all stakeholders should collaborate and build partnerships focused on students’ academic and social progress.

Hoover-Dempsey and Sandler (2005) expanded on this theoretical model by emphasizing the importance of home based parental interactions. These interactions include helping with homework, monitoring academic progress, and providing a study 
space that is free from distractions. They propose that these interactions do not constrain Latino parents, who may not speak English or are faced with barriers, from becoming involved in their children's education.

The results of the study did not indicate a significant relationship between parental involvement and students' reading and mathematics achievement. Although these results do not support Epstein's (2002) theoretical model in the context of this study, these findings are supported by Hawes and Plourde (2005) who found that there was not a significant relationship between parental involvement and reading achievement in a study conducted in a middle school with 48 six grade students. Notwithstanding, the correlational analysis results indicated a significant relationship between the parents’ socioeconomic status and mathematics performance which is consistent with recent research that claims that there is a relationship between parents who reside in underprivileged communities and their students’ academic achievement (Gordon \& Cui, 2014).

Further, the descriptive data suggested that the Latino seventh grade students in the study earned higher grades in reading than in mathematics, as evidenced by the first quarter report card grades. This finding was unconventional because the sample population was composed of English Language Learners, who obtained low achievement scores in reading on the state assessments. Research needs to be broadened to investigate the possible explanations of this outcome, which may include an analysis of Miami-Dade County district’s policy for grading ELL level 1 and 2 students. Variables associated with teacher grading, assignments that measure growth and are aligned with the state 
standards, as well as teacher expectations, should also be taken into consideration in conducting further research.

\section{Research Implications}

Research on parental involvement has increased over the last three decades. Many studies indicate that parental involvement is salient in the improvement of academic achievement and have highlighted numerous barriers to that involvement, such as socioeconomic status, level of parental education, self-efficacy, parents' own experience, and language. In contrast, parental involvement can be an ambiguous phrase that means different things to different people (Jeynes, 2003). Jeynes asserts that there are many characteristics of parental involvement and often studies do not distinguish which has the greatest benefit on student achievement.

This study also addressed the relationship between parental involvement and student achievement taking into consideration sex of the students and parents, socioeconomic status, single versus two-parent families, parents' level of education, selfefficacy, and language. Although the results of this study indicated that there was not a significant relationship between Latino parental involvement and students’ reading and mathematics achievement, there was a correlation between socioeconomic status and mathematics grade. This correlation concurs with Jeyne's (2003) claim that further studies are needed to examine why certain types of parental involvement, such as homebased or school-based, are beneficial for Latino students. In addition, current research studies should be expanded to examine the relationship of underprivileged communities and academic achievement (Gordon \& Cui, 2014). This would provide a clearer understanding on how schools can strategically design parental programs and activities to 
build a stronger community relationship and meet the needs of the students. Because Latino immigrant students come from different cultures, examining cultural practices aimed at enhancing parental involvement and understanding the diverse needs of the families and students (Malone, 2014) would assist schools with improving and increasing positive communication with parents.

\section{Implications for Practice}

Schools should make a sound effort to motivate parents to take an active role in their children's education. Understanding the diverse needs of the students and parents are at the forefront of being able to build productive parent-school relationships. This is consistent with studies that indicate that regardless of the barriers, Latino families are apprehensive about their children’s education (Auerbach, 2007; Jasis \& Ordonez-Jasis, 2012). Further, professional development programs must be available to teachers and administrators, and be focused on providing them with effective strategies and resources needed to enhance community relationship and meeting the needs of their diverse families.

\section{Recommendation for Further Research}

While results of the study did not support many of the research findings in the literature, with the exception of socioeconomic status and mathematics, other questions emerged and pertinent further research can be recommended. The following are recommendations for research that would further develop the findings in this research study. 
1. To expand the findings of the research study, additional research could be conducted at other secondary schools with similar demographic and social economic status.

2. A larger sample $N$ size could be tested in order to explore if the findings of the present study would be sustained.

3. This study could be replicated in other geographical regions in the United States with large Latino populations, so as to compare the findings of the present study.

4. Because this study was limited to parent surveys and analyzing students' first quarter report card grades, a longitudinal study utilizing an experimental design should be conducted in order to compare the finding to the present study.

5. The results of the study indicated that students in the sample study earned higher grades in reading than in mathematics yet data revealed the aforementioned students were English Language Learners (ELL) with low reading achievement scores on state assessments. Additional research should be conducted to explore: the grading policy of teachers of low achieving ELL students, Miami-Dade district's policy on grading ELL students, and the alignment of measurable assignments to the state standards, and teacher expectations.

6. Further research on specific types of parental involvement and the relationship on academic achievement could provide more nuanced and informative results.

7. Further research on cultural diversity could provide educators and administrators with a clearer understanding on the importance of building parental relationships and cultural awareness in schools. This will assist schools in breaking down barriers and strengthening the bridge between communities and schools. 


\section{Summary}

Chapter 5 completes this research study with a summary of the statistical analysis, implications to theory, research, and practice as well as recommendations. The findings revealed that there was not a significant relationship between parental involvement and reading and mathematics achievement. However, there was a relationship between socioeconomic status and mathematics.

Although the results of the study did not support Epstein’s (2007) theoretical model per se, further research should be conducted to examine the relationship between specific characteristics of parental involvement and student achievement in a larger sample or another geographical area with similar demographics. Implications of the present study propose providing professional development programs, for teachers and administrators, with emphasis on enriching community relations while understanding the needs of their diverse learners. Further, teachers and administrators should make a sound effort to collaborate with parents, especially those from lower SES, to enhance parents’ involvement skills and students' social and academic growth. 


\section{REFERENCES}

Alldred, P., \& Edwards, R. (2000). A typology of parental involvement in education centering on children and young people: Negotiating familialisation, institutionalization and individualization. British Journal of Sociology of Education, 21(3), 435-455.

Auerach, S. (2007). From moral supporters to struggling advocates. Urban Education, 42, 250-283.

Bandura, A. (1977). Self-efficacy: toward a unifying theory of behavioral change. Psychological review, 84(2), 191

Bandura, A. (1984). Recycling misconceptions of perceived self-efficacy. Cognitive therapy and research, 8(3), 231-255.

Bandura, A. (1986). The explanatory and predictive scope of self-efficacy theory. Journal of social and clinical psychology, 4(3), 359-373.

Barrueco, S., Lopez, M. L., Miles, J. C., \& Feinauer, E. (2007). Young Latino infants and families: Parental involvement implications from a recent national study. Family Involvement Research Digests. Harvard Family Research Project

Behnke, A. O. \& DeBord, K. (2006). Adolescent report of parental engagement and academic achievement in immigrant families. Journal of Youth and Adolescence, 38, 257-268.

Bhavnagri, N. P. \& Willete, L. (2011). Children's literature and understanding immigrant children. In R. V. Nata (Ed.), Progress in education: Vol. 1. (pp.1-24)

Hauppauge, N. Y.: Nova Science Publishers

Byrnes, H. (2003). Perspective. The Modern Language Journal, 87(4), 578-597.

Carter, R. S. \& Wojtkiewicz, R. A. (2000). Parental involvement within adolescents' education: Do daughters or sons get more help? Adolescence, 35, 129-137.

Ceballo, R. (2004). From barrios to Yale: The role of parenting strategies in Latino families. Hispanic Journal of Behavioral Sciences, 26(2), 171-186.

Chang, M., Park, B., Singh, K., \& Sung Y. (2009). Parental involvement, parenting behaviors, and children's cognitive development in low-income and minority families. Journal of Research in Childhood Education,.23(3), 309.

Chun, H. \& Dickson, G. L. (2010). A psychological model of academic performance among Hispanic adolescents. Journal of Youth and Adolescence. 40(12),15811594. 
Cohen, J. (1988). Statistical power analysis for the behavioral sciences (2nd ed.). Hillsdale, NJ.:Erlbaum.

Delgado-Gaitan, C. (1991). Involving parents in schools: A process of empowerment. American Journal of Education, 100, 20-46.

Delgado-Gaitan, C. (1994). Empowerment in Carpinteria: A five-year study of family, school, and community relationships. Washington, DC: Office of Educational Research and Improvement.

Dockterman, D. (2011). Statistical portrait of Hispanics in the United States, 2009. Washington, DC: Pew Hispanic Center.

Drake, D. D. (2000). Parents and families as partners in the education process: Collaboration for the success of students in public schools. ERS Spectrum, 18, 34-39.

Epstein, J. (1991). Literacy through family, community, and school interaction. In S.Silvern (Ed.), Advances in reading/language research (pp. 261-276). Greenwich, CT: JAI Press.

Epstein, J. L. (1995). School/family/community partnerships. Phi Deta Kappan, 76, 701712.

Epstein, J. L. (2007). Connections count. Improving family and community involvement in secondary schools. Principal Leadership, 8(2), 16-22.

Epstein, J. L. (2011). School, family, and community partnerships: Preparing educators and improving schools (2nd ed.). Boulder, CO: Westview.

Epstein, J. L. (2013) Ready or not? Preparing future educators for school, family, and community partnerships, Teaching Education, 24:(2), 115-118, DOI: 10.1080/10476210.2013.786887

Epstein, J. L., \& Sanders, M. G. (2002). Family, school, and community partnerships. In M. H. Bornstein (Ed). Handbook of parenting: 5, Practical issues in parenting (pp. 407-437). Mahwah, NJ: Erlbaum.

Epstein, J. L., \& Sanders, M. G. (2006). Prospects for change: Preparing educators for school, family, and community partnerships. Peabody Journal of Education, 81, 81-120.

Epstein, J. L., Sanders, M. G., Sheldon, S. B., Simon, B. S., Salinas, K. C., Jansorn, N. R., . \& Williams, K. J. (2009). School, family, and community partnerships: Your hand- book for action (3rd ed.). Thousand Oaks, CA: Corwin. 
Fishel, M \& Ramirez, L. (2005). Evidence-based parent involvement interventions with school-aged children. School Psychology Quarterly, 20, 371-402.

Fuligni, A. J. \& Fuligni, A. S. (2007). Immigrant families and the educational development of their children. Immigrant Families in Contemporary Society, 231249.

Gay, G. (2001).Preparing for culturally responsive teaching. Journal of Teacher Education-Washington DC, 53(2), 106-116.

Garcia, E., \& Jensen, B. (2009). Early educational opportunities for children of Hispanic origins. Social Policy Report, 23(2), 1-19.

Gaskell, A. (2006). Intercultural and interpersonal understanding. Open Learning, 21(3), 187-189.

Gonzalez, A. \& Wolters, C. (2006). The relation between perceived parenting practices and achievement motivation in mathematics. Journal of Research in Childhood Education, 21(2) 203-217.

Gordon, M., \& Cui, M. (2014). School-related parental involvement and adolescent academic achievement: The role of community poverty. Family Relations, 63,616-626.

Green, C. L., Walker, J. M .T., Hoover-Dempsey, K. V., Sandler, H. M. (2007). Parents motivation for involvement in children's education: An empirical test of a theoretical model of parental involvement. Journal of Educational Psychology, 99, 532-544.

Guthrie, J. T., \& Wigfield, A. (2000). Engagement and motivation in reading. In M. L.Kamil, P. B. Mosenthal, P. D. Pearson, \& R. Barr (Eds.) Handbook of reading research (3rd ed., pp. 403-422). New York, NY: Longman.

Hawes, C. A. \& Plourde, L. A. (2005).Parental involvement and its influence on the reading achievement of $6^{\text {th }}$ grade students. Reading Improvement; Spring 2005 42, pg. 47.

Hill, N. E., \& Taylor, L. C., (2004). Parental school involvement and children's academic achievement: Pragmatics and issues. Current Directions in Psychological Science, $13,161-164$

Hill, N. E., \& Tyson, D. F. (2009). Parental involvement in middle school: A metaanalytic assessment of the strategies that promote achievement. Developmental Psychology, 45, 740-763. 
Hoff, E. (2006). Environmental supports for language acquisition. In S. B. Neuman \& D. Dickinson (Eds.), Handbook of early literacy research (pp. 163-172). New York, NY: Guilford Press.

Hong, Y., Yoo, S., You, S., \& Wu, C. (2010). The reciprocal relationship between parental involvement and mathematics achievement: Autoregressive cross-lagged modeling. The Journal of Experimental Education, 78(4), 419-439.

Hoover-Dempsey, K. V., Bassler, O. C., \& Brissie, J. S. (1992). Explorations in parentschool relations. Journal of Educational Research, 85(5), 287-294.

Hoover-Dempsey, K. V., \& Sandler, H. M. (2005). Final Performance Report for OERI Grant \# R305T010673: The Social Context of Parental Involvement: A Path to Enhanced Achievement. Presented to Project Monitor, Institute of Education Sciences, U.S. Department of Education, March 22, 2005.

Hoover-Dempsey, K. V., Walker, J. M. T., Jones, K. P., \& Reed, R. P. (2002). Teachers Involving Parents (TIP): An in-service teacher education program for enhancing parental involvement. Teaching and Teacher Education, 18 (7), 843-467.

Hoover-Dempsey, K. V., Walker, J. M. T., \& Sandler, H. M. (2005). Parents' motivations for involvement in their children's education. In E. N. Patrikakou, R. P. Weissberg, S. Redding, H. J. Walberg (Eds.), School-family partnerships for children's success (pp.40-56). New York, NY: Teachers College Press.

Hoover-Dempsey, K.V., Walker, J. M., Sandler, H. M., Whetsel, D., Green, C. L., Wilkins, A. S., \& Closson, K. (2005). Why do parents become Involved? Research findings and implications. The Elementary School Journal, 106(2).

Jasis, P. M., \& Ordonez-Jasis, R. (2012). Latino parent involvement: Examining commitment and empowerment in schools. Urban Education, 47, 65-89.

Jeynes, W. (2003). A meta-analysis:The effects of parental involvement on minority children's academic achievement. Education and Urban Society, 35(2), 202-218.

Jeynes, W. (2012). A meta-analysis of the efficacy of different types of parental involvement programs for urban students. Urban Education, 47, 706-742.

Kalman, M. B. (2003). Adolescent girls, single-parent fathers, and menarch. Holistic Nursing Practice, 17(1), 36-40.

Kroeber, A.L., \& Kluckhohn, C. (1952). Culture: A critical review of concepts and definitions. Harvard University Peabody Museum of American Archeology and Ethonology Papers. 47 
Kuperminc, G. P. Darnell, A. J. \& Alvarez-Jimenez, A. (2007). Parent involvement in the academic adjustment of Latino middle and high school youth: Teacher expectations and school belonging as mediators. Journal of Adolescence, 31, 469483.

Ladson-Billings, G. (1994). The dreamkeepers. San Francisco: Jossey-Bass Publishing Co.

Lee, J., and Bowen, N., (2006). Parent involvement, cultural capital, and the achievement gap among elementary school children. American Educational Research Journal, 43, 193-218.

Lee, S., Kushner, J., \& Cho, S. (2007). Effects of parent's gender, child's gender, and parental involvement on the academic achievement of adolescents in single parent families. Sex Roles, 56(3-4), 149-157.

Loera, G., Rueda, R., \& Nakamoto, J. (2011). The association between parental involvement in reading and schooling and children's reading engagement in Latino families. Literacy Research and Instruction, 50, 133-155.

Lutkus, A., Grigg, W. \& Donahue, P. (2007). The nation's report card: Trial urban district assessment reading 2007 (NCES 2008-455). Washington, DC: National Center for Education Statistics, Institute of Education Sciences, U.S. Department of Education.

Mabry, M. \& Bhavnagri, N. P. (2012). Perspective taking of immigrant children: Utilizing children's literature and related activities. Multicultural Education, 19, 48-54.

Malone, D., (2014). Culture: a potential challenge for parental involvement in schools. International Journal for Professional Educators, 82, 14-18

Marchant, G. J., Paulson, S. E. \& Rothlisberg, B. A. (2001). Relations of middle school students' perceptions of family and school contexts with academic achievement. Psychology in the Schools, 38(6), 505-519.

Marschall, M. (2006). Parental involvement and educational outcomes for Latino students. Review of Policy Research. 23(5), 1053-1076.

Menard-Warwick, J. (2007). Biliteracy and schooling in an extended-family Nicaraguan immigrant household: The sociohistorical construction of parental involvement. Anthropology \& Education Quarterly, 119-137.

Morrison, F. J., McDonald Connor, C., \& Bachman, H. J. (2006). The transition to school. In S. B. Neuman \& D. Dickinson (Eds.), Handbook of early literacy research Vol. 2. (pp. 375-394). New York, NY: Guilford Press. 
Nathans, L. L., Oswald, F. L., \& Nimon, K. (2012). Multiple linear regression: A guidebook of variable importance. Practical Assessment, Research \& Evaluation, 17 (9), 1-19.

National Center for Education Statistics (2014). U.S. Department of Education. Racial/Ethnic Enrollment in Public Schools. Chapter 2, 13.nces.ed.gov/programs/coe/indicator_cge.asp

National Center for Education Statistics (2011). U.S. department of education. Achievement gaps: How Hispanic and White students in public schools perform in mathematics and reading on the national assessment of educational progress http://nces.ed.gov/nationsreportcard/pdf/studies/2011459.pdf

Neuman, S. (2006). The knowledge gap: Implications for early education. In S. B. Neuman \& D. Dickinson (Eds.), Handbook of early literacy research, (pp.29-40). New York, NY: The Guilford Press.

Newman, I. \& Newman, C. (1993). Conceptual statistics for beginners (2nd ed.). Lanham, MD: University Press of America.

Niemeyer, A. E., \& Wong, M. M., (2009). Parental involvement, familismo, and academic performance in Hispanic and Caucasian adolescents. North American Journal of Psychology, 11, 613-632.

No Child Left Behind Act of 2001, Pub L. No. 107-110, 2204(2002).

Nord, C. W., Brimhall, D., \& West, J. (1997). Fathers' involvement in their children's schools. U.S. Department of Education, National Center for Education Statistics, NCES 98-091, Washington, DC.

Ortiz, R. W., \& Ordoñez-Jasis, R. (2005). Leyendo juntos (reading together): New directions for Latino parents' early literacy involvement. The Reading Teacher, 59(2), 110-121.

Pomerantz, E. M., Moorman, E. A., \& Litwack, S. D. (2007). The how, whom, and why of parents' involvement in children's academic lives: More is not always better. Review of Educational Research. 77, 373-410.

Ramirez, F. (2003). Dismay and disappointment: Parental involvement of Latino immigrant parents. The Urban Review, 35(2).

Reay, D. (2000). A useful extension of Bourdieu's conceptual framework? Emotional capital as a way of understanding mothers' involvement in their children's education? The Sociological Review, 48(4), 568-585.

Reio, T. G., Jr., Whitehead, C., \& Dzhuryak, I. (2014). Booker T. Washington senior 
High school feeder pattern community compact program (Technical Report No.3).Miami, FL: Florida International University, Office of Graduate Studies, College of Education.

Reese, L. \& Goldenberg, C. (2008). Community literacy resources and home literacy practices among immigrant Latino families. Marriage and Family Review, 43, 109-139.

Reyes, I., \& Azuara, P. (2008). Emergent biliteracy in young immigrant children. Reading 165, Research Quarterly, 43, 374-398.

Ricciuti, H. (2004). Single parenthood, achievement, and problem behavior in white, black, and Hispanic children. The Journal of Educational Research, 97(4), 196207.

Sheldon, S. B., Epstein, J. L., \& Galindo, C. L., (2010). Not just numbers: Creating a partnership climate to improve math proficiency in schools. Leadership \& Policy in Schools, 9(1), 27-48.

Snell, P., Miguel, N., \& East, J. (2009). Changing directions: participatory action research as a parent involvement strategy. Educational Action Research, 17(2), 239-258.

St. Clair, L. \& Jackson, B. (2006). Effects of family involvement training on the language skills of young elementary children from migrant families. School Community Journal. 16(1), 31.

Stanley, P. H., Juhnke, G. A., \& Purkey, W. W. (2004). Using invitational theory of practice to create safe and successful schools. Journal of Counseling and Development : JCD , 82 (3), 302.

Stolz, H. E., Barber, B. K., \& Olsen, J. A. (2005). Toward disentangling fathering and mothering: An assessment of relative importance. Journal of Marriage and Family, 67, 1076-1092.

Suarez-Orozco, C. (2001). Afterword: Understanding and serving the children of immigrants. Harvard Educational Review, 71(3), 579-589.

Suarez-Orozco, C., Onaga, M., \& Lardemelle, C. D. (2001). Promoting academic engagement among immigrant adolescents through school-family-community collaboration. Professional School Counseling, 14, 15-26.

Tienda, M., \& Mitchell, F. (Eds). (2006). Multiple origins, uncertain destinies: Hispanics and the American future. National Research Council. Washington, DC: The National Academies Press. Retrieved May 6, 2015 from http://www.ncbi.nlm.nih.gov/books/NBK19892/\#a2000e49dddd00011 
Tillman, K. H. (2007). Family structure pathways and academic disadvantage among adolescents in stepfamilies. Sociological Inquiry, 77(3), 383-424.

Trumbull, E., Rothstein-Fisch, C., Greenfield, P. M., \& Quiroz, B. (2001). Bridging cultures between home and schools: A guide for teachers. Mahwah, NJ: Lawrence Erlbaum Associates.

Turney, K., \& Kao, G. (2009). Barriers to school involvement: Are immigrant parents disadvantaged? The Journal of Educational Research, 102(4), 257-271.

U.S. Census Bureau. (2012). The Hispanic population: 2012 Statistical Abstract.Retrieved October 15, 2014, from http://www.census.gov/compendia/statab/cats/population.htm.

U.S. Census Bureau. (2010a). Hispanic or Latino by type: 2010. Retrieved October 15, 2104, from http://factfinder2.census.gov/faces/tableservices/jsf/pages/ productview.xhtml?pid=DEC_10_SF1_QTP10 prodType=table.

U.S. Census Bureau. (2010b). The Hispanic population: 2010. 2010 Census Briefs. Retrieved October 15, 2014, retrieved from http://www.census.gov/prod/cen2010/briefs/c2010br- 04.pdf.

U.S. Department of Education. (1994). Goals 2000 legislation and related items. http://www.ed.gov/G2.

Vernon-Feagans, L., Scheffner Hammer, C., Miccio, A., \& Manlove, E. (2002). Early language and literacy skills in low-income African American and Hispanic children. In S. B. Neuman \& D. Dickinson (Eds.), Handbook of early literacy research (pp.192-210). New York, NY: Guilford Press.

Videon, T. M. (2005). Parent-child relations and their children's psychological wellbeing: Do dads matter? Journal of Family Issues, 26, 5-79.

Villalba, J. A., Brunelli, M. Lewis, L. \& Orfanedes, D. (2007) Experiences of Latino children attending rural elementary schools in the southeastern U.S.: Perspectives from Latino parents in burgeoning Latino communities. Professional School Counseling and Development, 10, 506-609.

Walker, J. M., Wilkins, A. S., Dallaire, J., Sandler, H. M., \& Hoover-Dempsey, K. V. (2005). Parental involvement: Model revision through scale development. Elementary School Journal, 106(2), 85-104.

Zhou, M. \& Logan, J. R. (2003). Increasing diversity and persistent segregation: Challenges of educating minority and immigrant children in urban Amnesiac. The End of Desegregations. (pp. 185-202). Nova Science Publishers. 
APPENDICES 
APPENDIX A.

SURVEY INSTRUMENT - ENGLISH 


\section{ent Involvement Project (PIP)} Parent Questionnaire

\section{Student Name:}

People have different feelings about school. Please CIRCLE THE NUMBER on each line below that best describes your feelings about your school experiences when you were a student. (Valence)

\begin{tabular}{|c|c|c|c|c|c|c|c|}
\hline \multirow{2}{*}{1} & \multirow{2}{*}{ My school: } & Disliked & & & & & Liked \\
\hline & & 1 & 2 & 3 & 4 & 5 & 6 \\
\hline \multirow{2}{*}{2} & \multirow{2}{*}{ My teachers: } & $\begin{array}{l}\text { Were } \\
\text { mean }\end{array}$ & & & & & $\begin{array}{l}\text { Were } \\
\text { nice }\end{array}$ \\
\hline & & 1 & 2 & 3 & 4 & 5 & 6 \\
\hline \multirow{2}{*}{3} & \multirow{2}{*}{ My teachers: } & Ignored me & & & & & $\begin{array}{c}\text { Cared about } \\
\text { me }\end{array}$ \\
\hline & & 1 & 2 & 3 & 4 & 5 & 6 \\
\hline \multirow{2}{*}{4} & \multirow{2}{*}{ My school experience: } & Bad & & & & & Good \\
\hline & & 1 & 2 & 3 & 4 & 5 & 6 \\
\hline \multirow{2}{*}{5} & \multirow{2}{*}{ I felt like: } & An outsider & & & & & I belonged \\
\hline & & 1 & 2 & 3 & 4 & 5 & 6 \\
\hline \multirow{2}{*}{6} & \multirow{2}{*}{ My overall experience: } & Failure & & & & & Success \\
\hline & & 1 & 2 & 3 & 4 & 5 & 6 \\
\hline \multicolumn{8}{|c|}{$\begin{array}{l}\text { Please indicate how much you AGREE or DISAGREE with each of the following statements. Please think about the current school } \\
\text { year as you consider each statement. (Parent-efficacy) }\end{array}$} \\
\hline & & $\begin{array}{l}\text { Disagree } \\
\text { very } \\
\text { strongly }\end{array}$ & Disagree & $\begin{array}{l}\text { Disagree } \\
\text { just a little }\end{array}$ & $\begin{array}{l}\text { Agree just } \\
\text { a little }\end{array}$ & Agree & $\begin{array}{l}\text { Agree } \\
\text { very } \\
\text { strongly }\end{array}$ \\
\hline 7 & $\begin{array}{l}\text { I know how to help my child do well in } \\
\text { school. }\end{array}$ & 1 & 2 & 3 & 4 & 5 & 6 \\
\hline 8 & $\begin{array}{l}\text { I don't know if I'm getting through to my } \\
\text { child. }\end{array}$ & 1 & 2 & 3 & 4 & 5 & 6 \\
\hline 9 & $\begin{array}{l}\text { I don’t know how to help my child make } \\
\text { good grades in school. }\end{array}$ & 1 & 2 & 3 & 4 & 5 & 6 \\
\hline 10 & $\begin{array}{l}\text { I feel successful about my efforts to help } \\
\text { my child learn. }\end{array}$ & 1 & 2 & 3 & 4 & 5 & 6 \\
\hline
\end{tabular}




\begin{tabular}{|c|c|c|c|c|c|c|c|}
\hline 11 & I don't know how to help my child learn & 1 & 2 & 3 & 4 & 5 & 6 \\
\hline \multicolumn{8}{|c|}{$\begin{array}{l}\text { Please indicate how much you AGREE or DISAGREE with each of the following statements. Please think about the current school } \\
\text { year as you consider each statement. (General School Invites) }\end{array}$} \\
\hline & & $\begin{array}{l}\text { Disagree } \\
\text { very } \\
\text { strongly }\end{array}$ & Disagree & $\begin{array}{c}\text { Disagree } \\
\text { just a little }\end{array}$ & $\begin{array}{l}\text { Agree just } \\
\text { a little }\end{array}$ & Agree & $\begin{array}{c}\text { Agree } \\
\text { very } \\
\text { strongly }\end{array}$ \\
\hline 12 & $\begin{array}{l}\text { Teachers at this school are interested and } \\
\text { cooperative when they discuss my child. }\end{array}$ & 1 & 2 & 3 & 4 & 5 & 6 \\
\hline 13 & I feel welcome at this school. & 1 & 2 & 3 & 4 & 5 & 6 \\
\hline 14 & $\begin{array}{l}\text { Parent activities are scheduled at this } \\
\text { school so that I can attend. }\end{array}$ & 1 & 2 & 3 & 4 & 5 & 6 \\
\hline 15 & $\begin{array}{l}\text { This school lets me know about meetings } \\
\text { and special school events. }\end{array}$ & 1 & 2 & 3 & 4 & 5 & 6 \\
\hline 16 & $\begin{array}{l}\text { This school's staff contacts me promptly } \\
\text { about any problems involving my child. }\end{array}$ & 1 & 2 & 3 & 4 & 5 & 6 \\
\hline 17 & $\begin{array}{l}\text { The teachers at this school keep me } \\
\text { informed about my child's progress in } \\
\text { school. }\end{array}$ & 1 & 2 & 3 & 4 & 5 & 6 \\
\hline \multicolumn{8}{|c|}{$\begin{array}{l}\text { Please indicate how much you AGREE or DISAGREE with each of the following statements. Please think about the current school } \\
\text { year as you consider each statement. (Knowledge and skills) }\end{array}$} \\
\hline & & $\begin{array}{l}\text { Disagree } \\
\text { very } \\
\text { strongly }\end{array}$ & Disagree & $\begin{array}{c}\text { Disagree } \\
\text { just a little }\end{array}$ & $\begin{array}{l}\text { Agree just } \\
\text { a little }\end{array}$ & Agree & $\begin{array}{l}\text { Agree } \\
\text { very } \\
\text { strongly }\end{array}$ \\
\hline 18 & I know about special events at school. & 1 & 2 & 3 & 4 & 5 & 6 \\
\hline 19 & $\begin{array}{l}\text { I know enough about the subjects of my } \\
\text { child's homework to help him or her. }\end{array}$ & 1 & 2 & 3 & 4 & 5 & 6 \\
\hline 20 & $\begin{array}{l}\text { I know how to supervise my child's } \\
\text { homework. }\end{array}$ & 1 & 2 & 3 & 4 & 5 & 6 \\
\hline
\end{tabular}




\begin{tabular}{|c|c|c|c|c|c|c|c|}
\hline 21 & $\begin{array}{l}\text { I know about volunteering opportunities } \\
\text { at my child’s school. }\end{array}$ & 1 & 2 & 3 & 4 & 5 & 6 \\
\hline 22 & $\begin{array}{l}\text { I know how to explain things to my child } \\
\text { about his or her homework. }\end{array}$ & 1 & 2 & 3 & 4 & 5 & 6 \\
\hline \multicolumn{8}{|c|}{$\begin{array}{l}\text { Parents and families do many different things when they are involved in their children's education. We would like to know how } \\
\text { often you have done the following since the beginning of the school year. (Involvement activities) }\end{array}$} \\
\hline & Someone in this family... & Never & $\begin{array}{l}1 \text { or } 2 \\
\text { times this } \\
\text { year }\end{array}$ & $\begin{array}{l}4 \text { or } 5 \\
\text { times this } \\
\text { year }\end{array}$ & $\begin{array}{l}\text { Once a } \\
\text { week }\end{array}$ & $\begin{array}{l}\text { A few times } \\
\text { a week }\end{array}$ & Daily \\
\hline 23 & ...talks with this child about the school day. & 1 & 2 & 3 & 4 & 5 & 6 \\
\hline 24 & ...supervises this child's homework. & 1 & 2 & 3 & 4 & 5 & 6 \\
\hline 25 & ...helps this child study for tests. & 1 & 2 & 3 & 4 & 5 & 6 \\
\hline 26 & $\begin{array}{l}\text {...practices spelling, math or other skills } \\
\text { with this child. }\end{array}$ & 1 & 2 & 3 & 4 & 5 & 6 \\
\hline 27 & ...reads with this child. & 1 & 2 & 3 & 4 & 5 & 6 \\
\hline 28 & ...volunteers to go on class field trips. & 1 & 2 & 3 & 4 & 5 & 6 \\
\hline 29 & ...attends PTA meetings. & 1 & 2 & 3 & 4 & 5 & 6 \\
\hline 30 & ....attends special events at school. & 1 & 2 & 3 & 4 & 5 & 6 \\
\hline 31 & .....helps out at this child's school. & 1 & 2 & 3 & 4 & 5 & 6 \\
\hline 32 & ...goes to the school's open-house. & 1 & 2 & 3 & 4 & 5 & 6 \\
\hline \multicolumn{8}{|c|}{$\begin{array}{l}\text { Parents and families do many different things when they help their children with schoolwork. We would like to know how true the } \\
\text { following things are for you and your family when you help your child with schoolwork. Please think about the current school year } \\
\text { as you read and respond to each item. (Encouragement) }\end{array}$} \\
\hline & We encourage this child... & $\begin{array}{l}\text { Not at all } \\
\text { true }\end{array}$ & $\begin{array}{c}\text { A little bit } \\
\text { true }\end{array}$ & $\begin{array}{l}\text { Somewhat } \\
\text { true }\end{array}$ & $\begin{array}{l}\text { Often } \\
\text { true }\end{array}$ & $\begin{array}{l}\text { Mostly } \\
\text { true }\end{array}$ & $\begin{array}{l}\text { Completely } \\
\text { true }\end{array}$ \\
\hline 33 & $\begin{array}{l}\text {...when he or she doesn't feel like doing } \\
\text { schoolwork. }\end{array}$ & 1 & 2 & 3 & 4 & 5 & 6 \\
\hline 34 & $\begin{array}{l}\text {...when he or she has trouble organizing } \\
\text { schoolwork. }\end{array}$ & 1 & 2 & 3 & 4 & 5 & 6 \\
\hline 35 & $\begin{array}{l}\text {...to try new ways to do schoolwork when } \\
\text { he or she is having a hard time. }\end{array}$ & 1 & 2 & 3 & 4 & 5 & 6 \\
\hline
\end{tabular}




\begin{tabular}{|c|c|c|c|c|c|c|c|}
\hline 36 & $\begin{array}{l}\text {...to be aware of how he or she is doing } \\
\text { with schoolwork. }\end{array}$ & 1 & 2 & 3 & 4 & 5 & 6 \\
\hline 37 & ...to develop an interest in schoolwork. & 1 & 2 & 3 & 4 & 5 & 6 \\
\hline 38 & $\begin{array}{l}\text {...to look for more information about } \\
\text { school subjects. }\end{array}$ & 1 & 2 & 3 & 4 & 5 & 6 \\
\hline 39 & $\begin{array}{l}\text {...to stick with a problem until he or she } \\
\text { solves it. }\end{array}$ & 1 & 2 & 3 & 4 & 5 & 6 \\
\hline 40 & ...to believe that he or she can do well. & 1 & 2 & 3 & 4 & 5 & 6 \\
\hline 41 & $\begin{array}{l}\text {...to believe that he or she can learn new } \\
\text { things. }\end{array}$ & 1 & 2 & 3 & 4 & 5 & 6 \\
\hline 42 & $\begin{array}{l}\text {...to ask other people for help when a } \\
\text { problem is hard. }\end{array}$ & 1 & 2 & 3 & 4 & 5 & 6 \\
\hline 43 & ...to follow the teacher's directions. & 1 & 2 & 3 & 4 & 5 & 6 \\
\hline 44 & $\begin{array}{l}\text {...to explain what he or she thinks to the } \\
\text { teacher. }\end{array}$ & 1 & 2 & 3 & 4 & 5 & 6 \\
\hline 45 & $\begin{array}{l}\text { When he or she has trouble doing } \\
\text { schoolwork. }\end{array}$ & 1 & 2 & 3 & 4 & 5 & 6 \\
\hline \multicolumn{8}{|c|}{$\begin{array}{l}\text { Parents and families do many different things when they help their children with schoolwork. We would like to know how true the } \\
\text { following things are for you and your family when you help your child with schoolwork. Please think about the current school year } \\
\text { as you read and respond to each item. (Reinforcement) }\end{array}$} \\
\hline & $\begin{array}{l}\text { We show this child we like it when he or } \\
\text { she... }\end{array}$ & $\begin{array}{l}\text { Not at all } \\
\text { true }\end{array}$ & $\begin{array}{l}\text { A little bit } \\
\text { true }\end{array}$ & $\begin{array}{c}\text { Somewhat } \\
\text { true }\end{array}$ & Often true & $\begin{array}{l}\text { Mostly } \\
\text { true }\end{array}$ & $\begin{array}{l}\text { Completely } \\
\text { true }\end{array}$ \\
\hline 46 & ...wants to learn new things. & 1 & 2 & 3 & 4 & 5 & 6 \\
\hline 47 & ...tries to learn as much as possible. & 1 & 2 & 3 & 4 & 5 & 6 \\
\hline 48 & $\begin{array}{l}\text {...has a good attitude about doing his or her } \\
\text { homework. }\end{array}$ & 1 & 2 & 3 & 4 & 5 & 6 \\
\hline 49 & $\begin{array}{l}\text {...keeps working on homework even when } \\
\text { he or she doesn't feel like it. }\end{array}$ & 1 & 2 & 3 & 4 & 5 & 6 \\
\hline 50 & ...asks the teacher for help. & 1 & 2 & 3 & 4 & 5 & 6 \\
\hline 51 & $\begin{array}{l}\text {...explains what he or she thinks to the } \\
\text { teacher. }\end{array}$ & 1 & 2 & 3 & 4 & 5 & 6 \\
\hline 52 & $\begin{array}{l}\text {...explains to us what he or she thinks } \\
\text { about school. }\end{array}$ & 1 & 2 & 3 & 4 & 5 & 6 \\
\hline 53 & ...works hard on homework. & 1 & 2 & 3 & 4 & 5 & 6 \\
\hline 54 & ...understands how to solve problems. & 1 & 2 & 3 & 4 & 5 & 6 \\
\hline 55 & $\begin{array}{l}\text {...sticks with a problem until he or she } \\
\text { solves it. }\end{array}$ & 1 & 2 & 3 & 4 & 5 & 6 \\
\hline
\end{tabular}




\begin{tabular}{|c|c|c|c|c|c|c|c|}
\hline 56 & ...organizes his or her schoolwork. & 1 & 2 & 3 & 4 & 5 & 6 \\
\hline 57 & ...checks his or her work. & 1 & 2 & 3 & 4 & 5 & 6 \\
\hline 58 & $\begin{array}{l}\text {...finds new ways to do schoolwork when } \\
\text { he or she gets stuck. }\end{array}$ & 1 & 2 & 3 & 4 & 5 & 6 \\
\hline \multicolumn{8}{|c|}{$\begin{array}{l}\text { Parents and families do many different things when they help their children with schoolwork. We would like to know how true the } \\
\text { following things are for you and your family when you help your child with schoolwork. Please think about the current school year } \\
\text { as you read and respond to each item. (Instruction) }\end{array}$} \\
\hline & We teach this child... & $\begin{array}{l}\text { Not at all } \\
\text { true }\end{array}$ & $\begin{array}{l}\text { A little bit } \\
\text { true }\end{array}$ & $\begin{array}{c}\text { Somewhat } \\
\text { true }\end{array}$ & Often true & $\begin{array}{l}\text { Mostly } \\
\text { true }\end{array}$ & $\begin{array}{c}\text { Completely } \\
\text { true }\end{array}$ \\
\hline 59 & $\begin{array}{l}\text {...to go at his or her own pace while } \\
\text { doing schoolwork. }\end{array}$ & 1 & 2 & 3 & 4 & 5 & 6 \\
\hline 60 & $\begin{array}{l}\text {...to take a break from his or her work } \\
\text { when he or she gets frustrated. }\end{array}$ & 1 & 2 & 3 & 4 & 5 & 6 \\
\hline 61 & $\begin{array}{l}\text {...how to check homework as he or she } \\
\text { goes along. }\end{array}$ & 1 & 2 & 3 & 4 & 5 & 6 \\
\hline 62 & $\begin{array}{l}\text {...how to get along with others in his or } \\
\text { her class. }\end{array}$ & 1 & 2 & 3 & 4 & 5 & 6 \\
\hline 63 & ...to follow the teacher's directions. & 1 & 2 & 3 & 4 & 5 & 6 \\
\hline 64 & ...ways to make his or her homework fun. & 1 & 2 & 3 & 4 & 5 & 6 \\
\hline 65 & $\begin{array}{l}\text {...how to find out more about things that } \\
\text { interest him or her. }\end{array}$ & 1 & 2 & 3 & 4 & 5 & 6 \\
\hline 66 & $\begin{array}{l}\text {...to try problems that help him or her } \\
\text { learn the most. }\end{array}$ & 1 & 2 & 3 & 4 & 5 & 6 \\
\hline 67 & $\begin{array}{l}\text {...to have a good attitude about his or her } \\
\text { homework. }\end{array}$ & 1 & 2 & 3 & 4 & 5 & 6 \\
\hline 68 & $\begin{array}{l}\text {...to keep trying when he or she gets } \\
\text { stuck. }\end{array}$ & 1 & 2 & 3 & 4 & 5 & 6 \\
\hline 69 & $\begin{array}{l}\text {...to stick with his or her homework until } \\
\text { he or she finishes it. }\end{array}$ & 1 & 2 & 3 & 4 & 5 & 6 \\
\hline 70 & ...to work hard. & 1 & 2 & 3 & 4 & 5 & 6 \\
\hline 71 & $\begin{array}{l}\text {...to talk with the teacher when he or she } \\
\text { has questions. }\end{array}$ & 1 & 2 & 3 & 4 & 5 & 6 \\
\hline
\end{tabular}




\begin{tabular}{|c|l|c|c|c|c|c|c|}
\hline 72 & $\begin{array}{l}\text {..to ask questions when he or she doesn't } \\
\text { understand something. }\end{array}$ & 1 & 2 & 3 & 4 & 5 & 6 \\
\hline 73 & $\begin{array}{l}\text { k.to make sure he or she understands one } \\
\text { part before going on the next. }\end{array}$ & 1 & 2 & 3 & 4 & 5 & 6 \\
\hline
\end{tabular}


We understand that the following information may be of a sensitive nature. We ask for this information because it helps us describe the range of families in our total group. Please bubble the response for each item that best describes you and your family.

1. Your Gender: Female
Male

\section{Marital Status}

Single
Married or with

partner
3. Please choose the job that best describes yours (please choose only one):

Unemployed, retired, student, disabled Warehouse, factory

worker, construction

Food services, restaurant

Retail sales, clerical, customer service

Bookkeeping, accounting, related administrative $\overline{\text { Sales }}$ Real Estate/Insuranc

eacher, nurse
Labor, custodial, maintenance Driver (taxi, truck bus, delivery) Skilled Craftsman (plumber, electrician, etc.)

Service technician

(appliances, computers, cars)

Singer, musician, writer, or artist

Social services, public service, related governmental

Professional, executive
4. Please choose the job that best describes your partner or spouse (please choose only one):

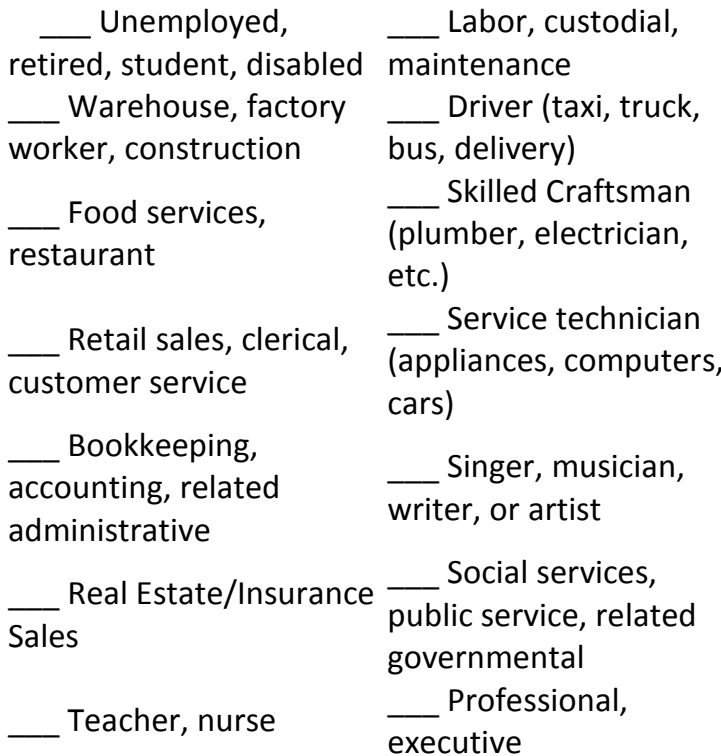

\section{Your partner or spouse level of education} (please check highest level completed): less than high school bachelor's degree high school or GED some graduate work some college, 2-year post graduate
7. Family income per year (check one): less than $\$ 5,000$ $\$ 5,100-\$ 10,000$ $\$ 10,001-\$ 20,000$ $\$ 20,001-\$ 30,000$
$\$ 30,001-\$ 40,000$

$\$ 40,001-\$ 50-000$ over $\$ 50,001$
8. Your race/ethnicity:

Asian/America

Black/African-American

Black/Hispanic-American

Hispanic/Hispanic-American

White/Caucasian

Other

THANK YOU FOR COMPLETING THE SURVEY!! 


\section{APPENDIX B.}

SURVEY INSTRUMENT - SPANISH 


\section{Troyecto de Familias en Compromiso (PIP)}

The Family-School onario para Padres de Familia

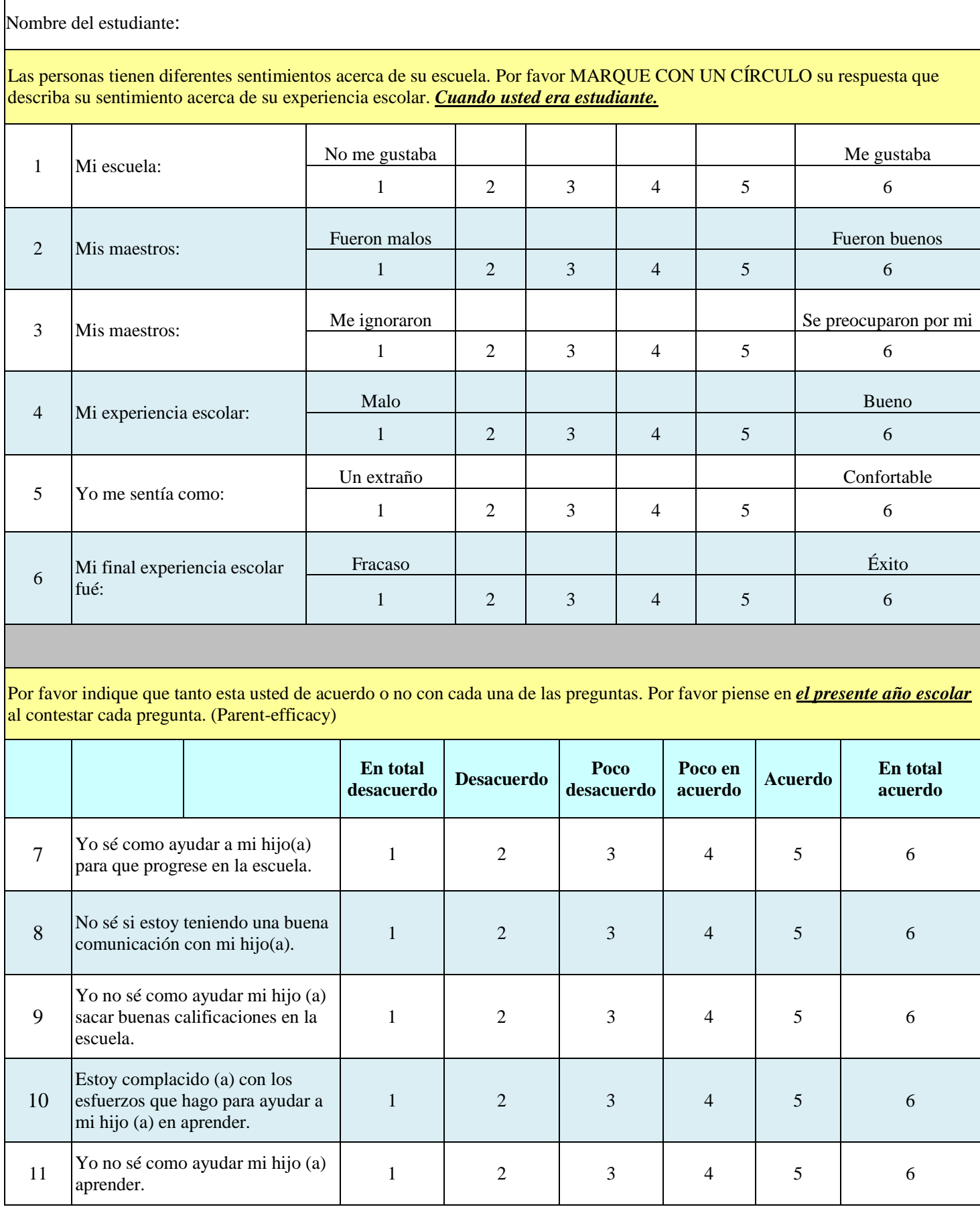


Por favor indique que tan seguido se ha comprometido con las siguientes conductas por lo que va DEL PRESENTE AÑO ESCOLAR.

\begin{tabular}{|c|c|c|c|c|c|c|c|}
\hline & & $\begin{array}{c}\text { En total } \\
\text { desacuerdo }\end{array}$ & Desacuerdo & $\begin{array}{c}\text { Poco } \\
\text { desacuerdo }\end{array}$ & $\begin{array}{l}\text { Poco en } \\
\text { acuerdo }\end{array}$ & Acuerdo & En total acuerdo \\
\hline 13 & $\begin{array}{l}\text { Yo me siento comfortable } \\
\text { en la escuela. }\end{array}$ & 1 & 2 & 3 & 4 & 5 & 6 \\
\hline 14 & $\begin{array}{l}\text { Las actividades para padres } \\
\text { de familia se llevan a cabo } \\
\text { en la escuela para que } \\
\text { podamos atender. }\end{array}$ & 1 & 2 & 3 & 4 & 5 & 6 \\
\hline 16 & $\begin{array}{l}\text { El personal de la escuela } \\
\text { hace contacto conmigo por } \\
\text { cualquier problema con mi } \\
\text { hijo(a). }\end{array}$ & 1 & 2 & 3 & 4 & 5 & 6 \\
\hline 17 & $\begin{array}{l}\text { Los maestros de la escuela } \\
\text { me mantienen } \\
\text { informado(a) acerca del } \\
\text { progreso académico de mi } \\
\text { hijo(a). }\end{array}$ & 1 & 2 & 3 & 4 & 5 & 6 \\
\hline \\
\hline & & $\begin{array}{c}\text { En total } \\
\text { desacuerdo }\end{array}$ & Desacuerdo & $\begin{array}{c}\text { Poco } \\
\text { desacuerdo }\end{array}$ & $\begin{array}{l}\text { Poco en } \\
\text { acuerdo }\end{array}$ & Acuerdo & En total acuerdo \\
\hline 18 & $\begin{array}{l}\text { Estoy informado(a) acerca } \\
\text { de eventos especiales en la } \\
\text { escuela. }\end{array}$ & 1 & 2 & 3 & 4 & 5 & 6 \\
\hline 19 & $\begin{array}{l}\text { Yo tengo los suficientes } \\
\text { conocimientos para poder } \\
\text { ayudar con las tareas de } \\
\text { mi hijo(a). }\end{array}$ & 1 & 2 & 3 & 4 & 5 & 6 \\
\hline 20 & $\begin{array}{l}\text { Yo sé como supervisar las } \\
\text { tareas de mi hijo(a). }\end{array}$ & 1 & 2 & 3 & 4 & 5 & 6 \\
\hline 21 & $\begin{array}{l}\text { Yo sé acerca de } \\
\text { oportunidades para ser } \\
\text { voluntario(a) en la escuela } \\
\text { de mi hijo(a). }\end{array}$ & 1 & 2 & 3 & 4 & 5 & 6 \\
\hline 22 & $\begin{array}{l}\text { Yo sé como explicar las } \\
\text { tareas a mi hijo(a). }\end{array}$ & 1 & 2 & 3 & 4 & 5 & 6 \\
\hline
\end{tabular}




\begin{tabular}{|c|c|c|c|c|c|c|c|}
\hline & Alguien en la familia... & Nunca & $\begin{array}{l}\text { Una vez } \\
\text { hasta } \\
\text { ahora }\end{array}$ & $\begin{array}{c}\text { Una vez al } \\
\text { mes }\end{array}$ & $\begin{array}{l}\text { Una vez cada } \\
2 \text { semenas }\end{array}$ & $\begin{array}{c}\text { Una vez a la } \\
\text { semana }\end{array}$ & A diario \\
\hline 23 & $\begin{array}{l}\text {...habla con el niño(a) acerca del año } \\
\text { escolar. }\end{array}$ & 1 & 2 & 3 & 4 & 5 & 6 \\
\hline 24 & ...superviza las tareas del niño(a). & 1 & 2 & 3 & 4 & 5 & 6 \\
\hline 25 & ... ayuda en la escuela. & 1 & 2 & 3 & 4 & 5 & 6 \\
\hline 26 & ...atiende eventos especiales. & 1 & 2 & 3 & 4 & 5 & 6 \\
\hline 27 & $\begin{array}{l}\text {...ayuda al niño(a) a estudiar para el } \\
\text { exámen. }\end{array}$ & 1 & 2 & 3 & 4 & 5 & 6 \\
\hline 28 & $\begin{array}{l}\text {...es voluntario(a) en paseos } \\
\text { escolares. }\end{array}$ & 1 & 2 & 3 & 4 & 5 & 6 \\
\hline 29 & ....atiende a las juntas de PTA. & 1 & 2 & 3 & 4 & 5 & 6 \\
\hline 30 & $\begin{array}{l}\text {...practica matemáticas, ortografía y } \\
\text { otras materias con el estudiante. }\end{array}$ & 1 & 2 & 3 & 4 & 5 & 6 \\
\hline 31 & ...lee con el niño(a). & 1 & 2 & 3 & 4 & 5 & 6 \\
\hline 32 & ... asiste a "open house" en la escuela. & 1 & 2 & 3 & 4 & 5 & 6 \\
\hline \multicolumn{8}{|c|}{$\begin{array}{l}\text { Padres y familiares hacen diferentes cosas para ayudar con la educación de sus hijos. Nos gustaría saber que tan verdaderas son } \\
\text { las siguientes preguntas para usted y sus familiares. Piense en el presente año escolar en cada pregunta y respuesta. } \\
\text { (Encouragement) }\end{array}$} \\
\hline & $\begin{array}{l}\text { Nosotros animamos al niño(a) } \\
\text { cuando: }\end{array}$ & Falso & $\begin{array}{c}\text { Un poco } \\
\text { verdadero }\end{array}$ & $\begin{array}{c}\text { Algo } \\
\text { verdadero }\end{array}$ & $\begin{array}{c}\text { Varias } \\
\text { verdadero }\end{array}$ & $\begin{array}{c}\text { Mayoría } \\
\text { verdadero }\end{array}$ & Verdadero \\
\hline 33 & $\begin{array}{l}\text {...cuando él/ella no tienen ganas de } \\
\text { hacer la tarea. }\end{array}$ & 1 & 2 & 3 & 4 & 5 & 6 \\
\hline 34 & $\begin{array}{l}\text {...cuando él/ella tiene problemas en } \\
\text { organizarsus tareas. }\end{array}$ & 1 & 2 & 3 & 4 & 5 & 6 \\
\hline 35 & $\begin{array}{l}\text {...buscar nuevas maneras para que } \\
\text { él/ella hagan su tarea. }\end{array}$ & 1 & 2 & 3 & 4 & 5 & 6 \\
\hline 36 & $\begin{array}{l}\text {...estar pendiente de como hacen sus } \\
\text { tareas. }\end{array}$ & 1 & 2 & 3 & 4 & 5 & 6 \\
\hline 37 & $\begin{array}{l}\text {...desarrollar intéres en tareas } \\
\text { escolares. }\end{array}$ & 1 & 2 & 3 & 4 & 5 & 6 \\
\hline 38 & $\begin{array}{l}\text {....buscar más información acerca de } \\
\text { las materias escolares. }\end{array}$ & 1 & 2 & 3 & 4 & 5 & 6 \\
\hline 39 & $\begin{array}{l}\text {...que no deje sin terminar un } \\
\text { problema. }\end{array}$ & 1 & 2 & 3 & 4 & 5 & 6 \\
\hline
\end{tabular}




\begin{tabular}{|c|c|c|c|c|c|c|c|}
\hline 40 & $\begin{array}{l}\text {...creer que él/ella pueden hacerlo } \\
\text { bien. }\end{array}$ & 1 & 2 & 3 & 4 & 5 & 6 \\
\hline 41 & $\begin{array}{l}\text {...creer que él/ella pueden aprender } \\
\text { nuevas cosas. }\end{array}$ & 1 & 2 & 3 & 4 & 5 & 6 \\
\hline 42 & $\begin{array}{l}\text {...buscar ayuda cuando el problema } \\
\text { es difícil. }\end{array}$ & 1 & 2 & 3 & 4 & 5 & 6 \\
\hline 43 & $\begin{array}{l}\text {...cumplir con las instrucciones del } \\
\text { maestro(a). }\end{array}$ & 1 & 2 & 3 & 4 & 5 & 6 \\
\hline 44 & $\begin{array}{l}\text {...explicar que es lo que él/ella piensa } \\
\text { de su maestro(a). }\end{array}$ & $\mathrm{a}$ & 2 & 3 & 4 & 5 & 6 \\
\hline 45 & $\begin{array}{l}\text {...cuando él/ella tienen problemas en } \\
\text { hacer tareas. }\end{array}$ & 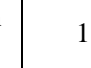 & 2 & 3 & 4 & 5 & 6 \\
\hline \multicolumn{8}{|c|}{$\begin{array}{l}\text { Padres y familiares hacen diferentes cosas para ayudar con la educación de sus hijos. Nos gustaría saber que tan verdaderas son } \\
\text { las siguientes preguntas para usted y sus familiares. Piense en el presente año escolar en cada pregunta y respuesta. } \\
\text { (Reinforcement) }\end{array}$} \\
\hline & $\begin{array}{l}\text { Nosotros apreciamos cuando el } \\
\text { niño(a): }\end{array}$ & Falso & $\begin{array}{l}\text { Un poco } \\
\text { verdadero }\end{array}$ & $\begin{array}{c}\text { Algo } \\
\text { verdadero }\end{array}$ & $\begin{array}{l}\text { Varias } \\
\text { verdadero }\end{array}$ & $\begin{array}{c}\text { Mayoría } \\
\text { verdadero }\end{array}$ & Verdadero \\
\hline 46 & ...quiere aprender cosas nuevas. & 1 & 2 & 3 & 4 & 5 & 6 \\
\hline 47 & $\begin{array}{l}\text {...trata de aprender todo lo que } \\
\text { puede. }\end{array}$ & 1 & 2 & 3 & 4 & 5 & 6 \\
\hline 48 & $\begin{array}{l}\text {...tiene una actitud positiva cuando } \\
\text { hace sus tareas. }\end{array}$ & 1 & 2 & 3 & 4 & 5 & 6 \\
\hline 49 & $\begin{array}{l}\text {...continua trabajando en su tarea, } \\
\text { aunque él/ella no tenga ganas. }\end{array}$ & 1 & 2 & 3 & 4 & 5 & 6 \\
\hline 50 & $\begin{array}{l}\text {...pregunta a su maestro(a) por } \\
\text { ayuda. }\end{array}$ & 1 & 2 & 3 & 4 & 5 & 6 \\
\hline 51 & $\begin{array}{l}\text {...explíca que es lo que piensa de } \\
\text { su maestro(a). }\end{array}$ & 1 & 2 & 3 & 4 & 5 & 6 \\
\hline 52 & $\begin{array}{l}\text {...nos explíca que es lo que piensa } \\
\text { de su escuela. }\end{array}$ & 1 & 2 & 3 & 4 & 5 & 6 \\
\hline 53 & ...trabaja muy bien en sus tareas. & 1 & 2 & 3 & 4 & 5 & 6 \\
\hline 54 & $\begin{array}{l}\text {...entiende como resolver } \\
\text { problemas. }\end{array}$ & 1 & 2 & 3 & 4 & 5 & 6 \\
\hline 55 & $\begin{array}{l}\text {...no deja un problema hasta que lo } \\
\text { termina. }\end{array}$ & 1 & 2 & 3 & 4 & 5 & 6 \\
\hline 56 & ...organiza sus tareas. & 1 & 2 & 3 & 4 & 5 & 6 \\
\hline 57 & ...reviza sus tareas. & 1 & 2 & 3 & 4 & 5 & 6 \\
\hline 58 & $\begin{array}{l}\text {...encuentra nuevas formas en } \\
\text { hacer sus tareas, cuando se ve en } \\
\text { problemas. }\end{array}$ & 1 & 2 & 3 & 4 & 5 & 6 \\
\hline
\end{tabular}


Padres y familiares hacen diferentes cosas para ayudar con la educación de sus hijos. Nos gustaría saber que tan verdaderas son las siguientes preguntas para usted y sus familiares. Piense en el presente año escolar en cada pregunta y respuesta. (Instruction)

\begin{tabular}{|c|c|c|c|c|c|c|c|}
\hline & $\begin{array}{l}\text { Nosotros le enseñamos al } \\
\text { niño(a) que: }\end{array}$ & Falso & $\begin{array}{c}\text { Un poco } \\
\text { verdadero }\end{array}$ & $\begin{array}{c}\text { Algo } \\
\text { verdadero }\end{array}$ & $\begin{array}{c}\text { Varias } \\
\text { verdadero }\end{array}$ & $\begin{array}{l}\text { Mayoría } \\
\text { verdadero }\end{array}$ & Verdadero \\
\hline 59 & $\begin{array}{l}\text {...que haga su tarea en paz y } \\
\text { en el lugar indicado. }\end{array}$ & 1 & 2 & 3 & 4 & 5 & 6 \\
\hline 60 & $\begin{array}{l}\text {...que tome un descanso } \\
\text { cuando él/ella se sienta } \\
\text { cansado(a) o molesto(a). }\end{array}$ & 1 & 2 & 3 & 4 & 5 & 6 \\
\hline 61 & $\begin{array}{l}\text {...como revizar su tarea en el } \\
\text { momento de estar haciendola. }\end{array}$ & 1 & 2 & 3 & 4 & 5 & 6 \\
\hline 62 & $\begin{array}{l}\text {...como relacionarse con sus } \\
\text { compañeros de clase. }\end{array}$ & 1 & 2 & 3 & 4 & 5 & 6 \\
\hline 63 & $\begin{array}{l}\text {...seguir las instrucciones de } \\
\text { su maestro(a). }\end{array}$ & 1 & 2 & 3 & 4 & 5 & 6 \\
\hline 64 & $\begin{array}{l}\text {...maneras de hacer sus tareas } \\
\text { divertidas. }\end{array}$ & 1 & 2 & 3 & 4 & 5 & 6 \\
\hline 65 & $\begin{array}{l}\text {...como encontrar más } \\
\text { información en actividades que } \\
\text { le interesan. }\end{array}$ & 1 & 2 & 3 & 4 & 5 & 6 \\
\hline 66 & $\begin{array}{l}\text {...ayudarle con sus problemas } \\
\text { para que aprenda más. }\end{array}$ & 1 & 2 & 3 & 4 & 5 & 6 \\
\hline 67 & $\begin{array}{l}\text {...que tenga una actitud } \\
\text { positiva en relación con sus } \\
\text { tareas. }\end{array}$ & 1 & 2 & 3 & 4 & 5 & 6 \\
\hline 68 & $\begin{array}{l}\text {...que continúe tratando de } \\
\text { resolver un problema. }\end{array}$ & 1 & 2 & 3 & 4 & 5 & 6 \\
\hline 69 & $\begin{array}{l}\text {...que termine su tarea } \\
\text { completamente. }\end{array}$ & 1 & 2 & 3 & 4 & 5 & 6 \\
\hline 70 & ...que trabaje duro. & 1 & 2 & 3 & 4 & 5 & 6 \\
\hline 71 & $\begin{array}{l}\text {...que hable con su maestro(a) } \\
\text { cuando él/ella tenga alguna } \\
\text { pregunta. }\end{array}$ & 1 & 2 & 3 & 4 & 5 & 6 \\
\hline 72 & $\begin{array}{l}\text {...que haga preguntas cuando } \\
\text { él/ella no entienda algo. }\end{array}$ & 1 & 2 & 3 & 4 & 5 & 6 \\
\hline 73 & $\begin{array}{l}\text {...que esté seguro(a) que } \\
\text { entienda desde el principio, } \\
\text { para que pueda continuar } \\
\text { adelante. }\end{array}$ & 1 & 2 & 3 & 4 & 5 & 6 \\
\hline
\end{tabular}


Nosotros entendemos que las siguientes preguntas son de carácter delicado. Hacemos estas preguntas para identificar el total del grupo familiar. Por favor señale la respuesta que más lo describa a usted y su pareja.

\section{Su género:}

Femenino
Masculino

3. Por favor describa el empleo que describa su trabajo (por favor escoja uno solamente):

Desempleado,
jubilado, estudiante,
deshabilitado
Empleado de almacén
fábrica, construcción
Servicio de comida,
resturante
recepcionista, servicio al
cliente
contador, servicios
administrativos
Agente de Bienes
Raices/Venta de Seguros
Maestro(a),

Obrero, conserje,
mantenimiento

Chofer (taxi, trailer, autobus, entrega) Habilidades especiales (ploméro, electricista, etc)

Servicio técnico

(electrodomésticos, computadoras, automóbiles

\section{Cantante/ musocp/escritor/artista}

Servicios sociales, servicio público, relacionado con el gobierno

Profesional, ejecutívo

\section{Estado Civil}

Solo

Casados o con paraja

4. Por favor escoja el trabajo u oficio que mejor describa a su esposo(a) o pareja:

Desempleado, jubilado, estudiante, deshabilitado

Empleado de almacén, fábrica, construcción Servicio de comida, resturante

Empleado de ventas, recepcionista, servicio al cliente

_Contabilidad, contador, servicios administrativos

Agente de Bienes Raices/Venta de Seguros enfermero(a)
__ Obrero, conserje, mantenimiento

_Chofer (taxi, trailer, autobus, entrega) Habilidades especiales (ploméro, electricista, etc) Servicio técnico (electrodomésticos, computadoras, automóbiles) musocp/escritor/artista

Servicios sociales, servicio público, relacionado con el gobierno

Profesional, ejecutívo

5. Su nivél de educación (por favor marque el grado más alto que atendió):

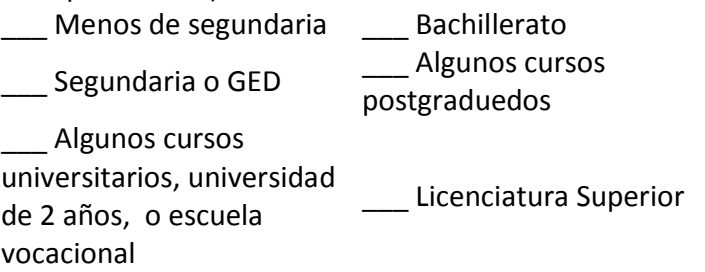

6. Nivél educativo que su esposo(a) o pareja atendió: (por favor marque el grado más alto que atendió):
Menos de segundaria
Segundaria o GED

Algunos cursos

universitarios, universidad de 2 años, o escuela vocacional
7. Ingreso familiar por un año (marque uno): less than $\$ 5,000$

$\$ 5,100-\$ 10,000$

$\$ 10,001-\$ 20,000$ $\$ 20,001-\$ 30,000$
$\$ 30,001-\$ 40,000$

$\$ 40,001-\$ 50-000$

over $\$ 50,001$

\section{Su raza/étnico:}

Asiatico-Asiatico Americano

Negro/Americano Africano

Negro/ Hispano-Americano

Hispano/Hispano-Americano

Blanco/Caucásico

Otro

¡iMUCHAS GRACIAS POR COMPLETAR ENCUESTA!! 
VITA

CORY R. RODRIGUEZ

Born, Rio de Janeiro, Brasil

1992

B.S., Elementary Education

Nova Southeastern University

Miami, Florida

$1992-2001$

Teacher

Miami-Dade County Public Schools

Miami, Florida

1996

M.S., Emotional Handicap Education

Nova Southeastern University

Fort Lauderdale, Florida

1997

Educational Leadership Certification

Nova Southeastern University

Miami, Florida

$1998-2003$

Adjunct Faculty

College of Education

Nova Southeastern University

Miami, Florida

$2001-2006$

Assistant Principal

Miami-Dade County Public Schools

Miami, Florida

$2006-2008$

Regional Center VI Supervisor

Special Education

Miami-Dade County Public Schools

Miami, Florida

2008 - Present

Principal

Miami-Dade County Public Schools

Miami, Florida

$2010-2016$

Doctoral Candidate

Educational Administration and Supervision

Florida International University

Miami, Florida 


\section{PRESENTATIONS}

Rodriguez, C.R. (2016). Seventeenth Annual Teacher Recruitment \& Professional Development Symposium. Presentation for teachers for Miami Dade College InterAmerican Campus. Miami, FL

Rodriguez, C.R. (2010). Instructional Performance Evaluation and Growth Systems (IPEGS) for administrators. Presentation at meeting and training for Miami-Dade County School Administrators. Miami, FL

Rodriguez, C.R. (2009). Florida Comprehensive Assessment Test (FCAT) and MiamiDade County South Dade Feeder Pattern. Presentation for community and parent representatives of South Region. Miami FL.

Rodriguez, C.R. (2007). Exceptional Student Education programs and guidelines. Presentation for administrators, principals, and teachers of Regional Center VI of Miami Dade County Public Schools. Homestead, FL. 